\author{
A Dissertation \\ Submitted to the Faculty \\ of \\ Xavier University \\ in Partial Fulfillment of the \\ Requirements for the Degree of \\ Doctor of Psychology \\ by
}

Amy L. Karbasi, M.A.

December 2010

Approved:

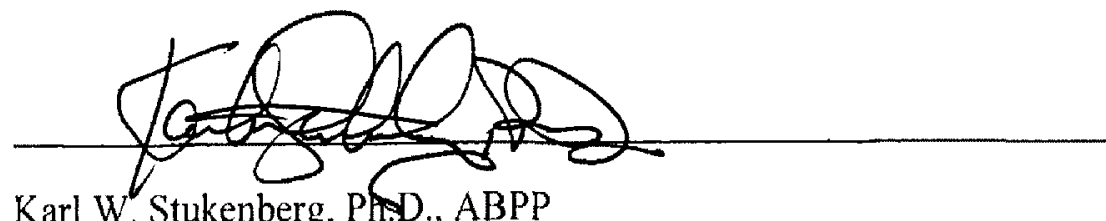

Karl W. Stukenberg, PASD., ABPP

Chair, Department of Psychology

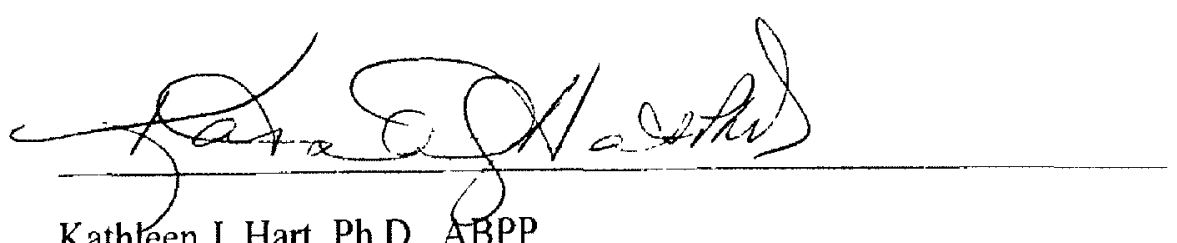

Kathleen J. Hart, Ph.D., ABPP

Dissertation Chair 
A Randomized Clinical Trial Examining the Effectiveness of a Hope Intervention for Low SES Children 
UMI Number: OP20300

All rights reserved

INFORMATION TO ALL USERS

The quality of this reproduction is dependent upon the quality of the copy submitted.

in the unlikely event that the author did not send a complete manuscript and there are missing pages, these will be noted. Also, if material had to be removed, a note will indicate the deletion.

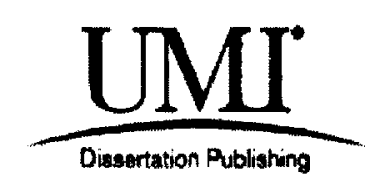

UMI DP20300

Published by ProQuest LLC (2013). Copyright in the Dissertation held by the Author.

Microform Edition @ ProQuest LLC.

All rights reserved. This work is protected against unauthorized copying under Title 17, United States Code

\section{ProQuest \\ ProQuest LLC. \\ 789 East Eisenhower Parkway \\ P.O. Box 1346 \\ Ann Arbor, Ml $48106-1346$}




\section{Dissertation Committee}

Chair

Member

Member
Kathleen J. Hart, Ph.D., ABPP

Professor of Psychology

Kathleen A. Burklow, Ph.D.

Psychologist

Harmony Garden

Nicholas L. Salsman, Ph.D., ABPP

Assistant Professor of Psychology 


\section{Acknowledgements}

The completion of this dissertation has been a challenging, rewarding academic endeavor. It is a pleasure to thank those who made this dissertation possible with their support, guidance, and patience. Dr. Kathleen Hart oversaw this highly-involved project as my advisor, despite her many other academic and professional commitments. Her wisdom, knowledge, commitment, and support throughout this process were invaluable. Working with Dr. Hart has been a pleasure. My committee members, Dr. Kathleen Burklow and Dr. Nicholas Salsman, provided valuable insights into my project, and their support and dedication throughout this process have been extremely helpful and appreciated. I would like to thank Harmony Garden and the Cincinnati Metro Housing Authority, whose generous financial, practical, and moral support made this project possible. Additionally, their hard work made my job much easier and more enjoyable. Erica Eisenman, my co-investigator, and the student research assistants involved in this process (Amanda Ball, Ashley Arnott Barroquillo Bailey Bryant, Jessica Buker, Melanie Castillo, Jennifer Daniel, Rachel Doty, Helmer Figueiredo, Alexandra Gee, Susan Kissel, Julie Adcock Meade, Andrea Perry, and Amanda Pizzi) were a tremendous asset, as this large-scale project could not have been conducted successfully without their participation, enthusiasm, initiative, and strong leadership abilities. Finally, and importantly, the support, patience, and encouragement of my husband and best friend, Tyler, has been a significant factor in my success not only in this project, but in my academic, professional, and personal life as a whole. 


\section{Table of Contents}

\section{Page}

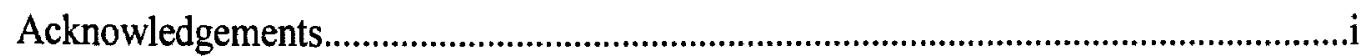

Table of Contents......................................................................................................

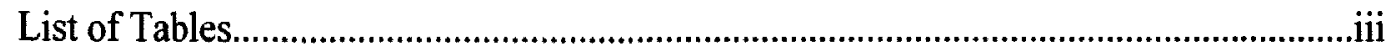

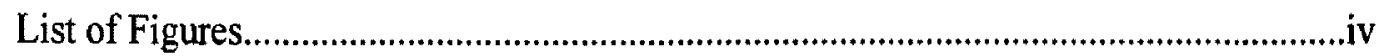

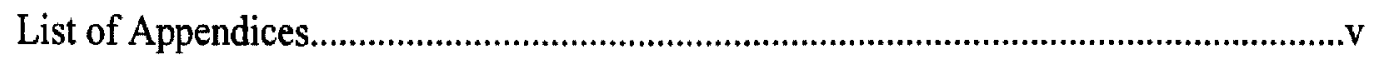

Chapter

I. Review of the Literature ....................................................................

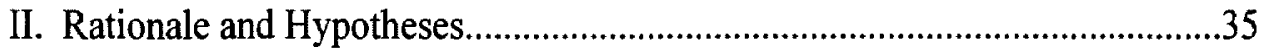

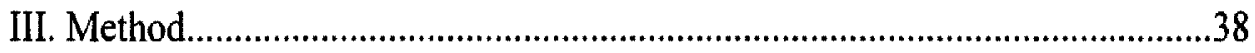

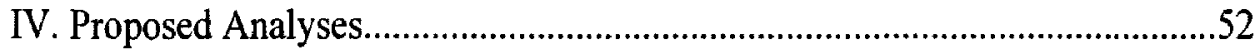

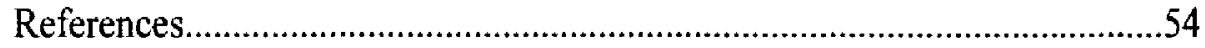

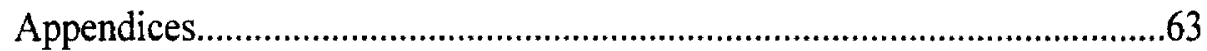

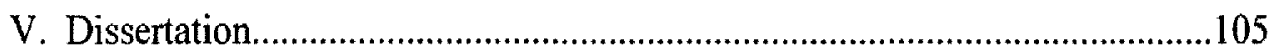

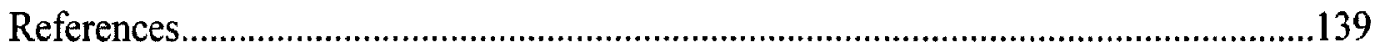

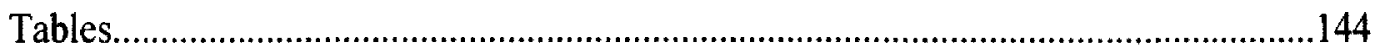

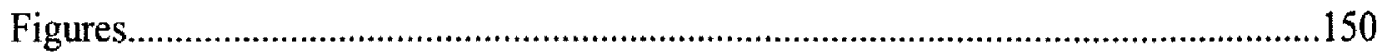

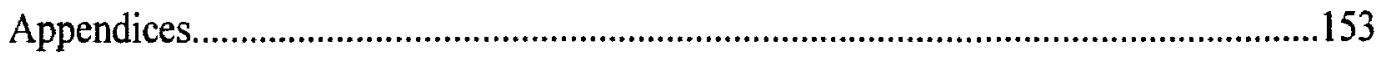

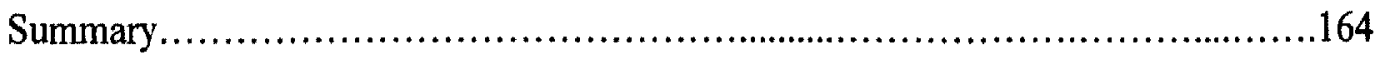




\section{List of Tables}

1. Means, standard deviations, and percentage characteristics of the $\mathrm{HI}$ and RE groups with t-test or Chi Square results

2. Intercorrelations among number of sessions attended and scores from the CHS, HSC, BMSLSS, YLOT, Adult Hope Scale, and Adult Hopelessness Scale for the entire sample at pre-test.

3. Intercorrelations among number of sessions attended and scores from the CHS, HSC, BMSLSS, YLOT, Adult Hope Scale, and Adult Hopelessness Scale for the entire sample at post-test.

4. Intercorrelations among number of sessions attended and scores from the CHS, HSC, BMSLSS, YLOT, Adult Hope Scale, and Adult Hopelessness Scale for the entire sample at follow-up.

5. Means, standard deviations, and longitudinal outcome measures for the $\mathrm{HI}$ and RE groups. 148

6. Effect size and required sample size calculations for the $\mathrm{HI}$ and $\mathrm{RE}$ entire sample and completers. 


\section{List of Figures}

Chapter V

Page

1. Difference in slopes between the HI and RE groups on the HSC from pre-test through follow-up for the entire sample. .151

2. Difference in slopes between the HI and RE groups on the HSC from pre-test through follow-up for completers only...............................................152 
List of Appendices

Proposal Page

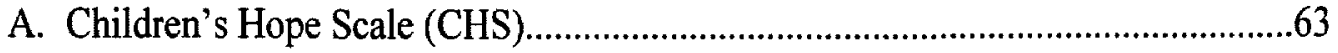

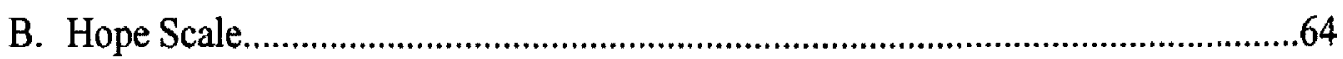

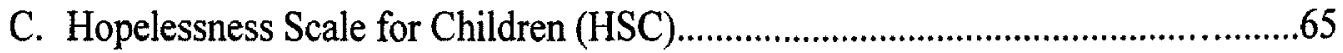

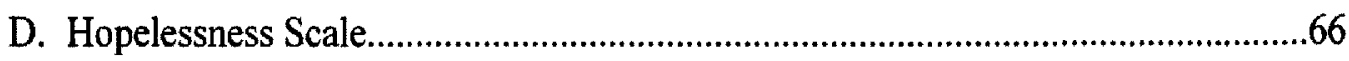

E. Brief Multidimensional Student's Life Satisfaction Scale (BMSLSS)..................67

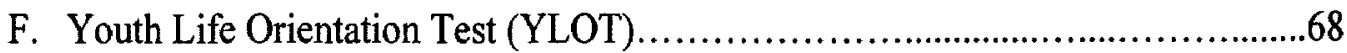

G. Parent/Guardian Consent Form..................................................... 71

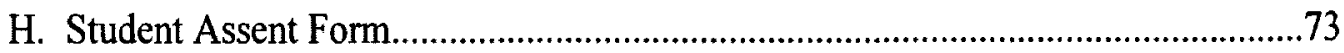

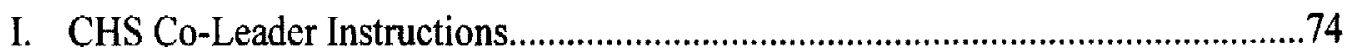

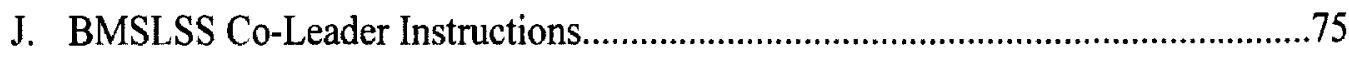

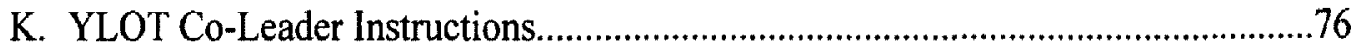

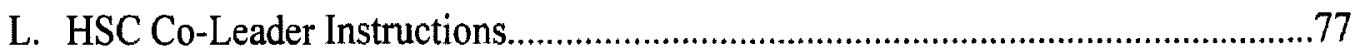

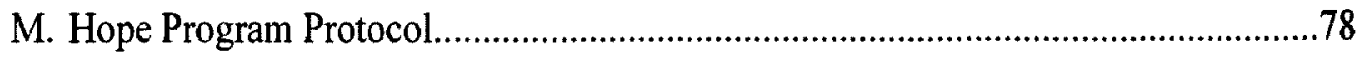

\section{Chapter V}

N. Letter of Permission from Cincinnati Metro Housing Authority.......................153

O. Institutional Review Board Approval Letter..........................................154

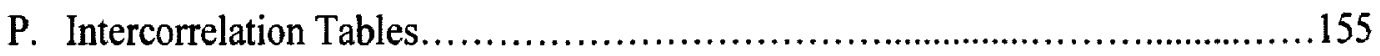

7. Intercorrelations among number of sessions attended and scores from the CHS, HSC, BMSLSS, YLOT, Adult Hope Scale, and Adult Hopelessness Scale for all completers at pre test...............................................155

8. Intercorrelations among number of sessions attended and scores from the CHS, HSC, BMSLSS, YLOT, Adult Hope Scale, and Adult Hopelessness Scale for the HI group (completers and non-completers) at pre test. 
9. Intercorrelations among number of sessions attended and scores from the CHS, HSC, BMSLSS, YLOT, Adult Hope Scale, and Adult Hopelessness Scale for the HI group (completers only) at pre-test.

10. Intercorrelations among number of sessions attended and scores from the CHS, HSC, BMSLSS, YLOT, Adult Hope Scale, and Adult Hopelessness Scale for completers only at post-test.

11. Intercorrelations among number of sessions attended and scores from the CHS, HSC, BMSLSS, YLOT, Adult Hope Scale, and Adult Hopelessness Scale for the HI group (completers and non-completers) at post-test.

12. Intercorrelations among number of sessions attended and scores from the CHS, HSC, BMSLSS, YLOT, Adult Hope Scale, and Adult Hopelessness Scale for the $\mathrm{HI}$ group (completers only) at post-test

13. Intercorrelations among number of sessions attended and scores from the CHS, HSC, BMSLSS, YLOT, Adult Hope Scale, and Adult Hopelessness Scale for completers only at follow-up.

14. Intercorrelations among number of sessions attended and scores from the CHS, HSC,BMSLSS, YLOT, Adult Hope Scale, and Adult Hopelessness Scale for the $\mathrm{HI}$ group (completers and non-completers) at follow-up.

15. Intercorrelations among number of sessions attended and scores from the CHS, HSC, BMSLSS, YLOT, Adult Hope Scale, and Adult Hopelessness Scale for the HI group (completers only) at follow-up 


\section{Chapter I}

\section{Review of the Literature}

A growing body of research has examined the role of hope in psychological wellbeing. Several studies have indicated that low hope has maladaptive effects on individuals' lives (e.g., Gilman, Dooley, \& Florell, 2006; Magaletta \& Oliver, 1999), including decreased resiliency (Ong, Edwards, \& Bergeman, 2006). One contributor to low levels of hope is low socioeconomic status (Garmezy, 1991). Conversely, high hope has demonstrated a variety of benefits, such as a higher likelihood of reaching goals (Snyder, Cheavens, \& Sympson, 1997), higher confidence (Hagen, Meyers, \& Mackintosh, 2005), and higher life satisfaction (Gilman et al.). Numerous researchers have identified specific factors that contribute to hopefulness. These factors have been combined to create interventions that are designed to increase hope in both children and adults (Alvord \& Grados, 2005; Synder, 1995). Research has demonstrated that increased hope in children correlates with increased parental hope (Venning, Eliott, Whitford, \& Honnor, 2007). Each of these areas of the literature will be explored in further detail.

\section{Maladaptive Effects of Poverty on Psychological States}

Poverty can lead to a variety of negative effects on human beings. In a review of the literature on the effects of poverty on individuals, Howard, Carothers, Smith, and Akai (2007) describe that for economically disadvantaged people, there exists an unfortunate cycle and interrelation of impoverished environments, poor health status, school dropout, and limited job opportunities, which predict a negative pattern of lifespan development and failure outcomes in childhood through adulthood. People who come from disadvantaged backgrounds typically display low levels of hope (Howard et al). 
Children in poverty have been found to function at lower levels psychologically than children who are wealthier. Muldoon (2000), using a series of questionnaires administered to children at 8 and 11 years of age, examined the development of selfperceptions in middle childhood. They also examined the effects of psychosocial factors (including socioeconomic status) on children's development. He found that with increasing age, young people's perceptions of themselves become increasingly stable. Children from lower socioeconomic status (SES) backgrounds and minorities demonstrated less positive self perceptions in several life domains at both ages 8 and 11 . Muldoon concluded that membership in lower status social groups places a psychological disadvantage on children in terms of self-esteem and self-competence.

Poverty can have detrimental effects on the entire family unit, especially when the family is headed by a single mother. Using qualitative interviews, Jarrett (1994) examined how low SES African American women responded to conditions of economic marginality in their daily lives. This author operated on the thesis that economic factors impede the construction and maintenance of mainstream family patterns by encouraging African American women to opt out of marriage, have children out of wedlock, head their own households, and rely on welfare for income. The consistent theme that emerged from the interviews was that while these women desired mainstream family patterns, they were not able to achieve this goal, mostly due to a lack of financial resources (Jarret).

The literature seems to demonstrate that poverty plays a maladaptive role in the psychological states and lives of children and adults alike. Because of the vulnerability to which this population is susceptible, it would be prudent to develop targeted interventions to improve the psychological states of economically disadvantaged people. While 
researchers may not be able to directly change the financial situations of impoverished individuals, they can utilize the knowledge that they have to improve their psychological functioning, with the aim of fostering change and improving their lives.

\section{Resiliency and Protective Factors}

Psychology has tended to focus on risks; more recent attention has been devoted to those factors that tend to "protect" individuals from adverse experiences. It is useful to understand the environmental factors that put people at risk and the protective factors that may be used to strengthen resilience. Alvord and Grados (2005) define resiliency as those skills, attributes, and abilities that enable individuals to adapt to hardships, difficulties, and challenges. Resilient characteristics are referred to as protective factors. Protective factors are influences that modify, ameliorate, or alter a person's response to some environmental hazard, thus helping the person avoid a maladaptive outcome (Alvord \& Grados, 2005). Protective factors are central to the development of success in the face of adversity (Howard et al., 2007). Some of these factors include dispositional attributes of the individual (i.e., temperament, responses to new situations, cognitive skills), having a relationship with an adult who is warm and caring (for children), and external support systems such as school or church (Garmezy, 1991; Howard et al.). Believing that resiliency skills can be strengthened and learned, Alvord and Grados suggest several protective factors to help children overcome risks associated with disadvantaged backgrounds. One factor is a proactive orientation, a characteristic that involves taking initiative in one's own life and believing in one's own effectiveness. Terms associated with this are self-efficacy, self-esteem, adaptive coping skills, and optimistic thinking. 
Another important factor is self-regulation, which means gaining control over one's attention, emotions, and behavior.

Richardson (2002) proposed a resiliency model that states that people, through planned disruptions (i.e., getting married) or reacting to life events, have the opportunity to consciously or unconsciously choose the outcomes of disruptions. To cope with life events, people acquire, through previous disruptions, resilient qualities so that most events become routine and are less likely to be disruptive. Chronic stressors negatively impact people when they do not develop resilient qualities or have not grown through the previous disruptions in their lives. According to Richardson, disruptions require changes to a person's world paradigm; outcomes can be positive or negative, depending upon the way the person perceives the change. Acquiring resiliency is a process in which one begins to recognize that one has choices to grow, recover, or lose in the face of disruptions. As a result of an extensive review of empirical studies on resiliency, Richardson concluded that when tracked into adulthood, most resilient, high-risk children grow up to be not only successful by societal indicators, but confident, competent, and caring. In many of the studies Richardson reviewed, the authors inferred resiliency by measuring such constructs as self-efficacy, planning skills, critical thinking skills, happiness, optimism, creativity and self-control. Those who demonstrated competency in these areas were labeled resilient.

Luthar (1991) examined vulnerability and resilience in adolescents. High-risk, inner-city ninth grade students completed measures of stress, personality variables (including intelligence, internal and external locus of control, social skills, ego development, and positive life events), and depression. Additionally, they provided 
information about their performance in school. Luthar found that an internal locus of control (the general belief that forces affecting one's life are within one's control) was a protective factor for assertiveness in the classroom. Children with an external locus of control (the general belief that forces affecting one's life are outside of one's control) demonstrated poorer functioning (as measured by a scale of depression) and increased levels of stress (as measured by scores on a negative life events scale) than children with an internal locus of control. This is consistent with the concept of learned helplessnessif individuals believe that their circumstances are outside of their control, they become passive in their coping abilities.

One important construct that is closely related to one's vulnerability, stress level, and overall functioning is hope. Hope, defined by Snyder (1995), is the cognitive energy and ability to create pathways to reach goals and is seen as an important source of resilience (Ong et al, 2006). People who are high in hope often experience many more psychological benefits (such as resiliency, optimism, and decreased stress) than those who are low in hope (Gilman et al., 2006; Wrosch \& Scheier, 2003). According to Snyder (2002), high hope adults, compared to low hope adults, possess a variety of psychological strengths that protect their future well-being. They are more easily able to establish clear goals, imagine pathways to those goals, and motivate themselves to follow up on these pathways. Maintaining hopeful thinking is a buffer against future, unforeseen life stressors.

Ong et al. (2006) investigated how variations in hope are associated with positive adaptation to stress in later adulthood. Older adults (aged 62 to 80 ) completed measures of personality and positive and negative affect, as well as the Adult Trait Hope Scale 
(Snyder et al., 1991) and the State Hope Scale (Snyder et al., 1996). They were also instructed to keep a diary of daily negative emotions, stressful events, and ratings of their perceptions of how stressful the events were. The researchers found that low hope individuals reported higher levels of daily stress. In contrast, high hope individuals demonstrated less reaction to stress and more effective emotional recovery from stress. The authors concluded that hope provides protective benefits by keeping negative emotions low, while also contributing to adaptive recovery from stress. The experience of hope exerts continual influence on health, well-being, and resiliency over time, indicating that hope is an important source of resilience in later adulthood (Ong et al.).

In summary, there are a variety of protective factors associated with resilience in children, adolescents, and adults, such as decreased stress, better ability to adapt to stress, optimistic thinking, and high self-esteem. Protective factors often lead to greater resiliency, which results in overall positive life benefits. Hope is one specific protective factor that increases resiliency and promotes positive life benefits. For this reason, hope is an important concept when considering one's psychological well-being, and it therefore may be important to consider teaching and increasing hope in individuals who lack it.

\section{Research on Hope}

Hope has become a popular area of study over the course of the last decade. Researchers studying hope have repeatedly found that hope creates positive benefits in peoples' lives and increases their resiliency (e.g., Gilman et al., 2006; Snyder, Feldman, Taylor, Schroeder, \& Adams, 2000). Important in the hope literature are the various ways 
hope has been conceptualized, the benefits of high hope and the disadvantages of low hope, interventions to teach and increase hope, and concepts related to hope.

Theories of Hope. Three theories of hope have dominated the literature over the course of the last three decades. Stotland (1969) suggested that the core of hope was "an expectation greater than zero of achieving a goal" (p. 2). This was based on a social psychological theory of cognitive schemas. Thus, high levels of hope reflect a perceived probability of attaining a goal. For Stotland, it is not appropriate or accurate to directly ask a person what his or her expectation of goal achievement is, but rather to infer the expectation by observing how a person reacts to antecedent conditions in terms of proceeding behavioral outcomes.

A more recent theory of hope is offered by Averill, Catling, and Chon (1990), who suggested that hope is an emotion that is governed by cognitive rules. The emotion of hope is viewed as being appropriate when a goal is important, under some control, feasibly attainable, and socially acceptable. This is based on a social constructionist approach that focuses on the norms or guidelines established in a given societal context.

Snyder (1995) provides the most recent, extensively-researched theory of hope, based on a unique definition of hope as "a cognitive set that is based on a reciprocally derived sense of successful a) agency (goal-directed determination) and b) pathways (plans for the ways to meet goals)" (p. 355). In this theory, goal thoughts are an especially important aspect of hope. Goals are defined as the targets of mental action sequences, and they provide the cognitive component that forms the basis for hope theory (Synder et al., 2000). Goals are the imagined endpoints for something that a person desires. There are two types of goals: those that involve preventing a negative outcome 
(deterring it so that it never appears or is delayed), and those that represent the desire for something positive (reaching a goal for the first time, sustaining a present goal outcome, or increasing the positive goal outcome when there has already been some desired movement).

According to Snyder (1995), all human beings are goal-directed, and goaldirected cognitions have two necessary components: agency (the cognitive willpower or energy to get motivated toward one's goal) and pathways (the perceived ability to generate routes to reach a goal). Agency thoughts provide motivation toward a goal; they reflect thoughts about one's perceived capacity to move along one's imagined pathways to goals (Snyder et al., 2000). They involve self talk such as, "I can do this." Agency thoughts are especially important when initial pathways are blocked and one needs to channel his or her motivation to appropriate alternate pathways. Pathways involve one's perceived capability of thinking of effective routes to reach a desired goal. In thinking about their goals, people perform a cognitive analysis of their agency and pathways. One must have both agency and pathways to reach a goal, and neither by itself is enough to produce high hope. High hope children and adults set more difficult goals for themselves, but not so difficult that they could not possibly be attained. They also tend to break down their goals into subgoals. High hope people are more likely to attain their goals than lowhope people. If two people are equal in ability but unequal in hope, the higher hoper will usually outperform the lower (Snyder et al., 1997).

Snyder, Feldman, Shorey, and Rand (2002) suggest that the first step in building hope in children is to help students identify a set of goals. Students should be encouraged to set goals in various life domains, which may be difficult for low-hope or hopeless 
students. Hopelessness is a state in which people have come to believe, perhaps through negative experiences, that they have little or no control over their own lives. Once clear goals are established, it is important to help students set clear endpoints to demonstrate that a goal has been achieved (i.e., "to get good grades" has no endpoint, whereas "to get a B on a science test" does). Children should be encouraged to choose approach goals (trying to get or do something) rather than avoidance goals (trying not to experience negativity). Research demonstrates that high hope students embrace approach goals, and low-hope students embrace avoidance goals (Snyder et al.). The next step in building hope involves helping students build the agency to pursue their goals. One should reexamine the student's list of goals to make sure they are personally important and challenging and that that the student is not simply aiming for something in order to make others happy. Then, students should be helped to establish plans for accomplishing goals (pathways). Larger goals should be broken into smaller subgoals-low hope children have major problems doing this (Snyder et al.).

According to Snyder et al. (2002), hope is not just a goal-directed process; it is also a hierarchically organized system of beliefs regarding one's ability to successfully engage in such a thought process. These beliefs are organized into three specific levels: global or trait hope (one's overall evaluation of his or her ability to construct specific pathways and generate the agency thoughts necessary to achieve goals in general), domain-specific hope (one's hope in specific areas of life, including family life, romantic relationships, academics, work, leisure, etc.), and goal-specific hope (one's level of hope pertaining to a specific goal in an area of life, such as receiving an A on a test). It is possible to be high in global hope but have low hope in more specific areas of life 
(domain-specific hope), but people who are high in global hope will likely be high in most other areas of hope. Snyder et al. emphasize that it is necessary to assess the entire hope hierarchy to understand individuals' goals for their education and lives.

Snyder's Hope Theory is cognitive in nature but does not neglect the importance of emotions (Snyder, 1995). A person's emotions reflect the perceived level of hope one has in a particular situation. Higher-hope people, with elevated agency and pathways, approach goals with a positive emotional state that focuses on success rather than failure, and lower-hope people, with deficient agency and pathways, approach a goal with a negative emotional state and a focus on failure rather than success.

The main advantage of Snyder's Hope Theory over other theories of hope is that it enables hope to be psychometrically measured rather than inferred from behaviors. Additionally, because it breaks the cognitive process of attaining goals into two components (agency and pathways), it may provide a more in-depth analysis of the goalseeking process (Snyder, 1995).

Development of Hope. Snyder, Cheavens, and Sympson (1997) contend that humans build pathways and agency thought almost from birth. These authors hypothesize that by sensing and perceiving the world, infants learn about linkages between events and begin to form goals in order to satisfy their needs. By the toddler stage, if proper parental care and attention have been established, hope is in place. Loss of hope in children can occur when newborns do not receive the necessary care and attention to develop hopeful thinking (Snyder, 2000; Snyder et al., 2002). Children who are neglected have no one to teach them hope. Children who are raised in an environment of physical and/or sexual abuse, or that lacks consistency, boundaries, and support also are at risk for not 
developing hopeful thinking. Additionally, if a caregiver forces his or her own goals and aspirations on a child, the child's hope may be hampered because he or she is not allowed to pursue goais that match his or her temperament and talents. Through the encouragement of role models (e.g., parents, caretakers, teachers, and friends), high hope children learn to find and maintain pathways and agency thoughts for reaching their goals despite barriers they may encounter (Snyder et al., 1997).

Benefits of Hope. Many studies have demonstrated that high hope is associated with a host of positive benefits in children, adolescents, and adults. In contrast, research has consistently demonstrated that low hope is related to various negative outcomes (including psychological distress and poor academic achievement; Gilman et al., 2006; Hagen et al., 2005; Snyder et al., 2000).

Hope is highly related to academic success. Snyder, Shorey, Cheavens, Pulver, Adams, and Wilklund (2002) examined the relationship between hope and academic success in college. They measured students' hope levels using the Hope Scale when they entered college, grade point average (GPA) at the end of their first and second semester, and cumulative GPA and graduating status at the end of a six-year period. They found that higher hope scores predicted higher cumulative GPAs, a higher likelihood of graduating from college, and a lower likelihood of being dismissed because of poor grades. Students with low hope scores performed more poorly in school and were much less likely to graduate than students with high hope scores. This demonstrates the educational utility of the construct of hope. Similarly, Curry, Snyder, Cook, Ruby, and Rehm (1997) investigated the role of hope in sports achievement, in addition to academics. They found that athletes obtained higher scores on the Hope Scale than 
nonathletes, and higher hope scores among athletes were related to better classroom achievement. Hope scores predicted higher athletic achievement beyond the amount of time athletes practiced each week and natural athletic talent.

Hope is also a predictor of one's reaction to success or failure in an academic situation. Snyder et al. (1991) investigated how college students who reported high and low hope scores would react when they received a poor grade in a class in which good grades were highly emphasized as a measure of success in the class. Students were administered the Hope Scale and were asked to set a realistic goal for their final grade in their psychology class before they had taken any exams. Three weeks later, participants were asked to report their grade on their first exam, and they were reminded of the goal they had set for their grade. Low hope students who had received a low exam grade experienced decreased pathways and agency thinking, and high hope students who had received either a low or high exam grade increased their agency and pathways thinking. These authors concluded that goal-directed thinking in high hope students kicked in especially when adversity was encountered. Snyder et al. concluded that high hope people experience advantages under regular circumstances as well as adverse circumstances.

Several researchers have also investigated the benefits of hope for children. Hagen et al. (2005) investigated the effects of hope, social support, and stress on behavioral problems in a high-risk group of 65 children (ages 6 to 12) of incarcerated mothers. Their aim was to investigate whether at-risk children's level of hope predicted adaptive behavior beyond the advantageous effects of social support and the detrimental effects of stress. Children completed scales measuring social support, internalizing and 
externalizing behavior, and the Children's Hope Scale. Results demonstrated that higher hope scores were correlated with self-reports of better adjustment and fewer internalizing and externalizing problems. Hagen et al. interpret this as an indication that being hopeful is predictive of adaptive functioning and that, in contrast, not being hopeful about themselves and their situation puts children at risk for developing behavioral problems. Stress and hope were independent of one another for these children, suggesting that hope is based on the interpretation of challenging events, not the frequency or severity. Hope Pathways were significantly related to social support, while hope Agency was not; thus, in attempting to increase a child's hopefulness, Hagen et al. suggest that efforts could be targeted at strengthening the child's hope Pathways. Being confident in one's ability to overcome challenges and having a positive outlook function as protective factors, whereas being less hopeful may place a child at risk for developing adjustment problems (Hagen et al.).

Gilman et al. (2006) studied the benefits of hope in adolescents. They examined the relationship between adolescent students' scores on the Children's Hope Scale and academic and psychological indicators of school adjustment. Middle and high school students $(n=341)$ completed measures of life satisfaction, extracurricular activities, and the Children's Hope Scale, and they provided their GPA. Results indicated that both Hope Scale subscales (Agency and Pathways) were significantly positively related to global life satisfaction, personal adjustment, GPA, and participation in extracurricular activities, while the subscales were negatively correlated with indicators of psychological distress and school maladjustment. Youth with average to high Hope Scale scores reported significantly less school and psychological distress and significantly higher 
personal adjustment and global life satisfaction than those with lower hope scores. The authors interpreted this finding to mean that low hope youth may possess cognitive strategies that are either inflexible or ineffective in pursuing goals. Many adolescents reporting low hope also reported levels of psychological distress and/or poor socialemotional functioning that would be considered clinically relevant. Very few students in the high and average hope groups endorsed clinically relevant levels of psychological distress, which Gilman et al. interpret as a reflection of the positive mental health and academic benefits of hopefulness. Similar findings have been obtained with both college students and older adults.

Further investigating hope in adolescents, Gilman and Huebner (2006) examined characteristics of adolescents who report very high life satisfaction. Participants were 485 adolescent students in grades 6 through 12 who completed measures of life satisfaction, interpersonal and intrapersonal social stress, school-related functioning, and behavioral functioning. The high life satisfaction group reported more positive relationships with others, less intrapersonal distress (i.e., less anxiety and depression), higher levels of hope, and a greater sense of personal control than those in the lower life satisfaction group. Taken together, these findings suggest that high life satisfaction is associated with some mental health benefits (such as hope) that are not found among youth with lower life satisfaction.

In summary, the emerging literature indicates that high levels of hope offer many benefits to people over the entire lifespan. It may be most important to intervene to increase hope during childhood, as this is the time when hope develops. Fostering high hope in children can lead to benefits for a lifetime. 
Interventions to Increase Hope. A wide variety of interventions have been proposed and implemented to increase hope in low-hope individuals. Most of these interventions have been aimed at increasing hope in adults.

The Hope Therapy Protocol (Cheavens, Feldman, Gum, Michael, \& Snyder, 2006) which is based on Snyder's (1995) Hope Theory, was developed to increase hopeful thinking and enhance goal-pursuit activities in adults. This program takes a psychoeducational approach to hope and involves introducing the principles of hope theory and then giving participants suggestions about how to apply these principles to their own lives. Participants learn how to set meaningful, achievable, measurable goals; develop multiple pathways to work toward goals; identify sources of motivation; monitor progress toward goals; and modify goals and pathways as needed. Cheavens et al. evaluated the efficacy of the Hope Therapy Protocol by randomly assigning adult participants to the treatment (hope) group or to a wait-list control group. Participants completed the State Hope Scale as well as measures of depression, anxiety, self-esteem, and purpose in life before and after the intervention. Results indicated that participants in the treatment group increased their Agency scores on the State Hope Scale significantly more than those in the control group. Participants in the treatment condition had a greater decrease in depressive and anxiety symptoms and greater increases in self-reported life meaning and self-esteem from pre-test to post-test than the control group. This demonstrates the potential value of hope interventions.

Trump (1997) concluded that exposure to hopeful narratives can impact the hope of survivors of trauma. Trump investigated the effects of a videotaped intervention consisting of hopeful narratives on state levels of hope, self-esteem, and positive and 
negative affect for 42 adult female survivors of childhood incest. Participants completed measures of the above-mentioned constructs immediately before and after watching the tape of a hopeful narrative or a comparison videotape. While the results indicated that positive affect did not significantly increase for either group, there was a significant increase on the Hope Will (Agency) subscale of the State Hope Scale for the experimental group.

Hope interventions have been tested in both older and younger adults. One intervention consisted of a 10-week series of hope-based group activities in a sample of depressed older adults. Participants completed measures of anxiety and depression as well as the Hope Scale at pre and post intervention. Results indicated that at posttreatment, adults in the Hope Intervention group, compared to those in the control group, had significantly fewer depressive symptoms and significantly higher activity levels (Eliott, 2005). A similar group therapy format was conducted and tested with younger, distressed adults. The intervention consisted of eight sessions focusing on goal-setting as well as pathways and agency skills. The intervention was effective in decreasing depressive and anxious symptoms and increasing Hope Scale scores (Eliott).

While most interventions to increase hope thus far have targeted adults, it may be more important to implement interventions with children due to the importance of the development of hope in childhood. Eliott (2005) describes a few studies in which hope interventions were implemented at the grade-school and junior high levels. In one intervention, grade-school children were exposed to an hour and a half long hope session once a week for five weeks. Results suggest that, when compared to the children who received no intervention in the control condition, children in the Hope Intervention 
condition had higher self-reported hope scores. Another hope program involved students at the junior high level, which is a critical time in development during which adolescents may be especially at risk. This hope intervention was conducted in the classroom setting at various junior high schools. Results indicated that hope was increased as a result of this intervention, and the increases in hope scores were accompanied by higher grades (Eliott).

In summary, the research on hope is vast and promising. Snyder's (1995) Hope Theory seems to be the most prominent theory of hope currently, as it integrates important aspects of other hope theories, including cognitions and emotions, but with the important added benefit of the ability to measure hope psychometrically. The benefits of hope in children, addolescents, and adults are myriad, rendering hope essential in human beings. High levels of hope provide substantial psychological and life benefits for people, and low hope leads to negative outcomes. There are a number of interventions and techniques available to increase hope in adults and children; however, interventions to increase hope in children are lacking. Additionally, the previously-mentioned studies may lack a certain amount of rigor in terms of short duration, lack of control or comparison groups, and lack of follow-up assessments. Therefore, in the current study, a hope intervention will be implemented that is of longer duration and that includes a comparison group and follow-up assessments to determine the durability of the intervention. It is also notable that there is a lack of peer-reviewed studies on hope, as most of the literature on hope stems from the theories of Snyder and his colleagues. 


\section{Concepts Related to Hope}

There are several psychological concepts that are related to hope, including optimism, life satisfaction, and hopelessness. These concepts will be discussed in relation to hope below.

Optimism. Optimism is defined by Seligman (2002) as "a pattern of making external, variable, and specific attributions for negative outcomes rather than internal, stable, and global attributions" (p. 13). Scheier and Carver (1985) explain that optimism is the generalized expectancy that the future will be positive- that good rather than bad things will happen. There are several similarities and differences between hope and optimism. Hope and optimism are both stable, dispositional traits (Snyder et al., 2002). Similar to hope, optimism is a positive anticipatory state, which is why the two have been portrayed similarly in the literature. Individuals who are high in hope tend to be high in optimism (Wrosch \& Scheier, 2003). Mental energy (agency) is a focus of both hope and optimism. When an optimistic person is unsuccessful, he views this as a temporary setback that is limited to a specific case and that is not directly his fault (Snyder \& Lopez, 2002). Hopeful individuals also view the setback as temporary because they have the ability to choose another path, and the failure of the path is a reflection of the inadequacy of the chosen route, not the inadequacy of the individual.

However, there are some distinctions between the two constructs. Averill et al. (1990) suggest that the primary difference is that hope is an emotion, whereas optimism is a cognitive state. In Snyder's et al. (1991) theory of hope, optimism is viewed as a focus on outcome expectancies determining goal-directed behavior, whereas hope involves a reciprocal action between efficacy expectancies (agency) and outcome 
expectancies (pathways). Optimism and hope are also different in terms of coping; a high hope individual has both the will and ways, whereas an optimist has only the will (Wrosch \& Scheier, 2003). Optimism theory holds that when an individual experiences failure, he externalizes this experience and distances himself from it. In contrast, hopeful individuals use these failures to learn and do not distance themselves from the experience (Snyder, 1994). Finally, according to Snyder (2000), optimism focuses on the end (outcome), whereas hope focuses on the process and the goal.

Bruininks and Malle (2005) asked undergraduates to describe a variety of affective states, including hope and optimism. Hope and optimism were found to be differentiated, as the students believed people are often optimistic about general outcomes (i.e., "today will be a good day") and hopeful about more specific outcomes (i.e., recovering from the flu). The students also viewed hope, but not optimism, as an emotion. Optimism appears to be associated with outcomes that encompass more positive affect than hoped-for outcomes (i.e., optimism occurs if the person anticipates good weather on the day of a picnic and therefore looks at the situation in a positive way; if the person just hopes for good weather, he or she is not sure the picnic will actually occur, so there is some negative affect associated with the hope). Thus, it appears that while hope and optimism are similar, people think about them in distinct ways (Bruininks \& Malle).

Bryant and Cvengros (2004) also investigated the similarities and differences in hope and optimism. They analyzed the adult Hope Scale (HS) and the Life Orientation Test (LOT), which was designed to measure optimism. They found that optimism correlated equally with both the Agency and Pathways subscales of the Adult Hope Scale, whereas pessimism was more strongly correlated with Agency than with 
Pathways. These researchers suggest that hope focuses more directly on the personal attainment of specific goals, while optimism focuses more broadly on the expected quality of future outcomes in general. They also concluded that hope has more to do with general self-efficacy than does optimism, whereas optimism has more to do with positive reappraisal coping than does hope. Optimism has stronger implications for dispositional cognitive appraisals of personal outcomes, whereas hope is more strongly tied to dispositional beliefs about personal capabilities (Bryant \& Cvengros).

Magaletta and Oliver (1999) examined the relationships between the construct of hope and the constructs of self-efficacy and optimism. Undergraduates $(n=204)$ completed measures of hope, self-efficacy, and optimism. The results supported the existence of self-efficacy, optimism, and hope as related but not identical constructs. Hope, self-efficacy, and optimism each made a significant and unique contribution to the prediction of well-being, demonstrating that while these three are related, they are are separate, distinct entities.

Life Satisfaction. Life satisfaction is defined as the cognitive evaluation of one's life, assessed globally or by specific domains (Diener, Emmons, Larsen, \& Griffin, 1985). Life satisfaction may reflect conscious, inner, pleasant experiences that motivate people to pursue goals (Frisch, 1992). Diener, Sapyta, and Suh (1998) describe life satisfaction as a person's evaluation of his or her own life; it results from people having a feeling of mastery and making progress toward their goals. This is similar to the concept of agency, which is a sense of successful determination in meeting goals in the past, present, and future. It is also similar to pathways, a sense of being able to generate successful plans to meet goals (Snyder et al., 1991). A strong predictor of life satisfaction 
is the presence of personal strivings that organize and integrate a person's goals (Emmons, 1986). Hope and optimism are two separate but related constructs that also predict life satisfaction (Bailey, Eng, Frisch, \& Snyder, 2007).

Bailey et al. (2007) investigated the hope and optimism constructs and their unique contributions in predicting life satisfaction by comparing the Agency and Pathways subscales of the HS (Snyder et al., 1991) and optimism and pessimism as measured by the Life Orientation Test-Revised (LOT-R; Scheier, Carver, \& Bridges, 1994). Both the HS and LOT-R were significantly correlated with life satisfaction; the Agency subscale of the HS was the strongest and most unique predictor of life satisfaction (Bailey et al.).

Bailey and Snyder (2007) compared the HS scores and the Satisfaction with Life Scale (SWLS; Diener et al., 1985) scores of 215 college students. The moderate and significant $(r=.51)$ correlation between the total HS and SWLS indicated that people who are satisfied with their lives are also hopeful. Agency appeared to be more significantly related to life satisfaction than Pathways.

Gilman and Huebner (2006) further describe the relationship between life satisfaction and hope, focusing on adolescents who report very high life satisfaction. Participants were 485 adolescents (grades 6-12) who completed measures of life satisfaction and the Children's Hope Scale (CHS; Snyder et al., 1997). Students with high levels of life satisfaction reported lower levels of depression, anxiety, and stress and higher levels of hope than students with low or average life satisfaction (Gilman \& Huebner). This relationship indicates that hope and life satisfaction are closely related. 
In a similar study, Gilman et al. (2006) also found significant relationships between hope and academic and psychological indicators of adjustment among adolescents. Results indicated that both subscales (Agency and Pathways) of the CHS were significantly positively related to global life satisfaction. Adolescents with average to high CHS scores reported less school and psychological distress and significantly higher global life satisfaction than those with lower hope. Higher hope thus may be correlated with positive mental health benefits, including high satisfaction with one's life (Gilman et al.).

It is apparent from the literature that hope and life satisfaction are related constructs. Hope is a significant predictor of life satisfaction, and those who are hopeful tend to have high levels of life satisfaction.

Hopelessness. Hopelessness is another construct that is related to, but very much different from, hope. Hopelessness is defined as negative expectancies about the future and is positively related to depression and suicidal ideation and behavior (Beck, Weissman, Lester, \& Trexler, 1974). Hopelessness theory proposes that there are three depressive styles that serve as vulnerability factors to depression (Abramson, Metalsky, \& Alloy, 1989). The first is a depressive attributional style, which is the tendency to impute negative events to global and stable causes. The second, a depressive inferential style about consequences, refers to the tendency to perceive negative events as having many disastrous consequences. The third is a depressive inferential style about the self, which is the tendency to view the self as flawed or deficient following negative events. Making these types of inferences increases the likelihood of developing hopelessness. Once hopelessness develops, depression is inevitable because, as hopelessness theory 
suggests, hopelessness is viewed as a cause of depression (Abramson et al.). In an extension of hopelessness theory, Rose and Abramson (1992) hypothesized that negative events in childhood, especially verbal victimization (e.g., teasing, rejection, and humiliation) would contribute to the development of a negative attributional style, which would then leave the child vulnerable to depression and hopelessness.

Testing the integration of hopelessness and self-esteem theories of depression, Abela and Payne (2003) asked children in third through seventh grade to complete measures of depression, attributional style, cognitive style, self-esteem, and negative life events. In line with hopelessness theory, the authors found that depressive inferential styles along with negative life events predicted higher hopelessness. Depressive inferential styles also interacted with negative events to predict increases in hopelessness in boys with low (but not high) self-esteem. This study highlights the tendency of some children to exhibit depressive, hopeless reactions to negative events (Abela \& Payne). Along with negative life events, poverty is one factor that has been found to be linked with feelings of hopelessness (Bolland, Lian, \& Formichella, 2005). Feelings of hopelessness seem to be a part of growing up poor for some children. Bolland et al. were interested more specifically in the origins of hopelessness among inner-city AfricanAmerican adolescents. Participants in this study were children and adolescents aged 10 to 18 who lived in impoverished neighborhoods. These youth answered survey questions about their risk behaviors (e.g., alcohol and drug use and sexual behavior), circumstances (e.g., family structure and peer pressure and support), attitudes (toward such things as violence and sexuality), and certain psychosocial variables (e.g., self-worth, hopelessness, etc.). The findings suggest that not all children living in poverty are 
hopeless, which indicates that there are both risk and protective factors within poverty that are associated with feelings of hopelessness. For those in this study who were hopeless, disruptive factors such as change in a mother figure, witnessing violence, traumatic stress, and worry were associated with increases in hopelessness over time. Connectedness to the neighborhood, the mother figure, and religious beliefs were correlated with lower hopelessness over time. The findings suggest that youth interventions aimed at changing youths' beliefs about their social environment may be the most effective way to reduce risky behaviors (Bolland et al.). Reducing hopelessness in inner-city adolescents may be crucial to their well-being and to their futures.

In a related study, Bolland, McCallum, Lian, Bailey, and Rowan (2001) investigated the link between hopelessness, uncertainty about the future, and risk behavior in inner-city youths. Certainly, adolescents growing up in inner cities have reason to approach their future with skepticism, as inner-city populations often have high mortality rates, a high level of violence, higher levels of health problems, and a higher percentage of people in prison or jail than in more economically advantaged populations. In this study, adolescents aged 9 to 19 living in public housing neighborhoods completed a questionnaire addressing hopelessness, expectations about the future, and experience with fighting and weapons. The results suggest that many youths raised in this type of environment recognize the futility of planning a future because of the hopelessness of escaping from the present. Over half (57\%) of youths living in public housing believe that the future is too uncertain to plan ahead, and $75 \%$ believe that it is best to live for today and let tomorrow take care of itself. The results also suggest that hopelessness is related to violent behavior, such as carrying and pulling knives and guns for males and 
fighting and carrying knives for females (Bolland et al.). An important implication of this study is that interventions that reduce hopelessness could reduce violent behavior in inner-city youth.

Tanaka, Sakamoto, Ono, Fujihara, and Kitamura (1998) investigated hopelessness in a community sample. Participants were adults aged 18 and older who completed an interview and measures of hopelessness, personality, and parental bonding. Regarding the association between hopelessness and perceived relations with parents, the authors found that parents who show little affection, particularly fathers, may contribute to subsequent hopelessness in their children. Loss experiences in childhood, particularly the loss of the father, may increase the later incidence of hopelessness and even suicide attempts. These findings suggest the importance of affectionate parenting by both the mother and father. If this is not available to a child, the child must learn another way to increase his or her hope and reduce hopelessness.

The literature indicates that hopelessness may be a problem for many children who are socioeconomically disadvantaged. An intervention to reduce their hopelessness and increase their hope may help them discover ways to circumvent their circumstances and achieve their goals.

\section{Correlations Among Psychological States in Parents and Children}

Parent and Child Depression and Anxiety. Research has demonstrated wellestablished correlations between children's and their parents' psychological states, such as depression and anxiety. Different researchers have speculated about the nature of the relationship between parent and child depression. One hypothesis is that children become depressed from living with a depressed parent, especially a depressed mother (Downey \& 
Coyne, 1990). Beardslee, Bemporad, Keller, and Klerman (1983) used diagnostic criteria and included a control group to assess depression in children and parents. In this study, $7 \%$ of children with a depressed parent met the diagnostic criteria for depression, and $25 \%$ showed depressive symptomatology, whereas none of the control children were depressed.

Abela, Skitch, Adams, and Hankin (2006) investigated whether depression and hopelessness were correlated in children and their parents. Parents with a history of major depressive episodes and their children completed measures of depression and hopelessness at six-week intervals over the course of a year. The results indicated that parents who had elevations in depression and hopelessness had children who also reported elevations in these domains. This association was especially strong for female children and their parents.

In an additional study assessing the relationship between hopelessness in parents and children, Melhem et al. (2007) identified clinical predictors of mood disorders in children of parents with a history of mood disorder. Offspring of parents with mood disorders were interviewed once yearly over a six year period. Depressive symptoms and hopelessness were assessed using the Beck Depression Inventory and the Beck Hopelessness Scale. Results indicated that offspring of parents who had mood disorders had higher incidences of mood disorders (including feelings of hopelessness) than those with parents who did not have mood disorders.

Ge, Conger, Lorenz, Shanahan, and Elder (1995) examined mutual influences in parent and adolescent psychological distress, including depression. Using measures of psychological distress at one-year intervals over a period of three years, they found that 
parent and adolescent stress were related reciprocally across time. These findings suggest that psychological distress experienced by close relatives is an interpersonal source of distress for other family members. The relationship between the distress experienced by adolescents and parents appears to be bidirectional and interrelated (rather than caused by the parent or child) with a significant association over time (Ge et al.)

Anxiety is another psychological state that has been found to be correlated in parents and children. Tsao, Myers, Craske, Bursch, Kim, \& Zelter (2005) investigated the relationship between parent and child anxiety sensitivity (AS - the tendency to interpret anxiety-related bodily sensations such as rapid heartbeat as leading to harmful physical or psychological consequences) in nonclinical samples. The authors examined this association in 207 healthy parent-child pairs using parent and child versions of an index of AS. They found that parental AS was significantly associated with child AS in girls, but not boys (Tsao et al.).

Parent and Child Positive Cognition. Positive cognitions are defined here as learned resourcefulness, positive self-evaluation, optimism, resiliency, and subjective well-being (Brewin, Andrews, \& Furnham, 1996; Greeff \& Human, 2004; Hasan \& Power, 2002). Brewin et al. investigated intergenerational influences in positive cognitions relevant to mental and physical health. Participants were undergraduate freshmen and their parents who completed measures of self-evaluation, learned resourcefulness, positive self-evaluation, and optimism. While optimism demonstrated no evidence of intergenerational influences, self-report measures of both learned resourcefulness and positive self-evaluation were associated in parents and children. This 
finding supports the possibility of within-family transmission of some kinds of positive cognitions relevant to physical and mental health (Brewin et al.)

Hasan and Power (2002) investigated optimism and pessimism in parents and children. A community sample of 81 children and their parents completed measures of optimism, pessimism, and depressive symptoms. Mothers' pessimism was positively correlated with children's pessimism $(r=.22)$. Hasan and Power interpret this as meaning that mothers who tended to anticipate bad outcomes had children who also tended to believe that things may not work out positively in the future. In addition, mothers' depressive symptoms were negatively correlated with child optimism $(r=-.26)$.

Positive cognitions, such as resilience and optimism, may be important for families that have experienced significant stressors such as the death of a family member. Greeff and Human (2004) administered questionnaires of family hardiness, family sense of coherence, and social support to an adolescent child and surviving parent after the other parent had died. They concluded that characteristics of individuals within the family, such as resiliency and optimism, tended to "rub off" on other family members, thus helping the family to cope with the death (Greeff \& Human). This delineates an important application of the correlations among psychological states in children and their family members (including parents); when just one person copes positively with situations, it can have positive effects on other family members in times of need.

Ben-Zur (2003) focused on the relationship of subjective well-being (SWB) in children and parents. One hundred twenty-one adolescents and their parents completed measures of mastery, optimism, and SWB. While no significant associations were found between adolescents' and parents' mastery and optimism, positive correlations were 
found between the adolescents' and their parents' (especially the fathers') SWB. Positive correlations were àlso found between adolescents' and mothers' life satisfaction. This suggests that parents and children share a subjective reality including values and worldviews and demonstrates a correlation between parents' and children's emotional responses (Ben-Zur).

Life satisfaction is similar to SWB. Shek (1999) investigated the relationships between perceived parenting characteristics and adolescent life satisfaction. Adolescents aged 12 to 16 years completed instruments assessing parenting characteristics and SWB, and parents completed a questionnaire measuring psychosocial adjustment at two times over a one year period. Adolescents' perceptions of their parents' SWB and life satisfaction were related to their own self-reported functioning in these domains. Shek (1999) interpreted this finding to mean that life satisfaction is correlated in parents and children.

Parent and Child Hope. Correlations between parent and child hope are scarce in the research. However, a few studies have attempted to describe this relationship, primarily with special populations. Kirpalani et al. (2000) investigated the importance of parental hope in the quality of life in their children with spina bifida. Parents completed a form to describe current functioning in their child, a hope measure, and a health-related quality of life (HRQL) questionnaire (children who were 13 years and older completed the questionnaire themselves). The researchers found a strong association between a child's HRQL score and parental hope. This study demonstrates, for the first time, that differences in HRQL for children and adolescents with spina bifida can be attributed, at least in part, to differences in the degree of parental hope. Hopefulness is critical for 
sustaining and maintaining a mother's work in the care of her disabled child, and the child's quality of life is affected by his or her parents' hope (Kirpalani et al.).

Venning et al. (2007) also investigated the correlation between hope in children and their parents. Specifically, they investigated the impact of a child's chronic illness on hopeful thinking in children and parents, assessing the impact of a child's congenital or acquired iliness, or no chronic illness (control group) on hope scores reported by 132 children and parents. The researchers demonstrated that children with a chronic illness (congenital or acquired) and their parents reported lower hope scores than controls. Hope scores of children and their parents were highest when the child was without a chronic illness and lowest when a child was faced with a chronic illness (Venning et al.).

Continuing with the research on childhood medical illness and hope in children and their parents, Wong and Heriot (2008) investigated how parents of children with cystic fibrosis hope, cope and despair. Coping, hope, and despair are constructs that may explain why some children and their parents adjust well to cystic fibrosis, while others adjust poorly. The transactional stress and coping model implies that parent coping interacts with child adjustment. The researchers found that high parental hope and low despair predicted better child mental health and less parental anxiety. Hope in parents was associated with better child physical functioning and child mental health and lower parent depression. Hope in parents was the strongest predictor of mental health in children. Therefore, hope, coping, and despair in parents are important predictors of mental health in children (Wong \& Heriot).

In another study focusing on hope, Westburg and Martin (2003) examined the relationship between a child's hope, a parent's hope, and student-directed, goal-directed 
academic instruction. Levels of hope were measured in 46 child-parent pairs before and after the children participated in four weeks of goal-directed academic instruction. Results demonstrated that children's Pathways scores increased, but parents' Hope Scale scores were not correlated with their child's scores (Westburg \& Martin). However, these results are tentative because this is one of the first studies to directly examine the relationship between a child's and parent's hope as the result of a hope intervention; therefore, further research must be conducted.

The body of literature on the relationships between psychological states among parents and their children, while sparse at the present time, suggests that in the majority of cases, the psychological states of children and their parents are correlated. Children of depressed parents are more likely to be depressed, and children of hopeful parents are more likely to exhibit hope. It seems that the psychological state of one or a few family members may affect the states of the others. The implication for the current study is that a hope intervention for children could increase hope in both children and their parent(s).

The aim of the current study is to enhance the program provided by Dinolfo (2009), who recently implemented an eight week hope intervention with 24 urban, low SES youth ages 7 to 11 utilizing components of Snyder's Hope Theory. In contrast to previous studies that have demonstrated increased hope scores in participants in the Hope Intervention (HI) group as a result of the intervention (e.g., Delancy, 2005), Dinolfo found no such increase. Indeed, it was participants in the comparison group who showed a significant increase in the Pathways scores of the Children's Hope Scale from pre-test through three-month follow-up. Contrary to expectation, the HI group experienced a trend level decrease in Pathways scores and Total CHS scores. However, these results 
may be explained by a number of limitations and issues identified in the study. Below, the issues identified in Dinolfo's study, as well as methods used to address these limitations in the current study, are discussed.

1. Dinolfo's study utilized a small sample size. One aim of the current study is to double the sample size to 48 children. In addition, inconsistent attendance by several children was identified as a possible problem. In the current study, children will be reminded of the importance of attending each group in every session and will be provided with incentives simply for attending the groups.

2. The current program will last three sessions longer than Dinolfo's. This will allow more time to present the material, repeat and practice hopeful activities, and provide children with more individualized attention.

3. Dinolfo indicated challenges with undergraduate and graduate student co-leaders, such as poor attendance, dropout, and lack of enthusiasm. This may have conveyed a negative tone to the children and thus negatively impacted the results of the study. In the present study, several strategies will be used to address this possible problem. For example, potential co-leaders will be interviewed and fully informed of their expectations and commitments as co-leaders. Specific tasks will be delegated to them, and their duties will be made clear to them in weekly meetings held outside of the group sessions. To provide feedback about their performance, co-leaders will rate themselves on their effort and whether they performed the tasks asked of them (i.e., demonstrate enthusiasm) to serve as a way to measure co-leader effectiveness. 
4. Dinolfo experienced problems with completion of homework assignments.

Therefore, the current program will utilize assignments completed in the sessions with one-on-one help from the co-leaders to ensure that the children fully understand the assignments.

5. Dinolfo speculated that elements of the HI curriculum may have been too conceptual for the children to understand. Therefore, features of the current program will be altered in an attempt to make material more concrete and behavioral.

6. There may have been problems with boredom in Dinolfo's program, as the program was heavily didactic. The current program will be altered to make it more active, with children participating in more activities. In addition, at the end of each session, children will rate whether they enjoyed that day's session and describe what they did not enjoy.

7. Dinolfo expressed concern that the program did not require participants to apply elements to their daily lives. One of the changes to the current program will be to have the children set personal goals in a variety of life domains for each session. They will also set group goals for a number of the sessions to make the program more relevant to their lives.

8. Finally, Dinolfo raised concern that the children did not adequately understand the content of the measures used to evaluate the effectiveness of the program. To address this in the current study, forms will be supplied to co-leaders who administer the measures to help the children understand the wording in a standardized manner when they need clarification. For example, if a child asks a 
co-leader what the word "active" means, all co-leaders will be required to give them the same explanation. As another example, cartoons of facial expression will be shown to children to help them differentiate between words such as "pleased" and "delighted."

With these changes, it is hypothesized that the intervention will instill the expected changes in participants in the HI group that were not found in Dinolfo's study. 


\section{Chapter II}

\section{Rationale and Hypotheses}

Available studies to date suggest that people who are of low SES suffer many disadvantages, including having low levels of hope (Garmezy, 1991). Low hope has been linked to negative outcomes such as school dropout, depression, psychological distress, poor personal adjustment and poor social-emotional functioning (Gilman et al., 2006). Hope is an important source of resilience, which refers to the strengths and assets that some people have to help them survive adversity. People who come from economically disadvantaged backgrounds but who have high resiliency may be able to protect themselves from negative outcomes (Richardson, 2002). Snyder's (1995) Hope Theory is cognitively-based and aims to teach and increase hope in those who are lacking in it.

To increase hope and consequently its benefits, a number of interventions and strategies have been suggested (Cheavens et al., 2006; Eliott, 2005; Snyder et al., 2002). Several studies (Delancy, 2005; Dinolfo, 2009; Eliott, 2005; Snyder et al., 2002) have examined the ability of a hope intervention to increase hope in children.

Many studies have found that psychological states in parents and children are correlated. Depression, hope, anxiety, despair, subjective well-being, resilience, and optimism in parents correlate with similar states in children (Ben-Zur, 2003; Fisak \& Grills-Taquechel, 2007; Greeff \& Human, 2004; Jacob \& Johnson, 1997; Kirpalani et al., 2000; Wong \& Heriot, 2008).

The purpose of the present study is to measure the effects of a hope intervention on socioeconomically disadvantaged children and their parents (or primary caregiver). Children are the population of choice because of the dearth of research in this area and 
the premise that hope develops in childhood. Therefore, it would be most useful to intervene at this stage of life. An area that warrants further exploration is how hope in children correlates with hope in parents. To date, only one study (Westburg \& Martin, 2003) has examined hope in parents as the result of a hope intervention for children, but its small sample size makes their failure to find a relationship tentative, warranting further investigation. Further, previous studies (e.g., Jarrett, 1994) suggest that parents who are economically disadvantaged demonstrate low levels of hope. Therefore, this study will determine whether parents could also benefit from the hope intervention in which their children participate.

Most studies examining the efficacy of hope interventions have involved small sample sizes. The present study will replicate a previous study (Dinolfo, 2009) and include the data from that study in the analyses in order to achieve a larger sample size. In addition to measuring hope, related concepts (optimism, life satisfaction, and hopelessness) will be assessed in this study.

Based on the literature reviewed, the following clinical hypotheses are proposed:

H I: There will be significantly greater increases in hope scores (as measured by the Children's Hope Scale) for participants in the hope intervention (HI) group than those in the comparison group across pretreatment through a 3-month follow-up.

H II: There will be significantly greater increases in hope scores (as measured by the Adult Hope Scale) in parents of children in the HI group than parents of children in the comparison group across pretreatment through a 3-month follow-up. 
H III: There will be significantly greater decreases in hopelessness scores (as measured by the Hopelessness Scale for Children) for participants in the HI group than those in the comparison group across pretreatment through a 3-month follow-up.

H IV: There will be significantly greater decreases in hopelessness scores (as measured by the Hopelessness Scale) for parents of children in the HI group than those in the comparison group across pretreatment through a 3-month follow-up.

$\mathrm{H} \mathrm{V:} \mathrm{There} \mathrm{will} \mathrm{be} \mathrm{significantly} \mathrm{greater} \mathrm{increases} \mathrm{in} \mathrm{life} \mathrm{satisfaction} \mathrm{scores} \mathrm{(as}$ measured by the Brief Multidimensional Students' Life Satisfaction Scale) for participants in the $\mathrm{HI}$ group than those in the comparison group across pretreatment through a 3-month follow-up.

H VI: There will be significantly greater increases in hope scores compared to optimism scores (as measured by The Youth Life Orientation Test) in participants in the HI group across pretreatment through a 3-month follow-up. 


\section{Chapter III}

\section{Method}

\section{Participants}

Participants in the current study will be a minimum of 48 children who are 8 to 12 years of age and one of their parents, for a total sample size of 96 . If necessary, children as young as seven years will be included in order to maximize participation. The children will be recruited from an after-school program at a community center operated by the Cincinnati Metro Housing Authority (CMHA). The children and parents in this study are expected to be primarily African Americans and of low SES. One parent of each child (most likely the mother, as many of these families are headed by single mothers) will participate in the study as well.

\section{Power Analysis}

To determine the sample size needed for the current study, a power analysis was conducted using the online G*Power program (Faul, Erdfelder, Lang, \& Buchner, 2007) for both of the statistical analyses used in this study (a mixed effects model and a paired samples $t$-test). An a priori power analysis utilizing an $F$ test (for the mixed effects model) with an alpha level of .05 and a power level of .80 indicated that to obtain a medium effect size, this study would require 14 participants in each group. For a small effect size, 82 participants would be needed in each group, and 6 participants in each group would be required for a large effect size. An a priori analysis utilizing a paired samples $t$-test (for calculating difference scores) with an alpha level of .05 and a power level of .80 indicated that to obtain a medium effect size, this study would require 27 
students in each group. A small effect size would require 156 participants in each group, and a large effect size would require 12 participants in each group.

Due to restrictions such as funding, limited supply of group leaders, and limited time, 24 children will complete the program in each condition. This will allow sufficient power to identify a medium effect.

\section{Measures}

Children's Hope Scale (CHS; Snyder et al., 1997; see Appendix A). When administering this scale to children, it is titled Questions about your Goals. This selfreport scale was developed to assess levels of hopeful thought in children ranging in age from 8 to 16. It is made up of six items that assess Pathways thinking (the three even items) and Agency thinking (the three odd items). An example question asks children, "How do you feel about things in general?" They respond to the statements, "I think I am doing pretty well" or "I am doing just as well as other kids my age." Respondents indicate how often each item describes them using a scale ranging from 1 ("none of the time") to 6 ("all of the time"). The items may be summed to create both subscale (Pathways and Agency) scores and an overall Hope score. To calculate a child's Total Hope score, responses to all six items should be added together, with "none of the time" $=1$, "a little of the time" $=2$, "some of the time" $=3$, "a lot of the time" $=4$, "most of the time" $=5$, and "all of the time" $=6$. The range of the total hope score is 6 to 36 points. The CHS can be completed and scored in three minutes (Snyder, 2000). Scores of 29 or higher indicate strong Pathways and Agency thinking. Scores of 21 or less indicate Pathways or Agency thinking only some of the time-the children in this range doubt 
their abilities to use hopeful thinking (Snyder). The average score is 25 and suggests that most people engage in hopeful thinking most of the time.

The authors have reported adequate internal consistency (ranging from .72 to .86 ) and temporal stability (test-retest correlations have been reported as ranging from .71 to .73 over one month). No gender differences were found for this scale. Hope, as measured by this scale, appears to be equally present in both males and females. Convergent validity has been established, as parents' ratings of their children's CHS scores correlated positively with their children's actual hope scores taken at the beginning of the study $(r=$ $.38)$ and one month later $(r=.37)$. Discriminant validity has been supported (i.e., the scale correlates .03 with intelligence). The scale has demonstrated good generalizability, having been administered to children from public schools, children with various medical problems, boys diagnosed with ADHD, adolescents exposed to violence, and children who have survived burn injuries.

Hope Scale (HS; Snyder et al., 1991; see Appendix B). This is a dispositional self-report measure of hope that is appropriate for adolescents and adults. This 12 -item scale includes four distracter items, four Agency items, and four Pathways items. The contents of the four Agency items tap the person's sense of successful determination in relation to his or her goals generally. The four Pathways items pertain to people's cognitive appraisals of their ability to generate ways to reach goals and circumvent obstacles to goals. The total HS score is derived by adding the Agency and Pathways items. The highest possible total HS score is 32 , and the lowest is 8. Example items are, "I energetically pursue my goals" (Agency) and, "I can think of many ways to get out of 
a jam" (Pathways). Responses to items are based on a 4-point Likert-type scale ranging from 1 ("definitely false") to 4 ("definitely true").

This scale has been used in studies of over 10,000 adults from various locations in the United States. The average scores for college and non-college samples of people is approximately 24 , with significantly lower scores for people seeking psychological help and who are inpatients at psychiatric hospitals. The Agency and Pathways items consistently emerge through factor analyses. This scale has been found to be both temporally stable (a test-retest reliability of .85 over several weeks has been found) and internally reliable (alphas of .74 to .88 have been reported). The scale has also demonstrated discriminant validity (correlations between this scale and Private and Public Self-Consciousness Scale were not significant). No sex differences have been found for this scale.

Hopelessness Scale for Children (HSC; Kazdin, Rodgers, \& Colbus, 1986; see Appendix C). This scale measures levels of hopelessness and negative expectations about the future. It is a modification of the Adult Hopelessness Scale developed by Beck et al. (1974). The HSC includes 17 items to which children respond as true or false for them. The measure is phrased in relatively simple language, with example items being, "I want to grow up because I think things will be better," and "I might as well give up because I can't make things better for myself." Readability falls in the range of first and second grade levels (children approximately six to seven years old). Yet, items are read to children to facilitate and ensure comprehension. Higher scores (maximum $=17$; scores range from 0-17) reflect greater hopelessness or negative expectations about the future. Children who score at or above the $67^{\text {th }}$ percentile (score $\geq 7.0$ ) are considered to be high 
in hopelessness, and children at or below the $33^{\text {rd }}$ percentile (score $\leq 4.0$ ) are designated as low in hopelessness.

In a sample of child psychiatric inpatients (ages 6 to 13) who were administered the HSC, the internal consistency of the scale yielded a coefficient alpha of .97 and a Spearman-Brown split-half reliability of .96, which suggests an acceptable level of internal consistency (Kazdin et al., 1986). Item-total score correlations were in the moderate range ( .10 to .58 with a mean of .44$)$ and were significant for all but one of the items. When a subsample of these children were retested six weeks later, test-retest reliability was .52 , indicating moderate stability. Thurber, Hollingsworth, and Miller (1996) conducted a study examining the psychometric properties of the HSC with a group of older adolescent inpatients ( $M$ age $=15.4$ years with a range of 12 to 18 years). Item-total correlations were in the moderate range with a mean of .42 . The Cronbach alpha coefficient was .81 , indicating reasonable internal consistency reliability. Compared to Kazdin et al.'s study, these authors found lower internal consistency (.81 vs. .96) and a weaker factor structure. The psychometric properties of the HSC appear to be less adequate for psychiatrically disturbed, hospitalized adolescents than for similar, but younger, children.

A study was also conducted with nonclinically referred $9^{\text {th }}$ grade students (Spirito, Williams, Stark, \& Hart, 1988). When this sample was re-tested 10 weeks after completing the HSC, results indicated moderate stability $(r=.49)$. When investigating the internal consistency, these authors found that the coefficient alpha was .69, and the Spearman-Brown split-half reliability coefficient was .75 , indicating acceptable internal 
consistency. Positive correlations were found between the HSC and depression and depressive attributional styles, indicating support for the validity of the scale.

To further examine the validity of the scale, interrelations of hopelessness, depression, self-esteem, and social behavior were examined (Kazdin et al., 1986). Hopelessness was positively correlated with two measures of depression $(r=.58$ and $r=$ $.44)$ and negatively correlated with self-esteem $(r=-.61)$ and social skills $(r=-.39)$. Children who were high in hopelessness were significantly higher in depression, lower in self-esteem and self-rated appropriate social behavior, and they were rated by their parents as participating in less social activities and demonstrating poorer school performance.

Hopelessness Scale (HS; Beck et al., 1974; see Appendix D). This scale is designed to quantify hopelessness and pessimistic cognitions in adults. It may also be used as a tool to measure suicide potential. This is a 20 -item true-false self-report inventory that was initially administered to a sample of depressed and nondepressed patients. Example items include, "I might as well give up because I can't make things better for myself," and, "I look forward to the future with hope and enthusiasm." Each response is assigned a score of 0 or 1 , and the total "hopelessness score" is the sum of the scores on the individual items. Thus, the possible range of scores is 0 to 20 .

For a population of adult hospitalized patients, the internal consistency yielded a reliability coefficient of .93 (Beck et al., 1974). All inter-item correlations were significant, ranging from .39 to .74 , demonstrating highly significant correlations between each item and the total HS score. Holden and Fekken (1988) investigated the test-retest reliability of the HS over a three-week time period in a nonclinical university 
population. They found the test-retest reliability to be .85 for the entire sample, .94 for males (quite high), and .67 for females (moderate). In another study of the psychometric properties of the HS in a nonclinical sample of undergraduates, internal consistency scores were satisfactory (Cronbach's alpha $=.88$; Lyndall, 2001). These data indicate that, in general, the HS provides reliable estimates of pessimistic cognitions in university undergraduates.

Concurrent validity was established by comparing HS scores with clinical ratings of hopelessness and with other tests designed to measure negative attitudes about the future. Correlations of the HS with two clinicians' ratings of hopelessness in a sample of outpatients was .74 and with a sample of individuals who attempted suicide was .62 (Beck et al., 1974). The interrater reliability of the two judges was .86. With a population of depressed patients, the correlation of the HS with a measure of future expectancies was .60 , and the correlation with the pessimism item on a depression inventory was .63 . The HS correlated more highly with this item than with any of the other items on this depression inventory. In Lyndall's (2001) sample of nonclinical undergraduates, convergent validity was demonstrated by high correlations with the Hope Scale and the Life Orientation Test. A correlation of .57 between the HS and perceived stress reduced to .24 when negative trait affect was controlled for, indicating a degree of discriminant utility. Overall, the reliability and validity data are sufficient to justify the use of the HS.

\section{Brief Multidimensional Students' Life Satisfaction Scale (BMSLSS;}

Seligson, Huebner, \& Valois, 2003; see Appendix E). This instrument is a brief version of the 40-item Multidimensional Students' Life Satisfaction Scale (MSLSS; Huebner, 1994), which is designed to provide a general life satisfaction score along with scores on 
five domains (family, friends, school, self, and living environment) for elementary, middle, and high school students (Seligson et al.), as well as college students ages 8 to 18 (Zullig, Huebner, Gilman, Patton, \& Murray, 2005). The BMSLSS consists of five items, each representing one of the five life satisfaction domains included on the MSLSS. For example, one item reads, "I would describe my satisfaction with my family life as..." while another reads, "I would describe my satisfaction with my school experience as..." and so forth. Responses to these items are on a 7-point scale with the following possible responses: terrible, unhappy, mostly dissatisfied, mixed (about equally satisfied and dissatisfied), mostly satisfied, pleased, and delighted. The five items are summed to create a total general life satisfaction score.

The BMSLSS demonstrated adequate internal consistency for the total score (coefficient alpha of .75) with an early adolescent sample (students in grades six, seven and eight with a mean age of 12 years; Seligson et al., 2003). Each of the items demonstrated desirable item-total correlations ranging from .65 to .73 . On the BMSLSS, students in lower SES groups reported lower life satisfaction than students in the higher SES groups, demonstrating the measure's high correlation with SES $(r=.24)$. No significant correlations were found for gender and race. Concurrent criterion-related validity was examined through relationships with known, validated measures of life satisfaction. Criterion-related validity coefficients yielded a relatively strong relationship between the total BMSLSS and total MSLSS scores $(r=.66)$ and between total BMSLSS and total Student Life Satisfaction Scale (SLSS) scores $(r=.62$ ). To determine construct validity, the authors examined correlations with instruments that are theoretically related to the BMSLSS. The PANAS-C is an instrument that measures the positive and negative 
affect components of subjective well-being. As expected, the BMSLSS demonstrated moderate correlations with the PANAS-C Positive Affect Scale $(r=.43)$. Also, the BMSLSS demonstrated negative correlations with the Negative Affect Scale of the PANAS-C $(r=-.27)$. Mutlitrait-multimethod (MTMM) correlations matrices were used to determine the convergent and discriminant validity of the BMSLSS. The authors found substantial convergent correlation coefficients between the BMSLSS and the MSLSS, ranging from 0.47 (Self) to 0.60 (Living Environment) with a mean of 0.53 , further supporting the validity of the instrument (Seligson et al., 2003). Overall, the BMSLSS appears to be a brief, valid, reliable measure of life satisfaction for adolescent students.

Youth Life Orientation Test (YLOT; Ey et al., 2005; see Appendix F). The YLOT is a 16-iter self-report measure of children's optimism and pessimism that is based upon the adult Life Orientation Test-Revised (LOT-R; Scheier et al., 1994). Ey et al. evaluated the reliability of this instrument with a sample of racially diverse children in grades three through six. The LOT-R items were re-worded to make them more understandable and appropriate to elementary school-aged children. On the YLOT, children are asked to rate "how true or not true each statements is for you" by coloring in the circle that "seems to describe you the best." Children endorse items on a scale of 0 to 3, where 0 = "not true for me", 1 = "sort of not true for me", 2 = "sort of true for me", and $3=$ "true for me." The scale includes six optimism items and six pessimism items. An example optimism item reads, "I usually expect to have a good day," and an example pessimism item reads, "Each day I expect bad things to happen." The YLOT yields three scores: an optimism score, a pessimism score, and a total optimism score. A higher number indicates a higher score (i.e., a high pessimism score means high on pessimism 
responses). The optimism score is calculated by summing all six optimism items, and the pessimism score is calculated by summing all six pessimism items. The total optimism score is the sum of the optimism and reverse-scored pessimism items.

In terms of reliability, internal consistency for the optimism, pessimism, and total optimism scores are all in the acceptable range with Cronbach alphas of $.79, .78$, and .83 respectively. Ey et al. (2005), assessing stability of children's ratings over a seven month period, determined that intraclass correlations were as follows: optimism $=.65$, pessimism $=.65$, and total optimism $=.75$. Assessing test-retest reliability, they measured students' optimism and pessimism YLOT scores early in the school year (Time 1) with their YLOT scores seven months later (Time 2). Optimism at Time 1 was significantly correlated with optimism at Time $2(r=.46)$, and pessimism was significantly related to later ratings of pessimism $(r=.45)$. Total optimism scores were also related at the two time points $(r=.50)$. In a sample that completed the YLOT two times over a one-month period, test-retest reliability was .68 for optimism and pessimism and .70 for total optimism.

To establish convergent and discriminant validity, the YLOT at Time 1 was compared with related measures such as hope and self-efficacy. There was a positive and moderate relation between the YLOT scales of optimism and total optimism and measures of hope and self-efficacy (Ey et al., 2005). In contrast, the YLOT pessimism scale was negatively correlated with these measures. To determine predictive validity (evaluation of whether the children's self-reports of optimism predicted their psychological adjustment approximately three months later), the children in this study and their parents completed take-home questionnaires of psychological adjustment. 
Results demonstrated that children's optimism early in the school year predicted fewer child-reported depressive symptoms three months later. In contrast, children's pessimism at Time 1 predicted anxiety symptoms three months later.

\section{Procedure}

Children aged 8-12 will be recruited from a community center operated by CMHA that is located in the West End area of Cincinnati. In addition, participation will be elicited via a registration night one week before the beginning of the program, in which parents will bring their children to learn about the program and decide if they would like to participate. The registration night will include the completion of consent and assent forms to participate in the program. In order for a child to participate, his or her parent must also participate. After the children have been identified, parents will receive information describing the program, the child's participation, and the parents' participation. Parents will be asked to provide written consent for their participation and their child's participation (see Appendix G). After permission is received from the parents, the child's assent to participate (see Appendix $\mathrm{H}$ ) will be requested before any measures are administered. The child's assent will also be requested after a description of the program is given during the first session.

Each child will be asked to complete the CHS, HSC, BMSLSS, and the YLOT. Each parent will be asked to complete the Hope Scale and the Hopelessness Scale. Measures will be read to children to rule out the effects of reading difficulties. Because a problem with Dinolfo's (2009) study may have been that children had difficulty understanding some of the questions and responses, forms will be supplied to co-leaders who administer the measures directing them how to clarify any misunderstandings to the 
children in a standardized manner (see Appendices I through $\mathrm{L}$ for the instructions used for co-leaders for the CHS, BMSLSS, YLOT, and HSC, respectively). For example, if a child asks what "active" means, each co-leader would be required to give them the same response. As another example, pictures of facial expressions will be shown to the children to help them differentiate between such words as "pleased" and "delighted." Coleaders will be fully trained on these modifications prior to the registration night; therefore, these instructions will serve as a reminder of what they are to say while administering the measures.

Students will be randomly divided into four groups: two identical Hope Intervention (HI) groups and two identical comparison groups. The two $\mathrm{HI}$ groups will consist of 12 students and 12 parents each, for a total of 48 participants. The two comparison groups will also consist of 12 students and 12 parents each, for a total of 48 participants. Two groups of each intervention will be run in order to achieve a lower number of participants in each group so that the children may receive more individualized attention and allow for active participation of all group members. Children in the comparison group will participate in a reading club. The HI will be a ten week program consisting of one hour sessions twice per week. For the HI groups, the sessions, run by two to three facilitators each, will utilize concepts based upon Snyder's Hope Theory to teach hope and increase resiliency (see Appendix $\mathrm{M}$ for a listing of the plan for each session). Children in the reading group, with the aid of two to three facilitators, will spend time improving their reading skills. The facilitators and co-facilitators of both the $\mathrm{HI}$ and comparison groups will be trained graduate and undergraduate students. The groups will be conducted as part of an after-school program. 
During the course of the program, each student will be asked to complete insession assignments (i.e., composing narratives, developing personal goals, etc.) and will receive tokens for their completion. A token economy will be implemented in which students who have a designated number of tokens receive a reward at the end of each session. The tokens will be given based upon group participation, compliance with group rules, and completion of in-session assignments. The co-facilitators will execute the token economy to help maintain order in the sessions. The students will be provided with a notebook that will contain stories, quotes, their homework and worksheets to maintain during the program. The notebooks will be kept along with the rest of the materials in the possession of the leader and co-leaders and will be brought to each session. At the end of the program, the children will take the notebooks home to keep and serve as a reminder of what they have learned.

Both students and co-leaders will complete ratings at the end of each session. Students will rate whether they enjoyed that day's session and, if not, what they did not like about it. This will help to determine what activities to continue or discontinue in subsequent sessions or implementations of this intervention. Co-leaders will rate how effective they thought they were for the session as well as other components expected of them, including punctuality, enthusiasm, and involvement with the children. This will help assess co-leader effectiveness.

Once the intervention has been completed, the children will participate in a graduation ceremony in which their families are invited, and they will receive a certificate for their completion of the program. At this time, children and their parents will be asked to complete the measures that they completed at pre-test. A reward will be 
given for doing so. Three months after the post-test measures have been completed, children and their parents will be asked to return to complete follow-up measures (the same measures that they completed at pre-test and post-test) in order to determine the long-term effects of the program. An incentive will be provided for doing so. 


\section{Chapter IV}

\section{Proposed Analyses}

The purpose of the current study is to examine the effectiveness of an intervention designed to increase hope in children and their parents. The design is to compare the HI group with a comparison group and to administer the measures described previously at pre- and post-intervention and at a 3-month follow-up to evaluate the effectiveness of the intervention. Hypotheses I and II state that there will be significantly greater increases in hope scores for children (as measured by the CHS) and parents (as measured by the Hope Scale) in the HI group than those in the comparison group across pretreatment through a 3-month follow-up. Hypotheses III and IV state that there will be significantly greater decreases in hopelessness scores for children (as measured by the HSC) and parents (as measured by the Hopelessness Scale) in the hope intervention group than those in the comparison group across pretreatment through a 3-month follow-up. Hypothesis V states that there will be significantly greater increases in life satisfaction scores (as measured by the BMSLSS) for participants in the HI group than those in the comparison group across pretreatment throụgh a 3-month follow-up. To evaluate each of these hypotheses, a mixed effects model will be used. More specifically, a random regression model (RRM, also termed a hierarchical linear model) will be used to compare differences in the slopes (or rates of change) between participants in the HI group and those in the comparison group.

A level of $p \leq .05$ will be used in order to maintain statistical power at $80 \%$ or above for detecting large effects that would be of expected clinical importance. In addition, effect sizes will be examined to detect trends in treatment response. 
Hypothesis VI states that there will be significantly greater increases in hope scores compared to optimism scores (as measured by the YLOT) in participants in the HI group across pretreatment through a 3-month follow-up. To evaluate this hypothesis, difference scores will be calculated for both hope and optimism scores to determine the amount of change in each that occurs over time. A paired samples $t$-test will then be conducted to determine whether the resulting difference score (the difference between the hope difference score and the optimism difference score) is greater than zero, which would indicate statistical significance at a predetermined level of $p \leq .05$. 


\section{References}

Abela, J., \& Payne, A. (2003). A test of the integration of hopelessness and self-esteem theories of depression in schoolchildren. Cognitive Therapy and Research, 27, 519-535.

Abela, J., Skitch, S., Adams, P., \& Hankin, B. (2006). The timing of parent and child depression: A hopelessness theory perspective. Journal of Clinical Child and Adolescent Psychology, 35, 253-263.

Abramson, L., Metalsky, G., \& Alloy, L. (1989). Hopelessness depression: A theory based subtype of depression. Psychological Review, 96, 358-372.

Alvord, M., \& Grados, J. (2005). Enhancing resilience in children: A proactive approach. Professional Psychology: Research and Practice, 36, 238-245.

Averill, J., Catlin, G., \& Chon, K. (1990). Rules of hope. New York: Springer-Verlag. Bailey, T., Eng, W., Frisch, M., \& Snyder, C. (2007). Hope and optimism as related to life satisfaction. The Journal of Positive Psychology, 2, 168-175.

Bailey, T., \& Snyder, C. (2007). Satisfaction with life and hope: A look at age and marital status. The Psychological Record, 57, 233-240.

Beardslee, W. (1989). Children of parents with affective disorder. Pediatrics in Review, 10, 313-319.

Beardslee, W., Bemporad, J., Keller, M., \& Klerman, G. (1983). Children of parents with a major affective disorder: A review. American Journal of $P_{\text {sychiatry, 140, 825- }}$ 832.

Beck, A., Weissman, A., Lester, D., \& Trexler, L. (1974). The measurement of 
pessimism: The Hopelessness Scale. Journal of Consulting and Clinical Psychology, 42, 861-865.

Ben-Zur, H. (2003). Happy adolescents: The link between subjective well-being, internal resources, and parental factors. Journal of Youth and Adolescence, 32, 67-79.

Bolland, J., Lian, B., \& Formichella, C. (2005). The origins of hopelessness among innercity African-American adolescents. American Journal of Community Psychology, $36,293-305$.

Bolland, J., McCallum, D., Lian, B., Bailey, C., \& Rowan, P. (2001). Hopelessness and violence among inner-city youths. Maternal and Child Health Journal, 5, $237-$ 244.

Brewin, C., Andrews, B., \& Furnham, A. (1996). Intergenerational links and positive self-cognitions: Parental correlates of optimism, learned resourcefulness, and selfevaluation. Cognitive Therapy and Research, 20, 247-263.

Bruininks, P., \& Malle, B. (2005). Distinguishing hope from optimism and related affective states. Motivation and Emotion, 29, 327-355.

Bryant, F., \& Cvengros, J. (2004). Distinguishing hope and optimism: Two sides of a coin, or two separate coins? Journal of Social and Clinical Psychology, 23, 273302.

Cheavens, J., Feldman, D., Gum, A., Michael, S., \& Snyder, C. (2006). Hope therapy in a community sample: A pilot investigation. Social Indicators Research, 77, 61-78.

Curry, L., Snyder, C., Cook, D., Ruby, B., \& Rehm, R. (1997). Role of hope in academic and sport achievement. Journal of Personality and Social Psychology, 73, 1257 1267. 
Delancy, D. (2005). Teaching hope: A path to resilience. Unpublished doctoral dissertation, Xavier University.

Diener, E., Emmons, R., Larsen, R., \& Griffin, S. (1985). The satisfaction with life scale. Journal of Personality Assessment, 49, 71-75.

Diener, E., Sapyta, J., \& Suh, E. (1998). Subjective well-being is essential to well-being. Psychological Inquiry, 9, 33-37.

Dinolfo, C. (2009). Efficacy of a hope program for inner-city children. Unpublished doctoral dissertation, Xavier University.

Downey, G., \& Coyne, J. (1990). Children of depressed parents: An integrative review. Psychological Bulletin, 108, 50-76.

Edwards, L., \& Lopez, S. (2000). Making hope happen for kids. Unpublished protocol. Eliott, J. (2005). Interdisciplinary perspectives on hope. Hauppauge, New York: Nova Science Publishers, Inc.

Emmons, R. (1986). Personal strivings: An approach to personality and subjective wellbeing. Journal of Personality and Social Psychology, 51, 1058-1068.

Ey, S., Hadley, W., Allen, D., Palmer, S., Klosky, J., Deptula, D., et al. (2005). A new measure of children's optimism and pessimism: The youth life orientation test. The Journal of Child Psychology and Psychiatry, 46, 548-558.

Faul, F., Erdfelder, D., Lang, A.-G., \& Buchner, A. (2007). G*Power 3: A flexible statistical power analysis program for the social, behavioral, and biomedical sciences. Behavior Research Methods, 39, 175-191.

Frisch, M. (Ed.). (1992). Use of the QOLI or Quality of Life Inventory in quality of life therapy and assessment. Hillsdale, NJ: Lawrence Erlbaum. 
Garmezy, N. (1991). Resilience and vulnerability to adverse developmental outcomes associated with poverty. American Behavioral Scientist, 34, 416-430.

Ge, X., Conger, R., Lorenz, F., Shanahan, M., \& Elder, G. (1995). Mutual influences in parent and adolescent psychological distress. Developmental Psychology, 31, 406419.

Gilman, R., Dooley, J., \& Florell, D. (2006). Relative levels of hope and their relationship with academic and psychological indicators among adolescents. Journal of Social and Clinical Psychology, 25, 166-178.

Gilman, R., \& Huebner, E. (2006). Characteristics of adolescents who report very high life satisfaction. Journal of Youth and Adolescence, 35, 311-319.

Greeff, A., \& Human, B. (2004). Resilience in families in which a parent has died. The American Journal of Family Therapy, 32, 27-42.

Hagen, K., Meyers, B., \& Mackintosh, V. (2005). Hope, social support, and behavior problems in at-risk children. American Journal of Orthopsychiatry, 75, 211-219.

Hasan, N., \& Power, T. (2002). Optimism and pessimism in children: A study of parenting correlates. International Journal of Behavioral Development, 26, 185191.

Holden, R., \& Fekken, C. (1988). Test-retest reliability of the hopelessness scale and its items in a university population. Journal of Clinical Psychology, 44, 40-43.

Howard, K., Carothers, S., Smith, L., \& Akai, C. (2007). Overcoming the odds: protective factors in the lives of children. Mawah, NJ: Lawrence Erlbaum Associates Publishers.

Huebner, E. (1994). Preliminary development and validation of a multidimensional life 
satisfaction scale for children. Psychological Assessment, 6, 149-158.

Jarrett, R. (1994). Living poor: Family life among single parent, African-American women. Social Problems, 41, 30-49.

Kazdin, A., Rodgers, A., \& Colbus, D. (1986). The hopelessness scale for children: Psychometric characteristics and concurrent validity. Journal of Consulting and Clinical Psychology, 2, 241-245.

Kirpalani, H., Parkin, C., Willan, A., Fehlings, D., Rosenbaum, P., King, D., et al. (2000). Quality of life in spina bifida: Importance of parental hope. Arch Dis Child, 83, 293-297.

Luthar, S. (1991). Vulnerability and resilience: A study of high-risk adolescents. Child Developmẹnt, 62, 600-616.

Lyndall, S. (2001). Further validity and reliability evidence for Beck hopelessness scale scores in a nonclinical sample. Educational and Psychological Measurement, 61, 303-317.

Magaletta, P., \& Oliver, J. (1999). The hope construct, will, and ways: Their relations with self-efficacy, optimism, and general well-being. Journal of Clinical Psychology, 55, 539-551.

Melhem, N., Brent, D., Ziegler, M., Iyengar, S., Kolko, D., Oquendo, M., et al. (2007). Familial pathways to early-onset suicidal behavior: Familial and individual antecedents of suicidal behavior. American Journal of Psychiatry, 164, 13641370.

Muldoon, O. (2000). Social group membership and self-perceptions in Northern Ireland: A longitudinal study. British Journal of Developmental Psychology, 18, 65-80. 
McDermott, D., \& Snyder, C. (1999). Making hope happen: A workbook for turning possibilities into reality. Oakland, CA: New Harbinger Publications.

McDermott, D., \& Snyder, C. (2000). The great big book of hope: Help your children achieve their dreams. Oakland, CA: New Harbinger Publications.

Ong, A., Edwards, L., \& Bergeman, C. (2006). Hope as a source of resilience in later adulthood. Personality and Individual Differences, 41, 1263-1273.

Richardson, G. (2002). The metatheory of resilience and resiliency. Journal of Clinical Psychology, 58, 307-321.

Rose, D., \& Abramson, L. (1992). Developmental predictors of depressive cognitive style: Research and theory. Rochester symposium of developmental psychopathology. Rochester, NY: University of Rochester Press.

Scheier, M., \& Carver, C. (1985). Optimism, coping, and health: Assessment and implications of generalized outcome expectancies. Health Psychology, 4, 219 247.

Scheier, M., Carver, C., \& Bridges, W. (1994). Distinguishing optimism from neuroticism (and trait anxiety, self-mastery, and self-esteem): A re-evaluation of the Life Orientation Test. Journal of Personality and Social Psychology, 67, 1063-1078.

Seligman, M. (2002). Authentic happiness. New York, NY: Free Press.

Seligson, J., Huebner, E., \& Valois, R. (2003). Preliminary validation of the Brief Multidimensional Students' Life Satisfaction Scale (BMSLSS). Social Indicators Research, 61, 121-145.

Shek, D. (1999). Parenting characteristics and adolescent psychological well-being: A 
longitudinal study in a Chinese context. Genetic, Social, and General Psychology Monographs, 125, 27-44.

Snyder, C. (1994). The psychology of hope: You can get there from here. New York, NY: Free Press.

Snyder, C. (1995). Conceptualizing, measuring, and nurturing hope. Journal of Counseling and Development, 73, 355-360.

Snyder, C. (Ed). (2000). Handbook of hope: Theory, measures, and applications. San Diego, CA: Academic Press.

Snyder, C. (2000). The past and possible futures of hope. Journal of Social and Clinical Psychology, 19, 11-28.

Snyder, C. (2002). Hope theory: Rainbows in the mind. Psychological Inquiry, 13, 249275.

Snyder, C., Cheavens, J., \& Sympson, S. (1997). Hope: An individual motive for social commerce. Group Dynamics: Theory, Research, and Practice, 1, 107-118.

Snyder, C., Feldman, D., Shorey, H., \& Rand, K. (2002). Hopeful choices: A school counselor's guide to hope theory. Professional School Counseling, 5, 298-307.

Snyder, C., Feldman, D., Taylor, J., Schroeder, L., \& Adams, V. (2000). The roles of hopeful thinking in preventing problems and enhancing strengths. Applied and Preventative Psychology, 9, 249-270.

Snyder, C., Harris, C., Anderson, J., Holleran, S., Irving, L., Sigmon, S., et al. (1991). The will and the ways: Development and validation of an individual-differences measure of hope. Journal of Personality and Social Psychology, 60, 570-585.

Snyder, C., Hoza, B., Pelham, W., Danovsky, M., Highberger, L., \& Rubinstein, H., et al. 
(1997). The development and validation of the Children's Hope Scale. Journal of Pediatric Psychology, 22, 399-421.

Snyder, C., \& Lopez, S. (2002). Handbook of positive psychology. New York: NY:

Oxford University Press.

Snyder, C., McDermott, D., Cook, W., \& Rapoff, M. (1997). Hope for the journey. Boulder, CO: Westview Press.

Snyder, C., Shorey, H., Cheavens, J., Pulver, K., Adams, V., \& Wilklund, C. (2002). Hope and academic success in college. Journal of Educational Psychology, 94, 820-826.

Snyder, C., Sympson, S., Ybasco, F., Borders, T., Babyak, M., \& Higgins, R. (1996). Development and validation of the State Hope Scale. Journal of Personality and Social Psychology, 70, 321-335.

Spirito, A., Williams, C., Stark, L., \& Hart, K. (1988). The hopelessness scale for children: Psychometric properties with normal and emotionally disturbed adolescents. Journal of Abnormal Child Psychology, 16, 445-448.

Stotland, E. (1969). The psychology of hope. San Francisco: Jossey-Bass.

Tanaka, E., Sakamoto, S., Ono, Y., Fujihara, S., \& Kitamura, T. (1998). Hopelessness in a community sample: Factorial structure and psychosocial correlates. The Journal of Social Psychology, 138, 581-590.

Thurber, S., Hollingsworth, D., \& Miller, L. (1996). The hopelessness scale for children: Psychometric properties with hospitalized adolescents. Journal of Clinical Psychology,52, 543-545.

Timko, C., Cronkite, R., Swindle, R., Robinson, R., Turrubiartes, P, \& Moos, R. (2008). 
Functioning status of adult children of depressed parents: A 23-year follow-up. Psychological Medicine, 38, 343-352.

Trump, M. (1997). The impact of hopeful narratives on state hope, state self-esteem, and state positive and negative affect for adult female survivors of incest.

Dissertation Abstracts International Section A: Humanities and Social Sciences, $58,1211$.

Venning, A., Eliott, J., Whitford, H., \& Honnor, J. (2007). The impact of a child's chronic illness on hopeful thinking in children and parents. Journal of Social and Clinical Psychology, 26, 708-727.

Westburg, N, \& Martin, D. (2003). The relationship between a child's hope, a parent's hope, and student-directed, goal-oriented academic instruction. Journal of Humanistic Counseling, Education, and Development, 42, 152-164.

Wong, M., \& Heriot, S. (2008). Parents of children with cystic fibrosis: How they hope, cope and despair. Child: Care, Health and Development, 34, 344-354.

Wrosch, C., \& Scheier, M. (2003). Personality and quality of life: The importance of optimism and goal adjustment. Quality of Life Research, 12, 59-72.

Zullig, K., Huebner, E., Gilman, R., Patton, J., \& Murray, K. (2005). Validation of the Brief Multidimensional Students' Life Satisfaction Scale among college students. American Journal of Health Behavior, 29, 206-214. 
Appendix A

Children's Hope Scale

This measure is publicly available at http://jpepsy.oxfordjournals.org

\section{Questions About Your Goals}

Dinctiots: The six sentences below describe how clildren think about themselves and how they do things in general. Read each sentence carefully. For each sentence, please think about how you are in most situations. Place a check inside the circle that describes YOU the best For example, place a check $(/)$ in the circle $(O)$ above. "None of the tine," if this describes you. Or, if you are this way "All of the time," check this circle. Please answier every question by putting a check in one of the circles. There are no right or wrong answers. .

I.I think I am doing pretty well.

\begin{tabular}{|c|c|c|c|c|}
\hline & $\begin{array}{c}O \\
\text { A litde of } \\
\text { die time }\end{array}$ & $\begin{array}{c}0 \\
\text { Some of } \\
\text { tie time }\end{array}$ & $\begin{array}{c}0 \\
\text { A lot of } \\
\text { the tince }\end{array}$ & $\begin{array}{c}0 \\
\text { Most of } \\
\text { the cime }\end{array}$ \\
\hline
\end{tabular}

2 I an thint of nany ways to get the things in life that are most inportine to inc.

0

Nonc of

$O$

A littic of

0

0

$A$ lat of

0

0

die time:

Somc of

the time

Most of

the tint:

All of ?

3.1 am doing just as well as other kids ny age.
0
0
0
$O$
0
0

the time

None of

A tirode of

Some of

A lot of

the time the time the time the time the rim: the time

4. When I lave a problem, I can come up with lots of ways to solve it.

0

0

0

0

0

0

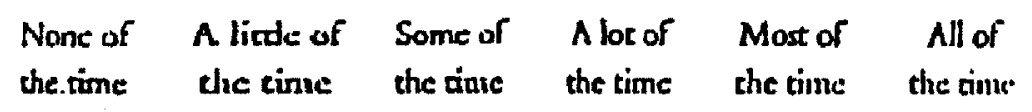

5. I think the things I have done in the past will help me in the future.

$\begin{array}{cccccc}0 & 0 & 0 & O & O & O \\ \text { None of } & A \text { litrle of } & \text { Sonxe of } & A \text { lot of } & \text { Most of } & \text { All of } \\ \text { the time } & \text { the inje } & \text { the time } & \text { the tint } & \text { the tine } & \text { the time }\end{array}$

6. Even when others want to quit, I know that I can find ways to solve the problem.

0

Noni: of

the time
$O$

A lintic of the cime
0

Somc of the rime
0

A lot of dic time
$O$

Most of the tinie
0 All of the tims: 
Appendix B

Hope Scale

This measure is publicly available at http://www.ppc.sas.upenn.edu/hopescale.pdf

Directions: Read each item carefully. Using the scale shown below, please select the number that best describes YOU and put that number in the blank provided.

1 = Definitely False, 2 = Mostly False, 3 = Mostly True, 4 = Definitely True

1. I can think of many ways to get out of a jam.

2. I energetically pursue my own goals.

3. I feel tired most of the time.

4. There are lots of ways around any problem.

5. I am easily downed in an argument.

6. I can think of many ways to get the things in life that are most important to me.

7. I worry about my health.

8. Even when others get discouraged, I know I can find a way to solve the problem.

9. My past experiences have prepared me well for the future.

10. I've been pretty successful in life.

11. I usually find myself worrying about something.

12. I meet the goals that I set for myself. 
Appendix C

Hopelessness Scale for Children

The Hopelessness Scale for Children (HSC) is protected by copyright, so it is not reproduced in this document. This measure is available through the following source:

Kazdin, A., Rodgers, A., \& Colbus, D. (1986). The hopelessness scale for children: Psychometric characteristics and concurrent validity. Journal of Consulting and Clinical Psychology, 2, 241-245. 
Appendix D

\section{Hopelessness Scale}

The Hopelessness Scale is protected by copyright, so it is not reproduced in this document. This measure is available through Pearson at www.pearsonassessments.com. 
Appendix E

Brief Multidimensional Students' Life Satisfaction Scale

This measure is publicly available at http://www.psych.sc.edu/pdfdocs/huebslssbrief.pdf

We would like to know what thoughts about life you've had during the past several weeks. Here are some questions that ask you to indicate your satisfaction with life. Circle the choice next to each statement that indicates how you would describe your satisfaction with each of these areas of your life.

I would describe my satisfaction with my life as:

Terrible Unhappy Mostly Dissatisfied Mixed Mostly Satisfied Pleased Delighted I would describe my satisfaction with my friends as:

Terrible Unhappy Mostly Dissatisfied Mixed Mostly Satisfied Pleased Delighted I would describe my satisfaction with my school experiences as:

Terrible Unhappy Mostly Dissatisfied Mixed Mostly Satisfied Pleased Delighted I would describe my satisfaction with my environment as:

Terrible Unhappy Mostly Dissatisfied Mixed Mostly Satisfied Pleased Delighted I would describe my satisfaction with myself as:

Terrible Unhappy Mostly Dissatisfied Mixed Mostly Satisfied Pleased Delighted I would describe my satisfaction with my overall life as:

Terrible Unhappx Mostly Dissatisfied Mixed Mostly Satisfied Pleased Delighted 
Appendix F

Youth Life Orientation Test

This measure is publicly available at http://www.sydneyey.org/forms

\section{Instructions}

Y-LOI Children: Revised OC1.1.97

Please answer the following questions about yourself by putting how true or not true each statement is for you. Please COLOR IN the oval that seems to describe you the best. There are no right or wrong answers. Just describe yourself as best as you can.

1. It's easy for me to have fun.
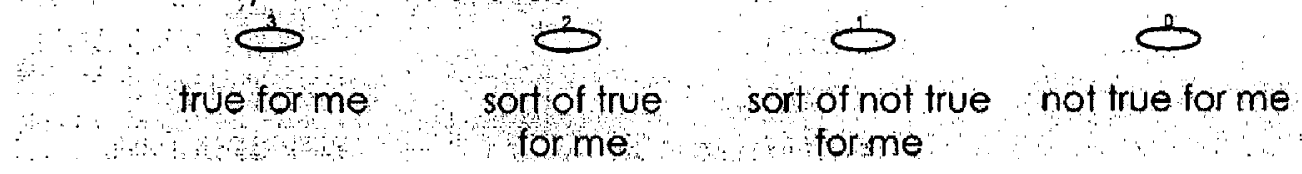

2. I like to be active.

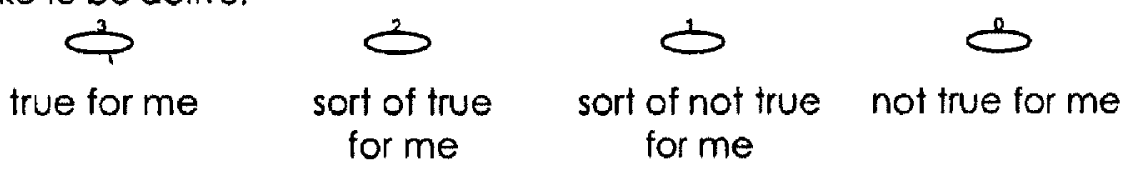

3. I'm always hopeful about my future.

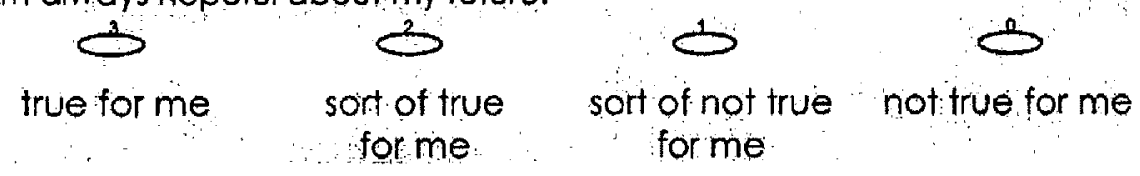

4. Things usually go wrong for me.
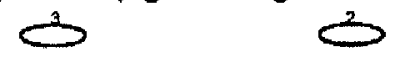
true for me
sort of true
for me
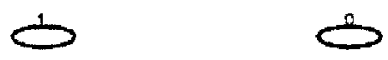
sort of not true not true forme for me

5. When 1 am not 'sure what will happen next. I usually expect it to be something good.

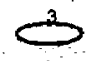
2

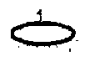

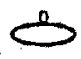
true for me
sort of true
sort of not true not true for me forme forme

6. Usually, I don't expect things to go my way.

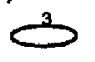

true for me

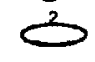

sort of true for me

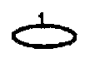

sort of not true not true for me for me

7. Usually, I don't expect good things to happento me.

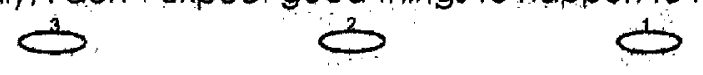


trueforme sort of true sont of not true not frue forme forme forme

8. I am a lucky person.

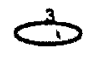

true for me

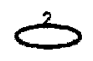

sort of true for me

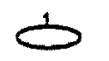

sort of not true not true for me for me

9. If something nice happens, chances are lit won't be to me.

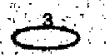

true for me

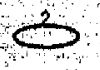

sort of true for me

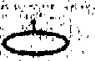

sort of not true not true for me forme

10. Each day llook forward to having a lot of fun.
$\sum_{3}^{3}$

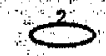
$\$$
true for me
sort of true
for me
sort of not true

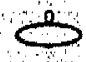
for me

11. When things are good, l expect something to go wrong.
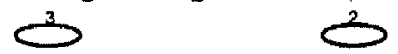

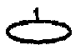

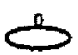
true for me
sort of true
sort of not true not true for me
for me for me

12. I usually expect to have good gay,
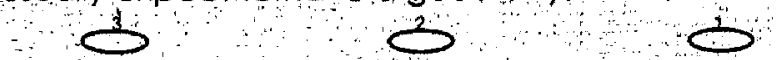
true forme
sort of true
for me
sort of not true not true forme for me

13. No matter what I try, I do not believe anything is going to work.
3

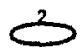

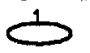
$\overbrace{}^{2}$
true for me
sort of true
for me
sort of not true not true for me for me

14. Overall, l expect more good things to happen to me than bad things.
$\rightarrow$

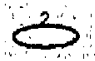

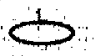
S
true for me
sort of true
for me
sort of not true not true forme for me

15. Each day l expect bad things to happen.

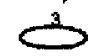

true for me

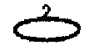

sort of true for me
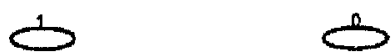
16. When things are bad, lexpect them to get befter.

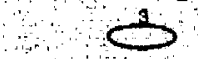
2

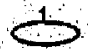
$\Leftrightarrow$
true for me
sort of true
sort of not true
not true for me for me

17. Even when people around me are sick, lexpect to be healthy.
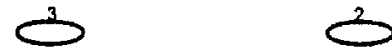
¿
S
true for me
sort of true sort of not true not true for me for me forme

18. If some illness is going around, I am sure to get it.
S
3
ఏ

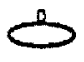
true for me
sort of true
for me
sort of not true not true for me for me

19. When I do not feel well, I expect that I will feel better soon.
3
3

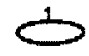

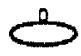
sort of true
for me
sort of not true not true for me
for me

true for me

Y-Lot: Page 2 


\section{Appendix G}

\section{Permission Form}

Amy Karbasi and Erica Eisenman, graduate students at Xavier University in the Clinical Psychology program, are working with the Cincinnati Metro Housing Authority and Harmony Garden to evaluate some programs offered at the Carl Lindner YMCA. As part of their educational requirements, they will be using information they gather in the evaluation of the programs to conduct a research project. You and your child(ren) are invited to participate in this project. They will be comparing how the children respond to the groups we are offering this fall. Each child who enrolls will be assigned to one of two groups. Both groups will involve reading and talking about stories, although one will only work on reading skills and the other will involve positive thinking and problem solving along with reading. We hope that all children learn from the groups and enjoy them. What we find out about the groups from this project will help us choose what programs to offer in the future.

If you and your child are interested in participating, your child must attend a registration night meeting before the program begins and an additional meeting 3 months after the program ends. At these meetings, you and your child will fill out surveys. While your child must attend these meetings, if you are not able to attend, you will be asked to complete a packet of information and return it to a staff member of Harmony Garden who will be responsible for giving you these packets and collecting them from you before the program begins and after it ends. During each of these meetings, your child will also take reading tests. Some of these will be audio taped so that we can fully analyze your child's reading skills. Refreshments will be provided and each mother and child will have the opportunity to win a prize. Mothers who participate and have a child who participates in the entire program will receive a $\$ 10$ Kroger gift card at the last meeting 3 months after the program ends. Each meeting will last approximately 1 to 1.5 hours.

Both of the groups for the children will meet on Tuesdays and Wednesdays from September 29, 2009-December 2, 2009. Each group will begin promptly at 5:00 pm and end at 6:00 pm. Your child may earn small prizes for attendance. Healthy snacks will be provided at each group.

There are no foreseen risks for you or your child's participation in the groups or their evaluation. Although your names will be on some of the forms that you complete, any answers you give will remain private. Only the researchers from Xavier will see the answers of individuals. When the findings are described, only the responses of groups of people will be presented; your answers and your child's answers will stay private.

You do not have to participate in this program, and either of you may quit at any time. However, you will not earn the $\$ 10$ gift card if you do not complete the program and the questionnaires.

If you and your child would like to participate in one of the programs, please sign the form below and return it to the person explaining it to you. If you have any questions about the project or the groups, you can reach Amy Karbasi or Erica Eisenman through Harmony Garden or you can contact the research supervisor, Dr. Kathleen J. Hart, Ph.D., ABPP at (513) 745-3278. Questions 
about your rights as a participant in research can be directed to the Xavier University Institutional Review Board at (513) 745-2870.

I, freely agree to participate in this project. I also give permission for my child(ren), to participate in his/her assigned program. I understand that as part of our participation, we will answer questions to help determine how effective the program was.

Parent Signature

Date

THE TIME APPROVAL STAMP ON THIS CONSENT FORM INDICATES THAT THIS PROJECT HAS BEEN REVIEWED AND APPROVED BY THE XAVIER UNIVERSITY INSTITUTIONAL REVIEW BOARD. 


\section{Appendix $\mathrm{H}$}

\section{Student Assent Form}

Students from Xavier University are working with CMHA and Harmony Garden to run groups for kids. The groups will involve reading fun stories and playing games and activities. Being in the group will also mean that you will need to be there (at the YMCA). Along with the group, you and your mother will be asked to come to a registration night before the groups start and another meeting 3 months after the groups end. At these meetings, you will be asked to answer some questions. You will also have snacks and a chance to win prizes.

If you want to be in the group, write your name on the line below. If you begin the group and decide that you want to quit, you can and nothing bad will happen to you. If you have questions, you can ask Amy Karbasi, Erica Eisenman, or call the supervisor, Kathleen J. Hart, Ph.D., ABPP, at (513) 745-3278.

Thanks for your help!

Yes, I want to be in the group.

Write your name on this line. 


\section{Appendix I}

\section{CHS Co-Leader Instructions}

- Read the answers each time. Use appropriate voice tone/inflection.

- Each bar represents an answer that corresponds to the measure (show this to the child for each question). For example, the left-most bar represents "none of the time", while the right-most bar represents "all of the time."

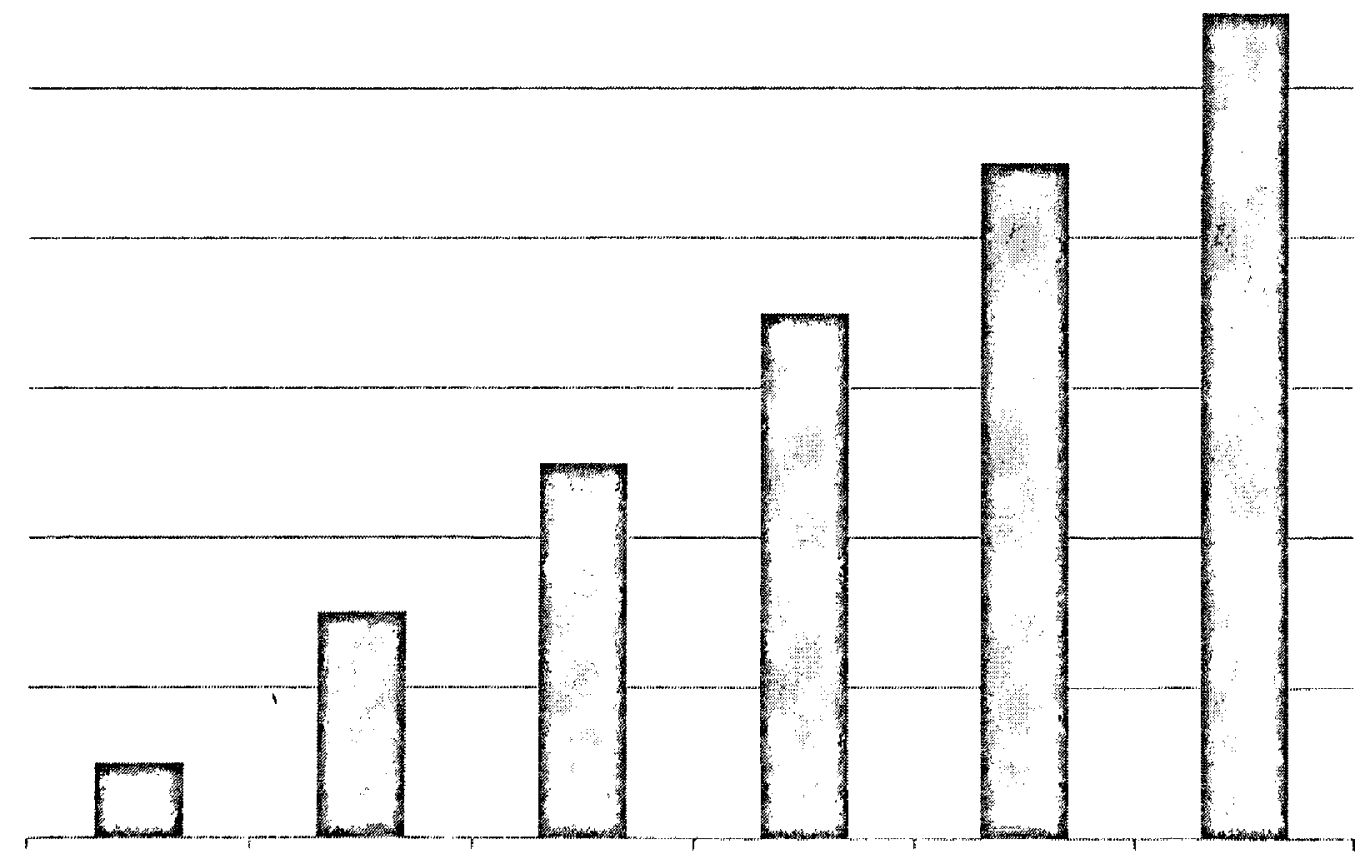




\section{Appendix J}

\section{BMSLSS Co-Leader Instructions}

- Read the answers each time. Use appropriate voice tone/inflection.

- Satisfaction = how I feel about (i.e., "I would describe how I feel about my family life as...") $\rightarrow$ This is for satisfaction in the question

- Satisfied = okay with (i.e., "mostly okay with"); Dissatisfied = not okay with (i.e., "mostly not okay with") $\rightarrow$ This is for the responses

- Environment = the area/things around me, like my school, community, neighborhood, home

- For pleased/delighted, emphasize with voice tone: pleased = happy with; delighted $=$ really happy with

Show these facial 'expressions for each response:

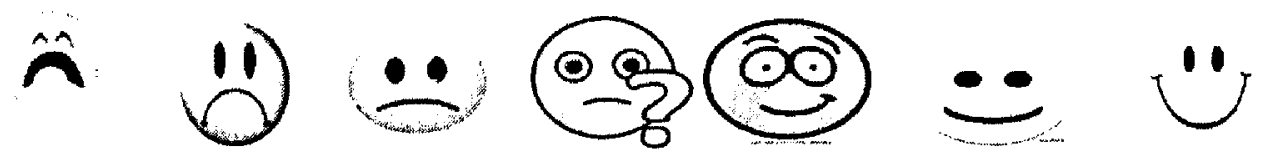




\section{Appendix K}

\section{YLOT Co-Leader Instructions}

- Read the answers each time. Use appropriate voice tone/inflection.

- "true for me" = always true for me

- "sort of true for me" = sometimes true for me

- "sort of not true for me" = not really true for me

- "not true for me" = not true at all for me

2: "active" $=$ do lots of things, do lots of activities

$5,6,7,11,12,14,15,16,17,19$ : "expect" = think (ie, "Usually, I don't expect things to go my way" = "Usually, I don't think things will go my way.")

$4,5,6,7,12:$ "usually" = most of the time

14: "overall" = most of the time

18. "illness" = some sickness, like a cold or the flu 
Appendix L

HSC Co-Leader Instructions

Make sure they understand the difference between "true" and "false"

4. Help them calculate how old they will be 10 years from now and insert that in the blank.

10. Whenever I really want something, I don't think I will get it.

15. Tomorrow (meaning my future) seems hard to understand and is confusing to me. 
Appendix $\mathrm{M}$

Hope Program Protocol

(Delancy, 2005; Dinolfo, 2009; Edwards \& Lopez, 2000)

Day One:

Group Welcome and Getting to Know Each Other (Part One)

\section{Session Goals:}

1.) To introduce the program and the overall structure of twice weekly sessions.

2.) To model and develop enthusiasm about the program.

3.) To introduce students to leaders and to one another in order to build group cohesion and develop rapport.

4.) To collaboratively develop group rules for the program.

\section{Order of Activities}

I. Welcome and Leader Introductions

a. Introduce co-leaders.

II. Icebreaker Activity

a. Children and leaders will decorate nametags and draw a picture of something that is important to them. Then, each person will share his or her name and what he or she drew.

III. Description of the study.

a. It is a program that uses fun stories, games, and activities to solve problems and reach goals.

b. It will last for nine weeks for 60 minutes twice weekly on Tuesdays and Wednesdays.

c. To'learn the skills best, it is important to be present each time. However, you will have the choice to quit coming at any time.

d. Emphasize the importance of attending each session. You will receive a prize just for coming to the group. Anyone who came to every group (did not miss one group) will receive an extra prize at the last group.

e. Fun assignments will be completed at the end of each session. Each assignment builds on one another, and the group leaders can help you. If the assignments are done, you will receive a reward at the next meeting.

f. You will also receive folders a little later on to hold all of your materials. These folders can help you remember what you learned in the group even after the group is completed.

IV. Assent

a. If you would like to be involved in these groups, please read this 
paper and sign your name on the line. Your parent(s) know about what you will be doing in the groups and have already given permission for you to participate. If you do not want to participate, you will not be punished.

V. Rules

a. Collaboratively, children and leaders will create approximately 3-5 basic rules.

b. One leader will record rules on poster board that will be present in each session.

c. Introduce token economy system, explaining that a reward will be given at the end of each group based upon the amount of tokens received.

VI. Fun Activity: Simon Says

VII. Closing

a. Collection of Tokens, Prizes

Materials: Leader and child nametags, poster board for rules, construction paper, scissors, crayons, markers, tape, tokens, stickers, snack

\section{Day Two:}

\section{Getting to Know Each Other (Part Two)}

\section{Session Goals:}

1.) To introduce the program and the overall structure of twice weekly sessions.

2.) To model and develop enthusiasm about the program.

3.) To introduce students to leaders and to one another in order to build group cohesion and develop rapport.

4.) To collaboratively review and understand group rules for the program.

\section{Order of Activities:}

I. Brief Welcome and Introduction of Group Leaders.

a. All leaders and children will be wearing their nametags.

b. Group leaders will come prepared with two truths and a lie.

II. Icebreaker Activity.

a. Have the children first say their names and then do two truths and a lie.

b. Group leaders will be prepared to offer the children ideas.

III. Description of Study.

a. Review concepts from last session. Ask for a volunteer or two to recall for everyone what the groups entail. 
b. If new children are present, ask for a volunteer to explain to the child what the study entails. Group leaders will help as needed. One group leader can take the new child(ren) away from the group to briefly explain the assent form.

IV. Review of Rules

V. Fun Activity: Musical Chairs

VI. Closing

a. Collection of Tokens, Prizes

Materials: Leader nametags, child nametags, poster board with rules, music, radio, tokens, prizes, snack

Day Three:

\section{Getting to Know Each Other (Part Three)}

\section{Session Goals:}

1.) To introduce the program and the overall structure of twice weekly sessions.

2.) To model and develop enthusiasm about the program.

3.) To introduce students to leaders and to one another in order to build group cohesion and develop rapport.

4.) To collaboratively review and understand group rules for the program.

\section{Order of Activities:}

I. Brief Welcome and Introduction of Group Leaders \& Children (0:05)

II. Review of Rules and Introduction of Any New Children

III. Brief review of study description

b. Ask for a volunteer (different from last week) to explain the procedure and rules. Group leaders will help as necessary.

IV. Fun Activity: Deep breathing and Relaxation.

a. Explain the reasoning for deep breathing and relaxation techniques.

b. With relaxing nature sounds playing in the background, teach the children how to breathe through the diaphragm.

V. Fun Activity: Read a Story to the Children.

a. Have children act out the story "Sebastian's Roller Skates" 
VI. Closing

a. Collection of Tokens, Prizes

Materials: Leader nametags, rules, child nametags, tape, calm music, radio to play music, book, story, tokens, prizes, snack

\section{Day Four:}

\section{Getting to Know Each Other (Part Four)}

\section{Session Goals:}

1.) To model and develop enthusiasm about the program.

2.) To introduce students to leaders and to one another in order to build group cohesion and develop rapport.

3.) To collaboratively review and understand group rules for the program.

Order of Activities:

I. Brief Welcome, Introduction of Leaders, Introduction of Children

II. Brief Review of Rules and Study Description

a. Ask for a volunteer (different from last week and the week before if possible) to explain the procedure and rules. Group leaders will help as necessary.

III. Fun Activity: Deep breathing and Relaxation.

a. Explain the reasoning for deep breathing and relaxation techniques.

b. With relaxing nature sounds playing in the background, teach the children how to breathe through the diaphragm.

c. Will do $1 \mathrm{~min}$. of deep breathing and lights out at the beginning of each session from now on.

IV. Fun Activity: Read a story to the children.

a. Have children act out the story--Stellaluna

V. Distribute and decorate group folders.

a. The folders provide the children with a way to organize their assignments and group handouts. The leaders will keep the folders to redistribute during meetings. The folders will contain the in-session assignments, a card with the definition of hope, and a card with a motivational Dr. Suess saying (see below). The folders will also have an envelope for each child to collect his or her tokens. At the end of the program, the children will be allowed to keep their folders to remind them of what they have learned. 
Dr. Seuss: "You have brains in your head, You have feet in your shoes, You can steer yourself, Any direction you choose."

ii. Ask the children for ideas as to what this means and correct them as necessary.

VI. Closing

a. Collection of Tokens, Prizes

Materials: Leader nametags, rules, folders, scissors, crayons, colored pencils, markers, tape, stickers, child nametags, tape, calm music, story, tokens, prizes, snack

\section{Day Five:}

\section{Group Welcome and Introductions to Hope}

Session Goals:

1.) To introduce children to the hope model.

\section{Order of Activities:}

I. Deep breathing/lights out

II. Introduction to hope theory

a. Group discussion - ask the children what they think hope is.

b. Define hope: "It is something you feel inside you. It has two parts. One part is feeling and knowing that you are able to reach your goal that you can do or get what you want. The second part is being able to think of lots of ways to reach your goal. When you have problems, you can think of ways to solve them. So, hope is feeling able to do a thing and finding ways to do it" (Delancy, 2005, p. 72).

c. Label the components of hope: willpower, pathways, and goals

III. Hope Picture Activity (Edwards \& Lopez, 2000):

a. Explain the picture of hope with the example of a boy whose goal is to learn how to ride a bike. Explain and label willpower and pathways. Coleaders will act this out for the children to model the hope picture.

b. Ask for volunteers to act out the hope picture. Tape goal sign about six feet away from the child. The individual's goal is to read a book. Have other volunteers be obstacles, wearing stop signs around their necks. Another volunteer will hold the pathway arrow and explain to the group what the pathway is. One more volunteer will hold the agency/ willpower arrow and explain to the group what the willpower thought is. 
c. Repeat activity with different volunteers. This time the individual's goal is to go outside to play. The obstacle is a parent or babysitter who tells the child that he or she needs to clean his or her room before going outside. Throughout examples, reinforce vocabulary (goals, obstacles, willpower, pathways) and encourage group members to volunteer ideas.

IV. Who can give an example?

(0:05-0:10)

a. Rationale: "After the children have been given a model of what 'hope' is, it is important to assess their understanding and further mold their conceptualizations into this specific definition of hope." Ask for children to volunteer their ideas to assess their understanding and further mold their conceptualizations into the specific definition of hope. Children will act out the examples.

V. Closing Activity: Create one example of hope that fits your goals. Write it down.

a. Children will complete this activity with the help of the co-leaders, who will keep the assignment for use in the next session.

VI. Closing

a. Collection of Tokens, Prizes

Materials: Hope Model picture, Signs for Hope Picture Activity (Goal, Agency, Pathways, Obstacles), rules, paper, pencils, folders, tokens, prizes, snack

\section{Day Six:}

\section{Define Hope}

\section{Session Goals:}

1.) To continue to teach children the hope model.

2.) To incorporate and facilitate a variety of activities and stories to help the children better understand the components of hope.

3.) To teach the children to start applying these concepts to hope in their own lives.

\section{Order of Activities:}

I. Deep breathing/lights out

II. Define hope, give examples, and label the three components.

a. Use picture model to review and act out one to two scenarios (i.e., clean my room, raise my hand before talking in class) based upon child participation and encouragement. 
III. Review last session's closing activity:

a. "Ask the children to share their examples of hope. Shape the definitions as necessary without degrading the child's efforts. For example, prompt the children to answer a missing component by saying, 'I see the goal is . I see the will is , but I can't seem to find the ways.

What were the ways in your example?' Reinforce completed assignments by giving the child a token" (Delancy, 2005, p. 74).

b. Ask each participant to label the hope components of another participant's example. "Engaging others in the process will sustain their attention and begin to build the social relationships and trust within the group. It will also allow children more practice at labeling the components of hope and see hope in different contexts" (Delancy, 2005, p. 74).

IV. Read "The Little Engine That Could"

a. Children will act out this story and stop to ask the following questions:

i. What is his goal?

ii. What is his will?

iii. What are his ways?

iv. Did he run into any problems?

v. How did he reach his goal?

V. Writing a Hopeful Story

a. McDermott and Snyder (2000) emphasize that writing stories is one way to increase hope in children.

b. Children will spend time writing about a problem they solved in the past. First, they will think of a goal they reached in the past. The following questions will be written on the board to help guide them with the storywriting:

i. Who are the characters in your story?

ii. What was your goal or problem you were trying to solve?

iii. What were the ways that you thought of trying to use to reach your goals? What ways did you actually use?

iv. What problems or obstacles came up?

v. What did you do about those problems? How did you solve them?

vi. How did you feel and what did you think while you were working for your goal?

vii. How does the story end?

c. Before writing their stories, a co-leader will come prepared with an example.

d. A few children will share their stories. If there is not enough time to share or not all children who want to share are able to, time will be allotted for each child to share in subsequent sessions. Leaders will help identify and reinforce positive words in the stories and help correct any misunderstandings the children had while writing the stories. 
e. The children will design covers for their stories and, if they wish, will give them to their mothers at the end of the program as a gift and as a way to share with them what they are learning in the group.

VI. Goal Domains

a. Snyder, Feldman, Shorey, and Rand (2002) and McDermott and Snyder (2000) discuss the value of setting goals in a variety of life domains.

b. Discuss the importance of setting goals in many life domains (friends, family, school, helping others, doing fun things, etc.).

c. Each week, you will set a goal in one area of life.

VII. Closing Activity: (Worksheet)

a. Think about a personal goal you would like to set for yourself. It should be one that you would like to work on before our session next week and be about doing something fun. What is the goal, will, ways, and problems you may run into along the way?

b. Group leaders will assist children with this activity and completing the worksheet and will keep the worksheets for review in the next session. Leaders should help to make sure that these goals are personally important for the children and that they are attainable and feasible.

VIII. Closing

a. Collection of Tokens, Prizes

Materials: Hope Model picture, Signs for Hope Picture Activity (Goal, Agency, Pathways, Obstacles), rules, folders, paper, pencils, "The Little Engine That Could," tokens, prizes, snack

\section{Day Seven:}

\section{Defining Hope and Teaching Goal Setting}

\section{Session Goals:}

1.) To continue to teach children the hope model.

2.) To incorporate and facilitate a variety of activities and stories to help the children better understand the components of hope, especially goal setting.

3.) To teach the children to start applying these concepts to hope in their own lives.

Order of Activities:

I. Deep breathing/lights out

II. Define hope. Give an example.

a. Leader and child participation. Encourage as needed. 
III. “Go WP!” Story (Edwards \& Lopez, 2000)

(0:15-20)

a. Introduce the activity by stating that the children are to listen carefully to a story about Wendy Parker. Children will be asked to volunteer to act out the story. The leaders will ask questions about the story once they are finished.

b. Read "Go WP" story.

c. On a chalk/ marker board or individual handouts, divide the writing space into three columns entitled "goals," "obstacles," "pathways," and "willpower." Facilitate group discussion and brainstorming for each construct.

IV. Goal Activity (Delancy, 2005, p.75)

a. Ask the children to keep his/her goal (from last week's closing activity) in mind while you explain the elements of a good goal. Incorporate an example to show them the elements of a goal. As always, be sure the example is something they value. Write the following on the board/Come prepared with the following concepts written on construction paper to tape up to the wall.

i. Important: What do I really want? (Be a good student)

ii. Specific: Needs to be clear and well defined. (Get good grades: Turn in homework or get a B on my math test.)

iii. Describe short-term and long-term goals: It can be either. Which one is yours?

iv. Large or small goal: It can be either. Which one is yours?

v. Break it down into smaller steps: There will be further discussion of this topic next week.

vi. Is my goal possible/ doable? Do I know all the steps?

1. What roadblocks could there be? Do I need to learn more skills before I start?

b. Have children announce their goals to the group. Reinforce with tokens. Ask the children if they reached their goal, and if not, what obstacles got in the way. Ask for suggestions for how the child can reach the goal from the other children

V. Group Goals

a. Have the children generate a "group goal" for the next two sessions $(7 \&$ 8). Leaders can help with this, shaping the children into generating good goals by making suggestions. Write this on the board/poster board.

b. Have children generate a "group goal" to reach by the end of the program. Leaders can help with this. Write this on the board/poster board.

VI. Read Molly's story (Delancy, 2005, p.75)

a. See The Great Big Book of Hope (McDermott and Snyder, 2000, p. 129). The story is about a girl named Molly who wanted a puppy, but her 
parents did not think she could handle the responsibilities involved in taking care of a dog. Molly started to read and learn about different breeds of dogs and began walking her neighbors' dogs. Eventually, her parents noticed her efforts and decided she was ready to own a dog. "In order to distinguish if Molly's goal was a good one, ask the following questions:

i. Is the goal clear and well defined?

ii. Is it a long-range or short-range goal?

iii. Is the goal large or small?

iv. Is the goal doable?

v. Can the goal be broken down into small steps?

vi. How much did Molly really want her goal?

vii. Was the goal personally important to her?

b. The children will act out this story.

VII. Closing Activity:

a. Evaluation of personal goals. Using a modified version of the worksheet provided on pg 148 of The Handbook of Hope (Snyder, 2002), the children will come up with a new, "good" personal goal to reach by the next session having to do with family. This is a way for the children to apply what they have been learning about the hope process to their own personal goals. The leaders will give the children cards with the elements of good goals listed to aid them in this assignment and to keep in their folders (Delancy, 2005, p, 76). Leaders will assist the children with this activity and will keep the worksheets to review in the next session. Leaders should help to make sure that these goals are personally important for the children and that they are attainable and feasible.

\section{Closing}

a. Collection of Tokens, Prizes

Materials: If room has no chalk/marker board individual handouts for WP activity \& concepts for goai setting activity, "Evaluation of personal goals" homework sheet, Molly's story, pencils, cards to assist with homework assignment, rules, poster board with group goals, folders, tokens, prizes, snack

\section{Dav Eight:}

\section{Defining Hope and Teaching Goal Setting (Part Two)}

\section{Session Goals:}

1.) To continue to teach children the hope model. 
2.) To incorporate and facilitate a variety of activities and stories to help the children better understand the components of hope, especially goal setting.

3. To teach the children to start applying these concepts to hope in their own lives.

\section{Order of Activities:}

I. Deep breathing/lights out

II. The HOPE game (Edwards and Lopez, 2000)

a. The HOPE game involves a board game and dice. Split the children into two teams. Each team has a game piece. Every player gets a turn. After rolling the die, he or she moves his or her team game piece to a space marked with a $G$ (goal), $O$ (obstacles), W (will), or $P$ (pathways). The player will choose a card from that letter pile and read it aloud to the group. If the player cannot do as the card instructs him or her, he or she can ask teammates for help. The first team to get to the goal wins.

III. Pull the goal out of the box (Delancy, 2005)

a. This activity requires that each child pull a goal out of a box and tell the group what might be a barrier in the way of that goal for the particular person and how the character could overcome the obstacle.

IV. Discuss Personal Goals

a. Several children will discuss the personal goals they set for themselves for last session's closing activity. For this session, two children will share their goals and, with the help of the rest of the group and the leaders, discuss the following questions:

i. What is the goal or problem?

ii. How was it solved?

iii. Did you run into any problems or roadblocks?

iv. What feelings (energy) were involved? How motivated were you?

v. Did you succeed or fail?

vi. If you failed, what could you have done differently?

vii. How did you feel when you were successful or failed?" (Delancy, 2005, p.76)

V. Discussion of Group Goal

a. Did we reach our group goal for the last 2 sessions? If not, what could we have done differently? Incorporate agency and pathways into this.

b. How are we doing on our big group goal?

VI. Closing Activity 
a. Leaders will help the children generate personal goals to reach before the next session. This time, the goal should have to do with their health. Leaders should help to ensure that the goals are personally important to the children and feasible. The leaders will help the children discuss specific agency thoughts and pathways to reach their goals. Two children will share their goals next session, continuing with the questions from activity III above.

\section{Closing}

a. Collection of Tokens, Prizes

Materials: HOPE game board, dice, cards, game pieces, box with goals, poster board with group goals, rules, folders, snack, tokens, prizes

\section{Day Nine:}

\section{Teaching Pathways}

Session Goals:

1.) To continue to teach children the hope model through focusing on pathways.

\section{Order of Activities:}

I. Deep breathing/lights out

II. Have two children tell about their goals.

a. Leaders should give positive reinforcement through verbal praise, stickers, and tokens. Leaders should also correct any pieces that may be inaccurate and facilitate an environment where other children can offer help.

III. Group Goal

a. Generate a group goal for the next two sessions $(9 \& 10)$. Write this on a piece of poster board.

b. What are the will and ways we can use to reach this goal?

IV. Define hope.

a. Give examples and review components. Today we will focus on "ways."

V. Pathways Activity: In pairs.

a. Rationale: Pathways thinking involves brainstorming various routes to take in order to reach a goal. Part of pathways thinking requires that the children break down the ultimate goal into smaller subgoals. This prevents the final goal from seeming too overwhelming. In striving towards almost 
any goal, obstacles arise that pose as challenges. While individuals low in hope are unable to think flexibly enough to overcome these challenges, those with hope have better chances of moving forward. Delancy (2005) suggests in line with the social learning component of hope that children ask someone for help. Asking for help is likely to increase social skills and pathways thinking. Another technique that may be useful is imagery, which helps to increase agency thinking or motivation towards reaching goals.

b. Activity: "This activity will walk the children through choosing a goal, being sure it is a good goal, recognizing the steps to achieve that goal, putting the steps in order, anticipating roadblocks, and finding ways to overcome the roadblocks. After the children have created the pathways, the facilitator should walk the children through the goal attainment process through the use of imagery being sure to cover roadblocks, mistakes, alternative pathways, self-talk, how it feels to be successful, and the idea that a failed pathway does not reflect upon the individual's skills.

i. Pick a goal to reach before the next session. This time, it should have to do with school. (Write it down).

ii. Ask yourself the goal questions from your homework. (Leaders will help with this).

iii. Once your goal is ready...(you may need to change it along the way)

iv. Write the steps of one way to get to your goal. (One step per sheet of paper)

1. You may need to ask someone who has done it before (friend, teacher, coach, principal, etc.).

2. Send the children out around the room to ask for help from the leaders and other children.

v. Put the steps in order. (Arrange papers in order).

vi. Brainstorm roadblocks (or mistakes). What could get in your way (Write them down).

vii. Brainstorm ways to get around the roadblocks. (Write them down).

viii. Imagery: The facilitator should walk the children through the following:

1. Close your eyes. Imagine yourself doing what my words say.

2. Go through roadblocks, mistakes, alternative ways, being successful and how it feels and the path not working (failing) and how that feels. If the path fails, you will need to find a new path." (Delancy, 2005, p. 77)

VI. Read story

a. Following the story in the Great Big Book of Hope (McDermott and Snyder, 2000, p.183), the children must choose the next step for the main character. Decisions should be consistent with those for low hope and high hope individuals. The story helps to teach the children the differences 
between wills and ways and high hope versus low hope. In addition, the children will learn about breaking down a big goal into subgoals, as well as the influence of hopeful thoughts and unhopeful thoughts in striving to reach goals.

b. The children will act out this story.

VII. Closing Activity

a. Ask the children to think of different ways (at least two) to his/her goal (same as above) and write them down. Ensure that the pathways are different from what the child generated in the above activity. The child is asked to consider the roadblocks and mistakes and how they can get around them. Finally, the child is asked to close his/her eyes and imagine going through the steps, conquering roadblocks, and successfully reaching his/her goals. The leaders will help with this activity. Two children will share their goals next week.

VIII. Closing

a. Collection of Tokens, Prizes

Materials: construction paper, markers, story, poster board with group goals, folders, paper, pencils, homework (pathways worksheet), snack, tokens, prizes

\section{Day Ten:}

\section{Teaching Agency}

Session Goals:

1.) To continue to teach children the hope model through focusing on pathways.

Order of Activities:

I. Deep breathing/lights out

II. Have two children tell about their goals.

a. Leaders should give positive reinforcement through verbal praise, homework stickers, and tokens. Leaders should also correct any pieces that may be inaccurate and facilitate an environment where other children can offer help.

III. Review the components of hope.

a. Today we will focus on agency/will.

b. Define wills.

IV. Read a story to the children. 
a. Read a story about Barack Obama. The children will be asked to identify his goals, obstacles to his goals, and the agency and pathways used to achieve his goals.

V. Using past successes.

a. Rationale: Snyder's conceptualization of hope involves the influence of past successes. That is, when an individual has had a previous success experience, he or she can revisit or reimagine that experience to give him or her the motivation and energy to try to reach other goals.

b. Activity: "The following activity seeks to remind and instill the concept of agency and what it 'feels' like: Think about a time when you reached your goal and you succeeded. Write down your goal and the feeling you had about it" (Delancy, 2005, p.78). Ask some of the children to volunteer to discuss their goals and their feelings about it.

VI. Imagery

a. Rationale: Using imagery is helpful in training the mind to realize that a goal is not out of reach. Imagery is a mental exercise for the children to practice working towards their goals.

b. Activity: "Now imagine (close your eyes, think, etc.) about our group goal that we want to reach by the end of the program (remind the children of the goal). You did it! You succeeded! Write how it feels to succeed" (Delancy, 2005, p.78). Have some of the children discuss their feelings.

c. Rationale: Imagery can also provide for a mental exercise depicting failure and allowing the child to experience how that may feel.

d. Activity: "Now imagine the group goal and not reaching it. Think back to last week, what if we tried a different way? Would you be successful? Sometimes we need to use our back-up plans" (Delancy, 2005, p. 78). Allow time for discussion of different ways to achieve the goal.

VII. Group Goal

a. Did we reach our group goal for the last two sessions? If not, were there other ways we could have done it?

b. Discuss feelings about succeeding or failing in this goal.

c. How are we doing on our big group goal?

VIII. Closing Activity

a. With the help of the leaders, come up with a personal goal to reach by next session. This time, it should have to do with helping others. Think of the will and the ways needed to reach that goal. Two children will share next week. 
Materials: Obama story, poster board with group goals, folders, paper, pencils, snack, tokens, prizes, rules

\section{Day Eleven:}

\section{Self Talk}

\section{Session Goals:}

1.) To teach the concept of self-talk in helping to reach goals.

Order of Activities:

I. Deep breathing/lights out

II. Have two children tell about their goals.

a. Leaders should give positive reinforcement through verbal praise, homework stickers, and tokens. Leaders should also correct any pieces that may be inaccurate and facilitate an environment where other children can offer help.

III. Group Goal

a. As a group, develop a new group goal for the next two sessions (11 \& 12). Write this on poster board.

IV. Introduction to self-talk

a. Rationale: Self-talk is a technique promoted by Snyder and colleagues as a way to define and instill agency.

b. Activity: "Sometimes we get in our own way of reaching our goals. We tell ourselves or make ourselves believe that we cannot reach our goal. This is called self-talk. We talk to ourselves" (Delancy, 2005, p. 78).

V. Read a story about self-talk

a. Making Hope Happen (McDermott and Snyder, 1999) contains two stories about Sarah; one that utilizes negative self-talk and one with positive selftalk. The group leader should facilitate a discussion about what it would feel like to talk to themselves negatively, in the way Sarah does in the first story versus the positive story. These stories help further teach the concept of agency and point out how different types of self-talk leads to different outcomes.

b. The children will act out this story. If time allows, the story will be read again, with the children who did not get to act it out doing so the second time.

VI. Read a story about self-talk

a. Use Caleb's story from The Great Big Book of Hope (McDermott and Snyder, 2000) to demonstrate how positive self-talk can be helpful in achieving goals. 
b. The children will act out this story, twice if time allows so that all children may participate.

VII. Closing Activity: Identifying your own self-talk

a. Think of a goal you want to reach for next session. This time, it should have to do with a sibling. If the child does not have a sibling, it should have to do with another relative such as a cousin. Write it down. With the help of a leader, write down the type of self-talk you will use to reach that goal. Two students will share their goals and self-talk next week.

VIII. Closing

a. Collection of Tokens, Prizes

Materials: Sarah story, Caleb story, any needed props for stories, homework sheet, paper, pencils snack, tokens, prizes, rules, poster board with group goals

\section{Day Twelve:}

\section{Defining Hope and Teaching Goal Setting (Repeated)}

Session Goals:

1.) To facilitate better understanding of the hope model.

Order of Activities:

I. Deep breathing/lights out

II. Have two children present their goals/self-talk.

a. Leaders should give positive reinforcement through verbal praise, homework stickers, and tokens. Leaders should also correct any pieces that may be inaccurate and facilitate an environment where other children can offer help.

III. Review the components of hope, as needed.

a. Review homework.

IV. The HOPE game (Edwards and Lopez, 2000)

a. The HOPE game involves a board game and dice. Split the children into two teams. Each team has a game piece. Every player gets a turn. After rolling the die, he or she moves his or her team game piece to a space marked with a $G$ (goal), $O$ (obstacles), $W$ (will), or P (pathways). The player will choose a card from that letter pile and read it aloud to the 
group. If the player cannot do as the card instructs him or her, he or she can ask teammates for help. The first team to get to the goal wins. (This week there will be different cards in comparison to the last time.)

V. Pull the goal out of the box (Delancy, 2005)

a. This activity requires that each child pull a goal out of a box and tell the group what might be a barrier in the way of that goal for the particular person and how the character could overcome the obstacle. (This week there will be different goals as compared to last time).

VI. Group Goals

b. Did we reach our group goal for the last two sessions?

c. How are we doing on our "big" group goal?

d. Discuss will and ways as necessary.

VII. Closing Activity

a. With the help of a leader, write down a goal you want to reach by the next session. This time, it should have to do with doing something fun. Write down two different ways you can reach the goal and the self-talk you will use. Two children will present next session.

VIII. Closing

b. Collection of Tokens, Prizes

Materials: HOPE game board, dice, HOPE game cards, hat, goal cards, snack, folders, poster board with group goals, paper, pencils, rules, tokens, prizes

\section{Day Thirteen:}

\section{Defining Hope and Teaching Goal Setting (Repeated)}

Session Goals:

1.) To facilitate better understanding of the hope model.

\section{Order of Activities:}

I. Deep breathing/lights out

II. Have two children present their goals.

a. Leaders should give positive reinforcement through verbal praise, homework stickers, and tokens. Leaders should also correct any pieces that may be inaccurate and facilitate an environment where other children can offer help. 
III. Review the components of hope, as needed.

IV. Group Goal

a. Come up with a group goal for the next two sessions ( $13 \& 14)$. Have some discussion about self-talk and pathways to use to reach the goal. Write this on a piece of poster board.

V. Hope Picture Activity (Edwards \& Lopez, 2000)

a. Explain the picture of hope with the example of a girl whose goal is babysit for families in her neighborhood in order to make some money. Explain and label willpower and pathways.

b. Ask for volunteers to act out the hope picture. Tape goal sign about six feet away from the child. The individual's goal is to read a book. Have other volunteers be obstacles, wearing stop signs around their necks. Another volunteer will hold the pathway arrow and explain to the group what the pathway is. One more volunteer will hold the agency/ willpower arrow and explain to the group what the willpower thought is.

c. Repeat activity with different volunteers. This time the individual's goal is to play on a sports team. The obstacle is a parent who tells the child that he or she must prove to them that he or she is responsible enough to play on the team. Throughout examples, reinforce vocabulary (goals, obstacles, willpower, pathways) and encourage group members to volunteer ideas.

d. Have children volunteer their own ideas and act it out.

VI. The HOPE game

a. The HOPE game involves a board game and dice. Split the children into two teams. Each team has a game piece. Every player gets a turn. After rolling the die, he or she moves his or her team game piece to a space marked with a G (goal), O (obstacles), W (will), or P (pathways). The player will choose a card from that letter pile and read it aloud to the group. If the player cannot do as the card instructs him or her, he or she can ask teammates for help. The first team to get to the goal wins. (This week there will be different cards in comparison to the last time.)

VII. Closing Activity

(0:10-0:20)

a. With the help of a leader, think of one goal you want to reach by the next session. This time, it should have to do with family. Write down the pathways and self-talk you will use.

VIII. Closing

a. Healthy Snack, Collection of Tokens, Prizes 
Materials: Hope Model picture, Signs for Hope Picture Activity (Goal, Agency, Pathways, Obstacles), tape, poster board with group goals, folders, paper, pencils, rules, HOPE board, HOPE cards, dice, snack, tokens, prizes

\section{Day Fourteen:}

\section{Bringing the Components Together}

\section{Session Goals:}

1.) To facilitate better understanding of the hope model.

2.) For children to physically apply their knowledge of the hope model.

3.) To enhance teamwork and positive social interactions among the children.

Order of Activities:

I. Deep breathing/lights out

II. Define Hope.

a. Have children label the three parts.

III. Have two children present goals.

a. Leaders should give positive reinforcement through verbal praise, homework stickers, and tokens. Leaders should also correct any pieces that may be inaccurate and facilitate an environment where other children can offer help.

IV. Create a hopeful story.

a. Rationale: Hopeful narratives have shown to instill hopeful thinking. This activity requires the children to work together to make a hopeful story. Through incorporation of problem-solving and teamwork, this activity evaluates the children's abilities to understand and utilize the components of hope.

b. Activity: Described by Snyder and McDermott, yet outlined in Delancy (2005, p. 81) as follows

i. The group will pass an object to designate turn-taking.

ii. On the board write the steps in creating a story:

1. Introduce the main character.

2. Tell about a problem and come up with a plan.

3. Talk to a wise person.

4. Try a new approach.

5. What did the character learn?

iii. The turn-taking rules are:

1. Say the first thing that comes to mind.

2. If you can't think of anything you can pass. 
3. If you want the person before you to keep going, point to them.

iv. After the story:

1. Who were the main characters?

2. What was the goal?

3. How did he or she reach the goal?

V. Problem solving Activity

a. This problem solving activity further demonstrates that both pathways and agency are necessary to reach goals. Split the group in half. One half of the group will become the "cheerleaders" and demonstrate agency, while the other half demonstrates pathways. Split the pathways group into three separate sections. Have all the pathways children stand at the far end of the room, each group with their own stack of papers. Each stack of papers will be pre-counted, allowing for each group to use all of the papers to get to the other end of the room without stepping directly on the floor. That is, each team will have to plan out and use their papers to step on the floor and make it to the goal of crossing the room, while the agency children on the other end of the room will cheer them on and encourage them to try different routes if one fails. This activity incorporates team work and building social relationships to the hope model.

I. The leaders must explain the roles of each group and the objective of the activity.

II. Each pathways group has three minutes to decide upon their plan. While they are strategizing, one leader will give the agency or wills group instructions. (Delancy, 2005)

\section{Group Goals}

a. Did we reach our group goal for the last two sessions?

b. How are we doing on our big group goal?

c. Discuss agency and pathways related to this as necessary.

\section{Closing Activities}

a. Ask a leader if he or she has ever achieved a goal (leaders will come prepared with ideas). After the leader responds, the child must distinguish the different parts of hope (goals, wills, ways), asking the leader for help if needed.

b. Think of a goal you want to achieve before the next session. This time, it should have to do with school. With the help of a leader, think of the agency and pathways you will use to reach that goal. Two children will present their goals next week.

\section{Closing}

a. Collection of Tokens, Prizes 
Materials: scrap papers for problem solving activity, ball/toy to pass, homework sheets, rules, poster board with group goals, paper, pencils, folders, rules, snacks, tokens, prizes

\section{Day Fifteen:}

\section{Teaching Hope through Social Means}

\section{Session Goals:}

1.) To facilitate better understanding of the hope model.

2.) To enhance teamwork and positive social interactions among the children.

\section{Order of Activities:}

I. Deep breathing/lights out

II. Have remaining children present their goals.

a. Leaders should give positive reinforcement through verbal praise, homework stickers, and tokens. Leaders should also correct any pieces that may be inaccurate and facilitate an environment where other children can offer help.

III. Group Goal

a. As a group, develop a group goal for the next two sessions (15\&16). Write this on a piece of poster board.

IV. Making Friends Activity

a. Rationale: Research has shown that individuals high in hope typically have many friends. Furthermore, Snyder suggests that WE goals, or goals that friends can strive for together, help to build social skills and friendships and are reflective of social learning theory.

b. Activity: The leader will introduce this session by saying, "The skills we have been learning can help us make friends... We can work together to reach a goal. We can be each other's cheerleaders. We can be flexible when working with others so we can reach our goal" "(Delancy, 2005, p.80).

c. Discussion after prompting the question "What do you look for in a friend?" Tie this to working together with other people (including friends) to reach goals.

V. A WE goal activity

a. The tower 
i. "The goal of the game is for each team to make a tower out of cups, plates, paper, straws, and tape that will be the tallest and able to withstand a small wind. The teams are given seven minutes to plan the 'ways' in which they will build. They will be reminded to be each other's cheerleaders and encourage positive talk. The children will be given six minutes to put together their tower. The team that 'fails' will be reminded that it is not their lack of skill, but just the 'way' did not work and now they will know to pick another way next time" (Delancy, 2005, p. 80).

ii. Both teams will help brainstorm for the team that failed different ways they could have succeeded.

VI. Read a hopeful story.

a. Read Tim's story from the Great Big Book of Hope (McDermott \& Snyder, p. 177) and ask the questions from p. 181.

b. Have the children act out the story and answer the questions.

VII. Closing Activity

a. Think of a WE goal you want to achieve with your friends before the next session. With the help of a leader, think of the willpower and pathways you will use to reach that goal. Two children will present their goals next week.

Materials: cups, plates, paper, straws, tape, fan, paper, pencils, rules, poster board with group goals, folders, rules, story, snacks, tokens, prizes,

\section{Day 16}

\section{Reviw of Components of Hope and Long-Term Goals}

Session Goals:

1.) To review the components of hope.

2.) Introduce the concept of making long-term goals.

Order of Activities:

I. Deep breathing/lights out

II. Have two children present their goals.

a. Leaders should give positive reinforcement through verbal praise, homework stickers, and tokens. Leaders should also correct any pieces that may be inaccurate and facilitate an environment where other children can offer help.

III. Group Goals 
a. Did we reach our goal for the last two sessions?

b. How are we doing on our big group goal?

IV. Future Goals/Closing Activity

a. Have a group discussion about future goals. The leaders will first discuss their future goals and how they plan to reach them.

b. Discuss breaking future goals into sub-goals and elicit examples from the children.

V. Writing a Hopeful Story

b. McDermott and Snyder (2000) emphasize that writing stories is one way to increase hope in children.

c. Children will spend time writing about a goal they would like to reach in the future. The following questions will be written on the board to help guide them with the story-writing:

i. Who are the characters in your story?

ii. What is the future goal you are trying to reach?

iii. What are the ways that you could use to use to reach your goals?

iv. What problems or obstacles might come up?

v. What are some things you can do about those problems? How will you solve them?

vi. What do you think you will FEEL and THINK while you are working for your goal?

vii. How does the story end?

d. Before writing their stories, a co-leader will come prepared with an example.

e. A few children will share their stories. If there is not enough time to share or not all children who want to share are able to, time will be allotted for each child to share in subsequent sessions. Leaders will help identify and reinforce positive words in the stories and help correct any misunderstandings the children had while writing the stories.

f. The children will design covers for their stories and, if they wish, will give them to their mothers at the end of the program as a gift and as a way to share with them what they are learning in the group.

VI. Closing

c. Collection of Tokens, Prizes

Materials: construction paper outlining hopeful story activity questions, paper, pencils, poster board with group goals, rules, folders, snack, tokens, prizes 


\section{Day Seventeen:}

\section{Review}

$\underline{\text { Session Goals: }}$

1.) To review knowledge of the hope model.

2.) To have children think about applying what they have learned in the program to the future.

\section{Order of Activities:}

\section{Deep breathing/lights out}

II. Have as many children as possible present their future goals.

a. Leaders should give positive reinforcement through verbal praise, stickers, and tokens. Leaders should also correct any pieces that may be inaccurate and facilitate an environment where other children can offer help.

b. Have children discuss how they will use what they have learned in the program to reach short-term and long-term goals.

III. Review.

a. Define hope and label the three parts.

b. Define the elements of a good goal.

c. Have many different ways to reach your goal. Be able to recognize and conquer roadblocks. Imagine yourself being successful.

d. Have will. Have energy and motivation. Use positive self-talk and dispute stereotypes.

e. You will need all three components of hope to be successful.

f. Use the skills from hope to help you make and keep friends and reach long-term goals.

IV. Identifying Strengths

a. Leaders will come prepared with examples of their strengths and how those have helped/can help them reach their goals.

b. Children will identify 3 strengths that they have and how these strengths can help them reach goals/have hope.

c. As many children as time allows will share their ideas.

V. Read a story.

a. In the Handbook of Hope (Snyder, 2000, p. 197), Ryan's example outlines the components of hope and how one can successfully achieve his or her goals.

b. Have the children act out this story.

VI. Group Goal 
a. Did we reach our group goal that we wanted to reach by the end of the program?

b. Have children discuss the obstacles that got in the way and what helped them to succeed or caused them to fail.

c. Provide plenty of reinforcement if the goal was reached.

VII. Reminder of importance of attending the last session!

VIII. Closing

a. Collection of Tokens, Prizes

Materials: hopeful story concepts for board*, paper, Ryan's story, pencils/markers, snacks, tokens, prizes

\section{Dav Eighteen:}

\section{Post-test Measures}

\section{Session Goals:}

1.) To complete posttest measures.

Order of Activities:

I. Complete post-test measures.

\section{Day Nineteen:}

\section{Post-Test Measures and Graduation}

\section{Session Goals:}

1.) To complete posttest measures.

2.) To congratulate and thank the children for their hard work and dedication to the program.

I. Completion of Post-Test Measures

a. Complete any remaining post-test measures 
II. Graduation Ceremony

a. Each child will receive a personalized certificate pointing out their unique contribution to the group and praising them for successfully completing the hope program. Each child will also receive a prize or goodie-bag.

b. Upon graduating, each child will state their future goal and how they plan to reach it (mentioning at least one of their strengths). If they wish, at this time they will give their 2 stories that they wrote in earlier groups to their mothers.

c. Children who had perfect attendance will receive an extra prize.

\section{Closing}

a. Snacks

IV. Reminder of follow-up measures in three months.

Materials: posttest measures, pencils, certificates, prizes, snacks 


\title{
Chapter V
}

\section{Dissertation}

\begin{abstract}
The present study implemented an intervention designed to increase hope based on Snyder et al.'s (1991) Hope Theory. This study included 49 children ages 7 through 13 from an inner-city after-school community center who participated in a nine-week Hope Intervention (HI) or a comparison group. One parent of each child also participated in the study by completing measures. In contrast to some previous studies that have demonstrated increased hope scores as a result of the intervention, no such increase was found in this study. However, participants in the HI showed significantly greater decreases in scores on the Hopelessness Scale for Children from pre-testing through follow-up testing than children in the comparison group. The present findings are discussed with reference to the development of meaningful programs to support resiliency in children.
\end{abstract}




\section{A Randomized Clinical Trial Examining the Effectiveness of a Hope Intervention}

\section{for Low SES Children}

Research in the field of positive psychology has been devoted to identifying and developing factors that "protect" individuals from adverse experiences. Protective factors strengthen resilience, which refers to the strengths and assets that some people have to help them survive adversity (Alvord \& Grados, 2005). Hope is one such protective factor that enhances resiliency. A growing body of research has examined the role of hope in psychological well-being. Several studies have indicated that low hope has maladaptive effects on individuals' lives (e.g., Gilman, Dooley, \& Florell, 2006; Magaletta \& Oliver, 1999), whereas high hope has demonstrated a variety of benefits, such as a higher likelihood of reaching goals (Snyder, Cheavens, \& Sympson, 1997), higher confidence (Hagen, Meyers, \& Mackintosh, 2005), and higher life satisfaction (Gilman et al.). Overall, the research to date indicates that maintaining hopeful thinking is a buffer against future, unforeseen life stressors.

Snyder (1995) provides the most recent, extensively-researched theory of hope, based on a unique definition of hope as "a cognitive set that is based on a reciprocally derived sense of successful a) agency (goal-directed determination) and b) pathways (plans for the ways to meet goals)" (p. 355). More specifically, agency is the cognitive willpower or energy to get motivated toward one's goals, and pathways is the ability to generate effective routes to reach goals. In this model, one must have both agency and pathways to reach a goal; neither by itself is enough to produce high hope. Goals are an additional, integral component of Snyder's theory; they are the imagined endpoints for something that a person desires and form the basis for hope theory (Snyder, Feldman, 
Taylor, Schroeder, \& Adams, 2000). The main advantage of Snyder's Hope Theory over other theories of hope is that it enables hope to be psychometrically measured rather than inferred from behaviors.

Much of the research available on hope investigates the development of hope, benefits of hope, and interventions to increase hope. Snyder et al. (1997) contend that hope develops (or fails to develop) in childhood, and thus it may be important to encourage the development of hope at this stage. While most of the research on hope is correlational rather than experimental, existing literature demonstrates that individuals high in hope evince a plethora of benefits, including greater academic success (Snyder, et al., 2002), better psychological adjustment (Hagen et al., 2005), and enhanced agency and pathways thinking (Snyder et al., 1991). Overall, the emerging literature indicates that high levels of hope offer many benefits to people over the entire lifespan. Thus, fostering high hope in children could lead to benefits for a lifetime.

Interventions aiming to increase hope specifically are limited, and, while some have been implemented with children (e.g., Delancey, 2005; Dinolfo, 2009; Eliott, 2005), most are targeted toward adults (e.g., Cheavens, Feldman, Gum, Michael, \& Snyder, 2006; Eliott; Trump, 1997). Several of these interventions, though not all, have resulted in increased hope scores. Interestingly, they have also resulted in decreases in negative emotions, such as depression and anxiety. Thus, decreasing problematic negative emotions may be an important by-product of such interventions.

Hopelessness is a negative emotion that is closely related to hope. Hopelessness is defined as negative expectancies about the future and is positively related to depression, suicidal ideation and suicidal behavior, including attempts and completions (Beck, 
Weissman, Lester, \& Trexler, 1974). Once hopelessness develops, depression is inevitable because hopelessness is a cause (and symptom) of depression (Abramson, Metalsky, \& Alloy, 1989).

The relationship between Beck et al.'s (1974) construct of hopelessness and Snyder's (1995) construct of hope is complex. Although the two constructs appear to be at extreme ends of one dimension, they are the outcomes of independent research programs and are not simply the inverse of one another; they differ qualitatively (Grewal \& Porter, 2007). Specifically, hopelessness theory was developed to account for depression, and hope theory originated from the positive psychology movement. Hopelessness theory tends to focus on the negative "immobilizing side of human behavior" (Henry, 2004, p. 352), whereas Snyder's hope theory has a positive viewpoint and maintains that change is possible (Henry). Beck's theory describes hopelessness as having negative thoughts about the future, whereas Snyder's theory equates low hope with having a lack of positive anticipation for the future. According to MacLeod, Rose, and Williams (1993), increased negative expectancies and decreased positive expectancies are not functionally equivalent. While Beck's theory tends to emphasize agency-like thought, hope theory places equal emphasis on agency and pathways thinking (Snyder, Cheavens, and Michael, 1999). Thus, hope and hopelessness tap into different constructs and are not simply opposites of one another.

Many studies have investigated the construct of hopelessness. Notably, the tendency of some individuals to exhibit depressive, hopeless reactions to negative life events has been documented (Abela \& Payne, 2003). Along with negative life events, poverty is a factor that has been found to be linked with feelings of hopelessness 
(Bolland, Lian, \& Formichella, 2005). Bolland et al. were interested more specifically in the origins of hopelessness among inner-city African-American adolescents. Participants in this study were children and adolescents aged 10 to 18 who lived in impoverished neighborhoods. These youth answered survey questions about their risk behaviors (e,g., alcohol and drug use and sexual behavior), circumstances (e.g., family structure and peer pressure and support), attitudes (toward such things as violence and sexuality), and certain psychosocial variables (e.g., self-worth, hopelessness, etc.). Findings suggested that for those in this study who had high hopelessness, disruptive factors such as change in a mother figure, witnessing violence, traumatic stress, and worry were most prominent. The findings suggest that interventions aimed at changing youths' beliefs about their social environment may be the most effective way to reduce hopelessness (Bolland et al.). Reducing hopelessness in inner-city adolescents may be crucial to their well-being and to their futures, so that they may learn effective ways to adapt to and cope with negative life events.

In a related study, Bolland, McCallum, Lian, Bailey, and Rowan (2001) investigated the link between hopelessness, uncertainty about the future, and risk behavior in inner-city youths. In this study, adolescents aged 9 to 19 living in public housing neighborhoods completed a questionnaire measuring hopelessness, expectations about the future, and experience with fighting and weapons. Their findings suggest that many youths raised in an impoverished environment experience futility in planning a future because of the hopelessness of escaping from the present. Over half $(57 \%)$ of the youths in their sample believed that the future is too uncertain to plan ahead, and $75 \%$ endorsed the item that it is best to live for today and let tomorrow take care of itself. The 
results also suggest that hopelessness is related to violent behavior, such as carrying and pulling knives and guns for males and fighting and carrying knives for females (Bolland et al.). An important implication of this study is that interventions that reduce hopelessness could reduce violent behavior in inner-city youth.

The literature indicates that hopelessness may be a problem for many children who are socioeconomically disadvantaged. While Synder's (1995) theory places importance on increasing hope, the research on hopelessness indicates that it may be equally, if not more, vital to decrease hopelessness, because hopelessness is associated with such detrimental outcomes as depression, suicidal ideation and behavior, and violent behavior. An intervention aimed at not only increasing hope but reducing hopelessness may help individuals discover ways to circumvent their circumstances and achieve their goals while also avoiding the debilitating outcomes that can accompany hopelessness.

The current study is the third in a recent series of studies aimed at evaluating the effects of an intervention for inner-city children based on Snyder's (1995) Hope Theory. Delancey (2005) implemented the first version of the program, an eight-week long intervention designed to increase hope in 37 high-risk 8-12 year old children at an urban elementary school. In her study, mean scores on the Children's Hope Scale (Snyder et al., 1997) did not significantly increase from pre-test to post-test, but the scores increased for $68 \%$ of the sample. Results also indicated that African American children's scores increased more from pre-test to post-test than Caucasian children's scores. Additionally, results suggested that various additional factors, such as friendships, positive social behaviors, and academic performance may have increased as a result of the intervention. 
Dinolfo (2009) recently implemented a second version of the program, an eight week hope intervention (with the addition of a reading comparison group) with 24 urban, low SES youth ages 7 to 11 . In contrast to some previous studies that have demonstrated increased hope scores in participants in the Hope Intervention (HI) group as a result of the intervention (ө.g., Delancy, 2005), Dinolfo found no such increase. Rather, participants in the comparison group showed a significant increase in the Pathways scores of the CHS from pre-test through three-month follow-up. Contrary to expectation, the HI group experienced a trend level decrease in Pathways scores and Total CHS scores.

However, these results may be explained by a number of limitations and issues identified in the study.

Because previous research indicates that childhood is an essential stage of life in which to develop hope, and because there exists a positive relationship between low socioeconomic status (SES) and hopelessness, a third installment of this intervention, with modifications, was deemed important to implement with low SES children. The aim of the current study was to replicate and address the limitations of Delancey's (2005) and Dinolfo's (2009) interventions to determine if expected positive results would occur with modifications to the programs and to examine variables and outcomes that had not been previously investigated. Due to the negative outcomes associated with hopelessness, the current study added a measure of hopelessness to determine whether the intervention affected hopelessness scores. Additionally, the current study aimed to investigate the correlation between psychological states (specifically, hope and hopelessness) in children and their parents (parent data had not been investigated in the previous two studies). To date, only one study (Westburg \& Martin, 2003) has examined hope and hopelessness in 
parents as the result of their children participating in a hope intervention, but its small sample size makes its failure to find a relationship tentative, warranting further investigation. Therefore, the present study sought to determine whether parents' attitudes shifted as the result of their children's participation in the intervention.

Further modifications made to the two previous hope interventions in the current study included: a larger sample size; increased intervention length; enhancing the effectiveness of graduate student research assistants involved in the study; completion of homework assignments during group sessions rather than at home where they were less likely to be completed; more concrete, behavioral, active instruction of material; obtaining children's ratings of enjoyment of each group; teaching the children to set personal goals in a variety of life domains; and taking additional steps to ensure that the children understood the questions on the standardized measures administered to them. With these changes, it was hypothesized that the intervention would instill the expected changes in participants in the HI group that were not found in Dinolfo's (2009) study. With the addition of a measure of hopelessness, the effects of the intervention were more thoroughly studied in terms of investigating whether negative emotions such as hopelessness were impacted by the intervention. Specifically, it was hypothesized that children and their parents in the Hope Intervention (HI) would evince greater increases in hope, optimism, and life satisfaction, and greater decreases in hopelessness, than children and parents in the comparison condition. Additionally, it was hypothesized that children in the HI condition would exhibit higher hope scores compared to optimism scores. 


\section{Method}

\section{Participants}

Forty-nine children ( 20 boys, 29 girls) who attended an after-school center located in an urban community in a large city in the Midwest began the present study (i.e., completed pre-testing and attended at least one session). All participants were of low socioeconomic status, and the majority lived in single-parent families. All participants were African American. The children ranged in age from 7 to 13 years with a mean age of $9.22(\mathrm{SD}=1.63)$. The mean number of sessions attended was $11.06(\mathrm{SD}=4.32$; range $=1$ to 18 ).

Completers of the programs are defined as children who participated in 11 or more $(61 \%)$ sessions. Just over half $(57 \%)$ of the children who began the program $(n=$ $28 ; 12$ boys, 16 girls) were in this group. They ranged in age from 7 to 13 years with a mean age of $9.18(\mathrm{SD}=1.83)$. They attended a mean number of 14.14 sessions $(\mathrm{SD}=$ $2.29 ;$ range $=11$ to 18$)$.

All children had a parent participate in the study (meaning a parent completed either pre or post, or both pre and post measures). Thirty-nine parents participated in pretesting, and 38 participated in post-testing; 36 parents completed both pre- and posttesting. All parents were African American. Eight of these parents had two children participate in the study.

The children were randomly assigned to either the Hope Intervention (HI) or reading (RE) comparison group. Table 1 represents the demographic characteristics of each group (e.g., the entire sample of $\mathrm{HI}$ and $\mathrm{RE}$ completers and non-completers, $\mathrm{HI}$ entire sample, RE entire sample, entire sample of $\mathrm{HI}$ and $\mathrm{RE}$ completers only, $\mathrm{HI}$ 
completers, and RE completers). When analyzing the entire sample of $\mathrm{HI}$ and $\mathrm{RE}$ completers and non-completers $(n=49)$, independent $t$-tests and Chi-Square analyses did not indicate significant differences between the groups in age, $t(49)=-.66, p>.05$, number of sessions attended, $t(49)=-.10, p>.05$, or gender, $\chi^{2}(1)=2.37, p>.05$. When analyzing $\mathrm{HI}$ and RE completers only $(\mathrm{n}=28)$, there were also no significant differences between the groups in age, $t(26)=-1.64, p>.05$, number of sessions attended, $t(23)=$ $.48, p>.05$, or gender, $\chi^{2}(1)=.57, p>.05$.

\section{Measures}

Children's Hope Scale (CHS). The CHS (Snyder et al., 1997; See Appendix A, p. 63) is a self-report scale that was developed to assess levels of hopeful thinking in children ranging in age from 7 to 16 . It is made up of six items that assess Pathways thinking (the three even items) and Agency thinking (the three odd items). Respondents indicate how often each item describes them using a scale ranging from 1 ("none of the time") to 6 ("all of the time"). The items may be summed to create both subscale (Pathways and Agency) scores and an overall Hope score. The range of the Total hope score is 6 to 36 points. Normative studies (e.g., Snyder et al.) have found that the average score is 25 , suggesting that most people engage in hopeful thinking most of the time. The CHS was normed on children from various locations in the United States representing a wide variety of populations, including children from public schools, children with various medical problems, boys diagnosed with $\mathrm{ADHD}$, adolescents exposed to violence, and children who have survived burn injuries. Snyder et al. report that the instrument demonstrates adequate internal consistency (ranging from .72 to .86 ) and test-retest reliability (ranging from .71 to .73 over one month). Convergent validity has been 
established by Snyder et al., as parents' ratings of their children's hope correlated with children's CHS scores at the beginning of the study $(r=.38)$ and one month later $(r=$ .37). Additionally, discriminant validity has been supported (e.g., the scale correlates only .03 with intelligence and -.18 to -.24 with hopelessness).

Hope Scale (HS). The Hope Scale (Snyder et al., 1991; see Appendix B, p. 64) is a dispositional self-report measure of hope for adults. This 12-item scale includes four distracter items, four Agency items, and four Pathways items. Responses to items are based on a 4-point Likert-type scale ranging from 1 ("definitely false") to 4 ("definitely true"). Adding the Agency and Pathways items creates a Total score that ranges from 8 to 32. This scale was normed in studies of over 10,000 adults from various locations in the United States. The average scores for college and non-college samples of individuals is approximately 24 , with significantly lower scores for people seeking psychological help or those who are inpatients at psychiatric hospitals. This scale has been found to be both temporally stable (a test-retest reliability of .85 over several weeks has been found) and internally reliable (alphas of .74 to .84 have been reported; Snyder et al.). The scale has also demonstrated discriminant validity (Snyder et al.). This measure appears to be a reliable, valid measure of hopeful thinking in adults.

Hopelessness Scale for Children (HSC). The HSC (Kazdin, Rodgers, \& Colbus, 1986; see Appendix C, p. 65) measures levels of hopelessness and negative expectations about the future. It is a modification of the Hopelessness Scale for adults developed by Beck et al. (1974). The HSC includes 17 items to which children respond true or false; scores range from 0 to 17 . Higher scores reflect greater hopelessness or negative expectations about the future. Kazdin et al. interpret scores based on extensive normative 
data: children who score at or above the $67^{\text {th }}$ percentile (score $\geq 7.0$ ) are considered to be high in hopelessness, and children at or below the $33^{\text {rd }}$ percentile (score $\leq 4.0$ ) are designated as low in hopelessness. In a sample of child psychiatric inpatients (ages 6 to 13 years), internal consistency of the scale was found to be acceptable, with a coefficient alpha of .97 and Spearman-Brown split-half reliability of .96 (Kazdin et al.). Test-retest reliability was found to be .52 , indicating lower stability than would be desirable. Investigating the psychometric properties of the HSC in a sample of older adolescent inpatients (ages 12 to 18 years), Thurber, Hollingsworth, and Miller (1996) found good internal consistency reliability (Cronbach's alpha $=.81$ ), although their findings were lower than those found by Kazdin et al. (Cronbach's alpha $=.97$ ). Thus, the psychometric properties of the HSC appear to be less adequate for psychiatrically disturbed, hospitalized adolescents than for similar, but younger, children. Internal consistency alphas in non-patient children have ranged from .76 (Abela, Gangon, \& Auerbach, 2007) to .95 (Rodriguez \& Eden, 2008). Kazdin et al. have also found good convergent and divergent validity for the scale. Overall, reliability and validity data appear to support the use of this scale in measuring hopelessness in children.

Hopelessness Scale (HS). The HS (Beck et al., 1974; see Appendix D, p. 66) is designed to quantify hopelessness and pessimistic cognitions in adults. This is a 20 -item true-false self-report inventory that was initially administered to a sample of depressed and non-depressed patients. Each response is assigned a score of 0 or 1 , and the total "hopelessness score" is the sum of the scores on the individual items. Thus, the possible range of scores is 0 to 20 . The mean score for a community sample of 394 adults was found to be 4.45 (Greene, 1981). Beck et al. found an internal consistency reliability 
coefficient of .93 and significance for all inter-item correlations. Test-retest reliability was .85 in a nonclinical university population (Holden \& Fekken, 1988). In a separate nonclinical sample of undergraduates, internal consistency scores were satisfactory (Cronbach's alpha $=.88 ;$ Lyndall, 2001). These data indicate that, in general, the HS provides reliable estimates of pessimistic cognitions in adults. Concurrent validity (Beck et al.), divergent validity, and convergent validity (Lyndall, 2001) have also been established. Overall, the reliability and validity data are sufficient to justify the use of the HS.

Brief Multidimensional Students' Life Satisfaction Scale (BMSLSS). The BMSLSS (Seligson, Huebner, \& Valois, 2003; see Appendix E, p. 67) is a shorter (5item) version of the 40-item Multidimensional Students' Life Satisfaction Scale (MSLSS; Huebner, 1994), which is designed to provide a general life satisfaction score along with scores on five domains (family, friends, school, self, and living environment) for students ages 8 to 18 (Seligson et al.; Zullig, Huebner, Gilman, Patton, \& Murray, 2005). Each one of the BMSLSS items represents one of the five life satisfaction domains included on the MSLSS. Responses to these items are presented on a 7-point scale with the following anchors: (from 1) terrible, unhappy, mostly dissatisfied, mixed, mostly satisfied, pleased, (to 7) delighted. The five items are summed to create a total general life satisfaction score. The BMSLSS demonstrated adequate internal consistency for the total score (coefficient alpha of .75) with an early adolescent sample (Seligson et al.). This measure has also demonstrated good concurrent, construct, convergent, and divergent validity (Seligson et al.). Overall, the BMSLSS appears to be a brief, valid, reliable measure of life satisfaction in adolescent students. 
Youth Life Orientation Test (YLOT). The YLOT (Ey et al., 2005; see Appendix F, p. 68) is a 19-item self-report measure of children's optimism and pessimism that is based upon the adult Life Orientation Test-Revised (LOT-R; Scheier et al., 1994). Respondents are asked to rate "how true or not true each statements is for you" by coloring in the circle that "seems to describe you the best." Children endorse items on a scale of 0 to 3 , where $0=$ "not true for me", and $3=$ "true for me." The scale includes six optimism items and six pessimism items, and yields three scores: an optimism score, a pessimism score, and a total optimism score. Ey et al. evaluated the reliability of this instrument with a sample of racially diverse children in grades three through six. Internal consistency for the optimism, pessimism, and total optimism scores are all in the acceptable range with Cronbach alphas of $.79, .78$, and .83 , respectively. Test-retest reliabilities over a seven-month time period were lower (optimism, $r=.46$; pessimism, $r$ $=.45$; total optimism, $r=.50$ ) than test-retest reliabilities over a one-month time period (optimism and pessimism, $r=.68$; total optimism, $r=.70$ ). Convergent, divergent, and predictive validity were also established (Ey et al.). The YLOT appears to be a reliable and valid measure of optimism and pessimism in youths.

\section{Procedure}

Permission to conduct this study at a local community center was granted by the Cincinnati Metro Housing Authority (see Appendix N), and it was approved by the Xavier University Institutional Review Board (IRB; see Appendix O). While the original intent was to include children ages 8 to 12 , the age range was adjusted to match available children and thus included children ages 7 through 13 . All children (and their parents) who participated in the after school program at the community center and were within 
this age range were offered the opportunity to participate by being made aware of the program by the staff at the facility and signing parental consent forms. Consent was obtained from the parent or guardian for 51 children (see Appendix G, p. 71) and each child provided his or her assent (see Appendix H, p. 73). However, two of these children did not attend any sessions and discontinued the program. Statistical analyses include the initial 49 children who participated in the programs (i.e., attended at least one session), as well as post-hoc analyses of the 28 children who were designated as completers of the programs.

In a two-week span prior to beginning the intervention, each child completed the CHS, HSC, BMSLSS, and the YLOT. Pre-testing also took place throughout the first two weeks of the intervention for children who had not yet completed measures and for those who joined the program after the start date. Parents completed the Hope Scale and the Hopelessness Scale during the same time frame. Parents were offered a small gift card after completing post and follow-up measures. Undergraduate and graduate student research assistants (co-leaders) administered the measures aloud to children to rule out the effects of reading difficulties. Measures were administered to the children in small groups of approximately 2 to 6 ; some children who were tested later were administered measures individually. Because a limitation of Dinolfo's (2009) study may have been that children had difficulty understanding some of the items on the self-report measures, forms were supplied to the co-leaders who administered the measures, instructing them how to clarify, in a standardized manner, any difficulty the children had understanding the wording (see Appendices I through L, pp. 74-77, for the instructions used for coleaders for the CHS, BMSLSS, YLOT, and HSC, respectively). For example, pictures of 
facial expressions were shown to the children to help them differentiate between such words as "pleased" and "delighted." Co-leaders were fully trained on these instruments and standardized procedures prior to pre-testing.

Students were randomly divided into four groups: two identical Hope Intervention (HI) groups and two identical comparison groups that focused on developing reading skills (RE groups). Dividing the students into four groups was done to allow for more individualized attention in each group. Both groups met two times each week, for one hour sessions, during September to December 2009 (18 total sessions) at the community center. While the original schedule included 19 sessions, the first session was not counted as a program session because several children were continuing to participate in pretesting, and therefore no program content was covered. The HI groups were each led by one leader (one of whom was the Principle Investigator). Leaders' responsibilities included explaining the program and details of daily activities, reading hopeful stories, leading group discussions, and coordinating activities (see Appendix M, p. 78, for a more detailed description of the content of the HI program). The HI groups also had two to three co-leaders each. Responsibilities of the co-leaders included implementing the token economy system, assisting children with various tasks and activities, and keeping attendance records. All seven $\mathrm{HI}$ co-leaders were graduate students in a doctoral program in clinical psychology; one of the seven RE co-leaders was an undergraduate student in psychology.

The HI group content was based upon Snyder's (1995) Hope Theory, designed to teach hope and increase resiliency. It included activities recommended by Edwards and Lopez (2000), Delancey (2005), and Dinolfo (2009). The two reading groups were also 
led by leaders and co-leaders, utilized a token economy system, and involved reading children's books. At the end of each session, children received small prizes based on the number of tokens they received. During the last session, they received prizes and certificates and participated in a graduation ceremony.

Participants (parents and children) completed the post-test measures throughout the final two weeks of the program. Parents who completed post-test measures received a $\$ 5$ gift card to a grocery store at this time. Children (but not parents) completed follow-up measures approximately three months after completion of the programs. Because there were doubts about the authenticity and accuracy of parent follow-up measures, this data was excluded from the analysis. At the time of follow-up, 39 children completed followup measures; four children were no longer members of the community center and thus were unable to complete follow-up testing.

\section{Results}

Pearson product-moment correlations were computed to examine the relationships among the dependent variables at pre-test, post-test, and follow-up. Tables 2, 3 and 4 show the correlations among the dependent variables (as well as number of sessions attended) for the entire sample ( $\mathrm{HI}$ and RE completers and non-completers) at pre, post, and follow-up assessment. Tables 7 through 15 in Appendix P show the correlations among the dependent variables (as well as number of sessions attended) for $\mathrm{HI}$ and $\mathrm{RE}$ completers only, $\mathrm{HI}$ completers and non-completers, and $\mathrm{HI}$ completers only at pre, post and follow-up assessment. Significant correlations revealed several patterns of findings for the entire sample (HI and RE completers and non-completers) at pre-test (see Table 2). The CHS Total score was moderately positively correlated with the YLOT Optimism 
Total score, $r=.39, p<.01$, and moderately negatively correlated with the YLOT

Pessimism score, $r=-.39, p<.01$. Child hopelessness (as measured by the HSC score) was strongly negatively correlated with life satisfaction, $r=-.50, p<.01$ Adult hopelessness (as measured by the Hopelessness Scale) was weakly positively correlated with the number of sessions his or her child attended, $r=.29, p<.05$, indicating that the more hopeless the parent at pre-test, the more sessions his or her child was likely to attend. Dinolfo (2009) found a significant negative correlation between adult hope and number of sessions his or her child attended, but this finding was not supported in this study. An interesting finding among those children who completed the program (see Table 7 in Appendix P) was that the CHS Total score was moderately negatively correlated with the number of sessions attended, $r=-.45, p<.05$, indicating that children with higher CHS scores at pre-test attended fewer sessions. Interestingly, as reported above, higher hopelessness in their parents predicted greater number of sessions attended. See Tables 7, 8 and 9 in Appendix P for other correlations found at pre-test.

Several significant correlations were found for the entire sample (HI and RE completers and non-completers) at post-test (see Table 3). Child hope was moderately positively correlated with life satisfaction, $r=.47, p<.01$. Additionally, as found in Dinolfo's (2009) study, child hope was moderately positively correlated with total optimism, $r=.45, p<.01$. Child hopelessness was moderately negatively correlated with child hope, $r=-.33, p<.05$, and total optimism, $r=-.48, p<.01$. Child hopelessness was also moderately positively correlated with pessimism, $r=.40, p<.01$. See Tables 10,11 , and 12 in Appendix $P$ for other correlations found at post-test. 
Several significant correlations were also present at follow-up for the entire sample (HI and RE completers and non-completers; see Table 4). The CHS score was strongly positively correlated with life satisfaction, $r=.60, p<.01$. Child hopelessness was strongly negatively correlated with total optimism, $r=-.58, p<.01$, and moderately negatively correlated with life satisfaction, $r=-.37, p<.05$. Child hopelessness was strongly positively correlated with pessimism, $r=.52, p<.01$. See Tables 13,14 , and 15 in Appendix $\mathrm{P}$ for other correlations found at follow-up.

In order to explore the differences in the dependent measures across pre-test, posttest, and follow-up assessment, a random regression model (RRM, also termed a hierarchical linear model) was used. The RRM allows for comparing the slopes of each group and investigating the change in each group over time, as well as whether this change is significantly different between groups. An RRM was run initially for the entire sample of participants (i.e., those who attended at least one session, $n=49$ ) and then as a post-hoc analysis for completers only (i.e., those who attended 11 or more sessions, $\mathrm{n}=$ 28) to determine whether greater attendance and completion of the programs resulted in additional significant changes. The RRM, based on the entire sample of participants, produced slopes that differed significantly between the two groups on the HSC. Specifically, the HI group had significantly greater reductions on the HSC than the RE group, $t=2.10, p<.05$ (see Figure 1). Contrary to the hypotheses, no significant differences were found in slopes between the HI and RE groups for the CHS Total score, YLOT Total Optimism Score, BMSLSS Total score, Adult Hope Total score, or Adult Hopelesssness Total score (see Table 5). The post-hoc RRM analysis conducted utilizing completers only yielded the same pattern of findings: the slopes differed significantly 
between the two groups on the HSC, $t=2.19, p<.05$ (see Figure 2), but no significant differences were found in slopes between the $\mathrm{HI}$ and RE groups for the other measures. Within the HI group, there were no significant changes in scores over time when analyzing both the entire sample and completers only. Similarly, there were no significant changes in scores over time within the RE group.

To evaluate whether the Total CHS score increased significantly more than the YLOT Total Optimism score for participants in the HI group compared to the RE group, difference scores were calculated for both Total CHS scores and YLOT Total Optimism scores, and then a paired samples $t$-test was conducted. When the entire sample (completers and non-completers) was analyzed, results indicated no significant difference between the two groups, $t(41)=.93, p>.05$. Similarly, no significant difference between the groups was found when analyzing completers only, $t(27)=.42, p>.05$. Thus, the hypothesis that Total CHS scores would increase significantly more than YLOT Total Optimism scores was not supported.

Effect sizes (Cohen's $d$ ) for several of the outcome variables (HSC, YLOT Optimism Total, YLOT Optimism, and Adult Hope Total) were calculated to determine if there was a stronger effect for children who completed the program compared to the entire sample of children. Calculated effect sizes were then utilized to conduct a power analysis in order to determine the required sample size needed for each condition (completers or the entire sample) to obtain a statistically significant finding for each of these variables. For the HSC, the effect was ultimately found to be stronger for completers than for the entire sample. The results indicated that, for the entire sample, the effect size was calculated to be $d=.56$ (medium effect size). An analysis of sample size 
with alpha $=.05$ and power $=.80$ indicated that 82 participants ( 41 in each group) would be required to obtain a statistically significant finding with this effect size. By contrast, the effect size for completers only was computed as $d=.61$ (medium-large effect size). An analysis of the sample size with alpha $=.05$ and power $=.80$ indicated that 70 participants ( 35 in each group) would be required to obtain a statistically significant finding with this effect size. Thus, a slightly stronger effect was apparent when comparing completers with the entire sample of participants, indicating that the completers had a more negative (i.e., greater reduction in) slope than the entire sample.

Although there were no significant differences found in slopes between the HI and RE group on the YLOT Optimism Total, YLOT Optimism, and Adult Hope Total variables, when using the same procedures as above, it was found that the effect sizes were stronger when analyzing completers of the program versus the entire sample. That is, for each of these variables, there was a more positive (i.e., greater increase in) slope for completers than for the entire sample. However, the sample size of this study did not have the power necessary to detect these effects and obtain statistically significant findings on these variables. See Table 6 for computed effect sizes and the number of participants required to obtain statistically significant findings on each of these variables when utilizing these effect sizes.

\section{Discussion}

The aim of the current study was to expand on previous research investigating the efficacy of interventions based on Synder's (1995) Hope Theory. Specifically, the current study aimed to utilize a randomized design, involve a larger sample size of participants, and make other modifications to previous interventions (e.g., Delancey, 2005; Dinolfo, 
2009) in order to determine whether such modifications would result in significant changes on several outcome variables in children and who participated in a nine-week hope intervention (HI). The present study compared those in the $\mathrm{HI}$ group to a reading (RE) comparison group at pre-test, post-test, and follow-up. Additionally, this study investigated changes in parent hope at these same time periods and added parent and child hopelessness measures to investigate the effects of the intervention on hopelessness scores. Studies that investigate parent outcomes and that measure hopelessness in an $\mathrm{HI}$ are rare in the literature.

There have been few studies that have systematically evaluated HIs for children, and most have involved small sample sizes. However, findings from many of these studies have yielded promising results, such as increases in hope scores and academic performance and decreases in negative emotions such as depression and anxiety (e.g., Eliott, 2005), as well as increases in friendships and positive social behaviors (Delancey, 2005). Such positive findings have warranted further investigation of HIs. However, a lack of significant findings (and contrary findings) has also been present in the recent literature (e.g., Buchanan, 2008; Delancey, 2005; Dinolfo, 2009), which may be explained by a number of limitations identified in these studies. The current study aimed to implement a similar version of these programs while addressing the limitations acknowledged by previous investigators.

The HI and RE groups were compared on several variables that were measured from pre-test through follow-up. A random regression model analysis yielded no significant differences in slopes between the two groups for the CHS Total score, YLOT Total Optimism Score, BMSLSS Total score, Adult Hope Total score, or Adult 
Hopelessness Total score. However, the slopes differed significantly between the two groups for the HSC (Hopelessness Scale for Children) score, such that the HI group exhibited significantly greater reductions in hopelessness scores than the RE group. Findings were the same when analyzing all participants of the program (including those who only attended one session) and analyzing only completers of the program (those who attended at least $61 \%$ of the sessions).

A significant decrease in hopelessness is an interesting, novel finding with regard to the research on HIs, as this variable has not been studied in previous $\mathrm{HI}$ research. Although it was expected (and has been found in some studies) that hope scores would increase as a result of an intervention designed to increase hope, this finding was not supported in this study. In fact, the current intervention only was successful in decreasing hopelessness. This is an interesting finding given that high hopelessness has been associated with violence (Bolland et al., 2001), depression, and suicide (Abramson et al., 1989 ) in youths. Therefore, by decreasing hopelessness in children, this intervention may also decrease children's risk for these negative future outcomes. It may be that while the current $\mathrm{HI}$ was not necessarily successful in instilling and increasing resiliency factors in children, it functioned to decrease dangerous risk factors. Hopelessness in children is associated with living in impoverished neighborhoods (Bolland et al., 2001; Bolland et al., 2005), which was the case for the children in this study. For inner-city youth who face a host of struggles and obstacles in their daily lives, it may be equally (if not more) important to decrease hopelessness and related risk factors as it is to increase resiliency factors, such as hope. 
It is important to note that at pre-test, Total CHS scores in the HI and RE groups were above the mean of 25 that is reported in the literature (Snyder et al., 1997). That is, the HI group Total CHS mean score at pre-test for the entire sample of participants was 29.04, and the mean for the RE group was 29.62. Dinolfo (2009) noted a similar pattern of pre-test mean CHS scores (HI $M=27.33$; RE $M=27.73$ ). Delancey (2005) also reported CHS pre-test scores that were slightly above the mean (HI $M=25.77)$. It appears that children in both groups in the current study (as well as in previous studies) were already quite high in hope even prior to the start of the study. One factor that may account for this is that the children were already part of an after-school program at the local community center where the intervention was held. As part of the community center, children engaged in social opportunities and activities and received help with their homework, which may have contributed to positive thinking and feelings. An analysis of intercorrelations also revealed that children who were higher in hope at pre-test attended fewer sessions over the course of the program. It may be that these children were especially highly-involved with other activities at the community center (leading them to demonstrate higher hope) and were therefore absent from the $\mathrm{HI}$ and $\mathrm{RE}$ program sessions more frequently due to other involvements.

Similar to children's hope scores, parent hope scores (as measured by the Hope Scale) at pre-test were higher than the average score of 24 (Snyder et al., 1991), at $M=$ 26.71 for the HI group and $M=26.41$ for the RE group. It may be that these parents have learned to cope with and survive adversity and challenges they have faced throughout life and thus have the skills necessary to engage in appropriate agency and pathways thinking. It may also be that these parents were simply not exhibiting low hope. Given 
that the Total CHS and adult Hope Scale scores in both groups (HI and RE) were above the mean before the interventions began, it may be very challenging to significantly increase the scores.

Children's mean HSC scores at pre-test yielded a similar pattern; children were initially low in hopelessness prior to beginning the intervention. Scores $\geq 7.0$ indicate high hopelessness, while scores $\leq 4.0$ suggest low hopelessness (Kazdin et al., 1986). The mean for the $\mathrm{HI}$ group at pre-test was 4.30, while the mean for the RE group was 3.62. Thus, while children were already low in hopelessness, the intervention was successful in decreasing features of hopelessness that were present in the HI group, while HSC scores in the reading group increased over time (post-test $M=4.23$, follow-up $M=4.62$ ). Similarly, parent Hopelessness Scale scores in the HI and RE groups at pre-test were below the mean of 4.45 that is reported in the literature (Greene, 1981). The mean score for the HI group was 1.50 , while the mean score for the RE group was 1.84. Therefore, decreasing hopelessness in parents, who were already well below the mean hopelessness score, may have been especially challenging.

Overall, utilizing the CHS, we could not demonstrate that hope significantly changed over time in the $\mathrm{HI}$ group. This is the third in a recent series of studies that have investigated HIs but have not found a significant increase in CHS scores. Buchanan (2008) also recently implemented a program (Making Hope Happen) and did not find changes in CHS scores in a sample of 20 students. One possible problem is with the CHS as a measure of hope in children. The CHS consists of only six items and may not be a sensitive enough measure to detect hope in children. Additionally, the Likert-type response scale seems to be difficult for children to understand. Although children in the 
current study were provided with further elaboration and direction on the meanings of the response options, it was observed that they continued to exhibit confusion with regard to the response options. This was especially the case for younger children (i.e., those who were seven or eight years old), even though they were within the age range on which the scale was normed ( 7 to 16$)$.

A further possibility is that the content utilized in current HIs does not serve its intended function of increasing hope. Perhaps a lack of significant increases on the CHS in HIs also indicates that hope is different for children than it is for adults and thus must be taught differently to children. It may be that adults have the cognitive capacity to understand hopeful concepts and learn them through didactic teaching, but perhaps more experiential interventions are necessary for children. Such interventions could provide children with a process in which they actively work to set and reach goals and achieve successes, which in turn could increase their hope. For example, Dinolfo (2009) found an unexpected increase in the Pathways score of the CHS in the RE (but not the HI) group. A possible reason for this finding is that children in the RE group completed various reading assignments and several books and thus experienced for themselves the feelings and cognitions involved in setting and reaching goals, without directly being taught the concepts of hope. It may have been the active experience of setting and achieving personal goals throughout the group that allowed children in the RE group to increase their hopeful thinking. The present $\mathrm{HI}$ implemented less didactic and more active, experiential, personal goal-setting components than previous interventions, and it was observed that the children enjoyed these components more. Perhaps this intervention would have benefited from even more of-or exclusively - this type of content. 
A lack of significant changes in hope, life satisfaction and optimism for the participants indicates that perhaps these constructs are more similar than has been suggested in the research. Hope and life satisfaction were significantly correlated at pretest, post-test and follow-up. Hope was also significantly correlated with optimism at all three time periods. Additionally, hope did not increase significantly more than total optimism scores (in contrast to what was predicted), further showing little contrast in these constructs. It may be that children view these constructs as similar and thus respond to the items on the scales in very similar ways. All three of these constructs are positive emotions; thus, questions about them may be understandably difficult for children to discriminate. In contrast, hopelessness (which did significantly change), a negative emotion, is quite different from these three constructs. The HSC consisted of items that may have been clearly more differentiable for the children and that resonated with them more. Additionally, the HSC requires children to respond in a true-false format, while the hope, life satisfaction, and optimism scales require them to respond based on a more complex, Likert-type format. It may be that children found responding to the HSC to be easier to understand, and thus they responded to it more accurately in terms of what was true or false for themselves.

\section{Limitations}

Several limitations were present in this study. One of the main limitations throughout the program for both the HI and RE groups was attendance. Though the timing of the sessions was made clear by the staff and informed consent forms, children were often picked up early by their parents, at times causing them to miss important content in the sessions. Many of the children were also involved in other programs and 
activities at the community center, which at times coincided with the times the $\mathrm{HI}$ and $\mathrm{RE}$ groups were held. The children sometimes elected to attend the other programs, thus limiting their attendance at the current intervention sessions. While 49 children initially began the study, only slightly over half of them (57\%) attended over half (61\%) of the sessions. Several girls, who were part of a jump-rope competition program, consistently missed $\mathrm{HI}$ and RE sessions or were defiant when coming to these sessions as a result of "missing out" on their jump-rope practice. This may have affected their enthusiasm and willingness to participate and learn during groups. Missing sessions or parts of sessions may have accounted for some of the children not learning the content and thus not increasing their hope scores. While no significant changes (with the exception of significant decreases on the HSC score) were found either when analyzing those who completed the program (attended $61 \%$ of the sessions) or all children who participated, attendance seemed to be an important factor, as stronger effects were apparent for completers than for all participants on several of the outcome variables.

Although the current study involved a larger sample size than previous studies, sample size continued to be a limitation. Effect size calculations demonstrated that while stronger effects were apparent for completers of the program than for the entire sample of participants on many of the variables, the sample size of this study did not have the power necessary to detect these effects and obtain significant findings. While this study had the power necessary to detect a significant finding for the HSC, significant findings on the other outcome variables may have been obtained had the sample size been larger.

Another potential limitation of this study is the possibility that the measures used may not truly reflect the constructs they are intended to measure. Recent studies 
implementing HIs (Buchanan, 2008; Delancey, 2005; Dinolfo, 2009), as well as the current study, did not find a significant increase in hope scores on the CHS. Perhaps the six items on the CHS measure some construct other than hope. While the CHS has adequate psychometric properties, it seemed that the children (especially those who were younger) did have difficulty understanding the content of the questions and, especially, how to respond based on the Likert-type scale. Both the BMSLSS (measuring life satisfaction) and YLOT (measuring optimism) also contained items and Likert-type response choices that were difficult for the children to understand. These difficulties remained even when implementing procedures designed to help the children better comprehend the questions and response items. Thus, their responses may not accurately reflect the variables measured. They also may have responded to the items based upon a variety of external factors. For example, many of the children noted that they were unhappy about the conclusion of groups at post-test and therefore may have responded to the items in a negative manner, making it appear that hope and some of the other variables (optimism, life satisfaction) did not increase. Many of the children were also pulled away from "fun" activities (such as playing games and participating in activities in the gym or outside) to participate in testing, about which they voiced unhappiness. This may have also negatively biased their responses on the measures.

Several limitations of previous HIs were addressed in the current study. A larger sample size was used than in previous studies (Buchanan, 2008, $\mathrm{n}=20$; Delancey, 2005, $\mathrm{n}=37$; Dinolfo, 2009, $\mathrm{n}=24$ ), although it was still not large enough to detect significant findings on all but one of the variables (the HSC). The intervention length was also increased to nine weeks (18 sessions), which is longer than previous interventions. One 
limitation found in Dinolfo's study was that the undergraduate and graduate student coleaders may have negatively affected the results of the intervention due to factors such as low enthusiasm and inconsistent attendance. The current program attempted to enhance the effectiveness of the co-leaders by conducting interviews wherein motivation of the co-leaders was assessed, and co-leaders were chosen based on their qualifications, motivation, and enthusiasm for the programs. Co-leaders were also briefed on the importance of attending sessions regularly. Additionally, after each session, they completed self-rating forms assessing their performance during that day's session. Qualitative analysis of the ratings indicates that the majority of the time, co-leaders rated themselves highly in terms of their enthusiasm, punctuality, helpfulness, preparedness, and warmth and kindness toward the children. This was also observed to be the case by the Principal Investigator; co-leaders were judged to be extremely effective throughout the duration of the intervention. A further modification was that "homework" assignments were completed during group sessions rather than at home where they were less likely to be completed. Leaders and co-leaders provided the children with direct, one-to-one assistance with these assignments, in an attempt to make the concepts of hope more understandable. As previously mentioned, more concrete, behavioral, active instruction of material was implemented with less emphasis on direct didactic teaching of the material. This included teaching the children to set and work toward personal goals in a variety of life domains (e.g., school, family, recreation, etc.). It was noted that the children enjoyed the more active, experiential components (e.g., acting out hopeful stories) as opposed to didactic instruction. As previously mentioned, to address possible problems with children understanding the measures, co-leaders were trained in 
techniques to help clarify items and response choices on the measures when they administered them to the children.

A lack of qualitative data has been a limitation of previous HI studies. Therefore, we added subjective, qualitative measures to gain an understanding of the children's enjoyment of the programs and what they gained from participating in the programs. First, children completed a simple measure after each session asking them whether they enjoyed that day's session. Children responded by circling "Yes" or "No." They also had the option of writing reasons for enjoying or not enjoying the sessions. Qualitative analysis of their responses indicated that, in the HI program, nearly all children responded "Yes" to nearly every session. Only two "No" responses were recorded throughout the entire program. Children who responded "No" elaborated that they would have liked to have acted out more stories or participated in activities such as drawing during those sessions. To obtain further data on what children learned and enjoyed throughout the program, they were individually asked a variety of interview questions at post-testing. The HI participants consistently responded that they liked the leaders and co-leaders; that they had talked with others (parents, teachers, friends, etc.) about what they learned in the group; that, if given the chance, they would participate in the group again; that being in the group facilitated positive emotions, making them feel happy, smart, hopeful, successful, proud, excited, and energetic; that they especially enjoyed acting out stories and playing games (i.e., the Hope Game); and they were able to articulate specific things they had learned in the group. While the standardized measures administered in this study revealed few significant changes in the children, qualitative data gained from direct questioning of the children clearly indicate that they enjoyed the 
program, that the program made them feel positively about themselves, and that they learned and retained information that the program was intended to teach them.

\section{Future Directions}

While the current study is one of a number of recent HI studies that found no significant change in hope scores, this does not necessarily mean that such interventions are not worth replicating with modifications. As described previously, the participants in the HI appeared to make some gains from the intervention and clearly enjoyed the sessions. The current study can provide useful direction for future research. First, teaching the components of hope may not be the optimal way to increase hope in children. When canducting HIs, it may be more useful for investigators to implement more experiential components, indirectly teaching children hope by helping them through the process of setting, working through, and reaching goals and experiencing successes. Children in the current intervention clearly enjoyed and remembered these aspects of the program the most; therefore, it is recommended that HIs contain more of (and perhaps exclusively) this kind of content.

Due to the novel finding of a significant decrease in hopelessness found in the current study, it will be useful for future research to continue to investigate the effects of HIs on hopelessness. Due to the negative effects of hopelessness, it may be prudent to begin turning our attention more to hopelessness in children and implementing interventions to reduce it. The current intervention, which was intended to increase hope, was successful in reducing hopelessness. Other interventions with the goal of reducing hopelessness should be investigated. 
When implementing HIs, researchers should give significant consideration to the scales being used. Attempts should be made to ensure that children understand the measures. However, taking such precautions may not completely prevent problems with understanding the measures (as demonstrated in the current study). Therefore, it will be important for researchers to also obtain qualitative data. Future research should also work to develop new scales (or modify current scales) that are more child-friendly. Such scales should involve simpler language and should utilize a clearer response format (such as true-false) rather than a Likert-type format.

Future HIs should include a larger sample size. As the results of this study indicate, the sample size did not have the power necessary to obtain statistically significant findings on many of the outcome variables. Researchers are encouraged to utilize the sample sizes reported in Table 6 that are needed to obtain such findings.

Finally, it may be useful for future investigators to consider conducting $\mathrm{HI}$ programs with children who are more deprived of social opportunities and activities than the children in the current study. Such children are likely to be lower in hope and higher in hopelessness and may experience more drastic benefits from such an intervention, resulting in a higher likelihood of obtaining significant findings. Such children will also be more likely to demonstrate more consistent attendance at sessions, as they are likely to have few other conflicts. This will help to eliminate problems with attendance at sessions and will rule out confounding variables (such as negative attitudes about missing out on other activities) that may have been present in the current study. It would be ideal for children to participate in the programs without having to "miss out" on other valued activities. Attendance at sessions should be reinforcing (rather than punishing) for 
children. Overall, the current intervention appeared to be beneficial for the participants.

Modifications to the intervention and re-conceptualizing how to measure hope in children will likely help facilitate more consistent, measurable effects on those who participate in such interventions in the future. 


\section{References}

Abela, J., Gagnon, H., \& Auerbach, R. (2007). Hopelessness depression in children: An examination of the symptom component of the hopelessness theory. Cognitive Therapy and Research, 31, 401-417.

Abela, J., \& Payne, A. (2003). A test of the integration of hopelessness and self-esteem theories of depression in schoolchildren. Cognitive Therapy and Research, 27, $519 \cdot 535$

Abramson, L., Metalsky, G., \& Alloy, L. (1989). Hopelessness depression: A theory based subtype of depression. Psychological Review, 96, 358-372.

Alvord, M., \& Grados, J. (2005). Enhancing resilience in children: A proactive approach. Professional Psychology: Research and Practice, 36, 238-245.

Beck, A., Weissman, A., Lester, D., \& Trexler, L. (1974). The measurement of pessimism: The Hopelessness Scale. Journal of Consulting and Clinical Psychology, 42, 861-865.

Bolland, J., Lian, B., \& Formichella, C. (2005). The origins of hopelessness among innercity African-American adolescents. American Journal of Community Psychology, $36,293-305$.

Bolland, J., McCallum, D., Lian, B., Bailey, C., \& Rowan, P. (2001). Hopelessness and violence among inner-city youths. Maternal and Child Health Journal, 5, 237244.

Buchanan, C. (2008). Making hope happen for students receiving special education services. Dissertation Abstracts International, Section B: The Sciences and Engineering. Vol 69 (3-B), 1943. 
Cheavens, J., Feldman, D., Gum, A., Michael, S., \& Snyder, C. (2006). Hope therapy in a community sample: A pilot investigation. Social Indicators Research, 77, 61-78.

Delancy, D. (2005). Teaching hope: A path to resilience. Unpublished doctoral dissertation, Xavier University.

Dinolfo, C. (2009). Efficacy of a hope program for inner-city children. Unpublished doctoral dissertation, Xavier University.

Edwards, L., \& Lopez, S. (2000). Making hope happen for kids. Unpublished protocol.

Eliott, J. (2005). Interdisciplinary perspectives on hope. Hauppauge, New York: Nova Science Publishers, Inc.

Ey, S., Hadley, W., Allen, D., Palmer, S., Klosky, J., Deptula, D., et al. (2005). A new measure of children's optimism and pessimism: The youth life orientation test. The Journal of Child Psychology and Psychiatry, 46, 548-558.

Gilman, R., Dooley, J., \& Florell, D. (2006). Relative levels of hope and their relationship with academic and psychological indicators among adolescents. Journal of Social and Clinical Psychology, 25, 166-178.

Greene, S. (1981). Levels of measured hopelessness in the general population. British Journal of Clinical Psychology, 20, 11-14.

Grewal, P., \& Porter, J. (2007). Hope theory: A framework for understanding suicidal action. Death Studies, 31, 131-154.

Hagen, K., Meyers, B., \& Mackintosh, V. (2005). Hope, social support, and behavior problems in at-risk children. American Journal of Orthopsychiatry, 75, 211-219.

Henry, P. (2004). Hope, hopelessness, and coping: A framework for class-distinctive cognitive capital. Psychology and Marketing, 21, 375-403.

Holden, R., \& Fekken, C. (1988). Test-retest reliability of the hopelessness scale and its 
items in a university population. Journal of Clinical Psychology, 44, 40-43.

Huebner, E. (1994). Preliminary development and validation of a multidimensional life satisfaction scale for children. Psychological Assessment, 6, 149-158.

Kazdin, A., Rodgers, A., \& Colbus, D. (1986). The hopelessness scale for children: Psychometric characteristics and concurrent validity. Journal of Consulting and Clinical Psychology, 2, 241-245.

Lyndall, S. (2001). Further validity and reliability evidence for Beck hopelessness scale scores in a nonclinical sample. Educational and Psychological Measurement, 61, $303-317$

MacLeod, A., Rose, G., \& Williams, J. (1997). Components of hopelessness about the future in parasuicide. Cognitive Therapy and Research, 17, 441-455.

Magaletta, P., \& Qliver, J. (1999). The hope construct, will, and ways: Their relations with self-efficacy, optimism, and general well-being. Journal of Clinical Psychology, 55, 539-551.

Rodriguez, C., \& Eden, A. (2008). Disciplinary style and child abuse potential: Association with indicators of positive functioning in children with behavior problems. Child Psychiatry and Human Development, 29, 123-136.

Seligson, J., Huebner, E., \& Valois, R. (2003). Preliminary validation of the Brief Multidimensional Students' Life Satisfaction Scale (BMSLSS). Social Indicators Research, 61, 121-145.

Snyder, C. (1995). Conceptualizing, measuring, and nurturing hope. Journal of Counseling and Development, 73, 355-360.

Snyder, C., Cheavens, J., \& Michael, S. (1999). Hopeing. In C.R. Snyder (Ed.), Coping: 
The psychology of what works. New York: Oxford University Press.

Snyder, C., Cheavens, J., \& Sympson, S. (1997). Hope: An individual motive for social commerce. Group Dynamics: Theory, Research, and Practice, 1, 107-118.

Snyder, C., Feldman, D., Taylor, J., Schroeder, L., \& Adams, V. (2000). The roles of hopeful thinking in preventing problems and enhancing strengths. Applied and Preventative Psychology, 9, 249-270.

Snyder, C., Harris, C., Anderson, J., Holleran, S., Irving, L., Sigmon, S., et al. (1991). The will and the ways: Development and validation of an individual-differences measure of hope. Journal of Personality and Social Psychology, 60, 570-585.

Snyder, C., Hoza, B., Pelham, W., Danovsky, M., Highberger, L., \& Rubinstein, H., et al. (1997). The development and validation of the Children's Hope Scale. Journal of Pediatric Psychology, 22, 399-421.

Snyder, C., Shorey, H., Cheavens, J., Pulver, K., Adams, V., \& Wilklund, C. (2002). Hope and academic success in college. Journal of Educational Psychology, 94, $820-826$.

Thurber, S., Hollingsworth, D., \& Miller, L. (1996). The hopelessness scale for children: Psychometric properties with hospitalized adolescents. Journal of Clinical Psychology, 52, 543-545.

Trump, M. (1997). The impact of hopeful narratives on state hope, state self-esteem, and state positive and negative affect for adult female survivors of incest.

Dissertation Abstracts International Section A: Humanities and Social Sciences, $58,1211$.

Westburg, N., \& Martin, D. (2003). The relationship between a child's hope, a parent's hope, and student-directed, goal-oriented academic instruction. Journal of 
Humanistic Counseling, Education, and Development, 42, 152-164.

Zullig, K., Huebner, E., Gilman, R., Patton, J., \& Murray, K. (2005). Validation of the Brief Multidimensional Students' Life Satisfaction Scale among college students. American Journal of Health Behavior, 29, 206-214. 


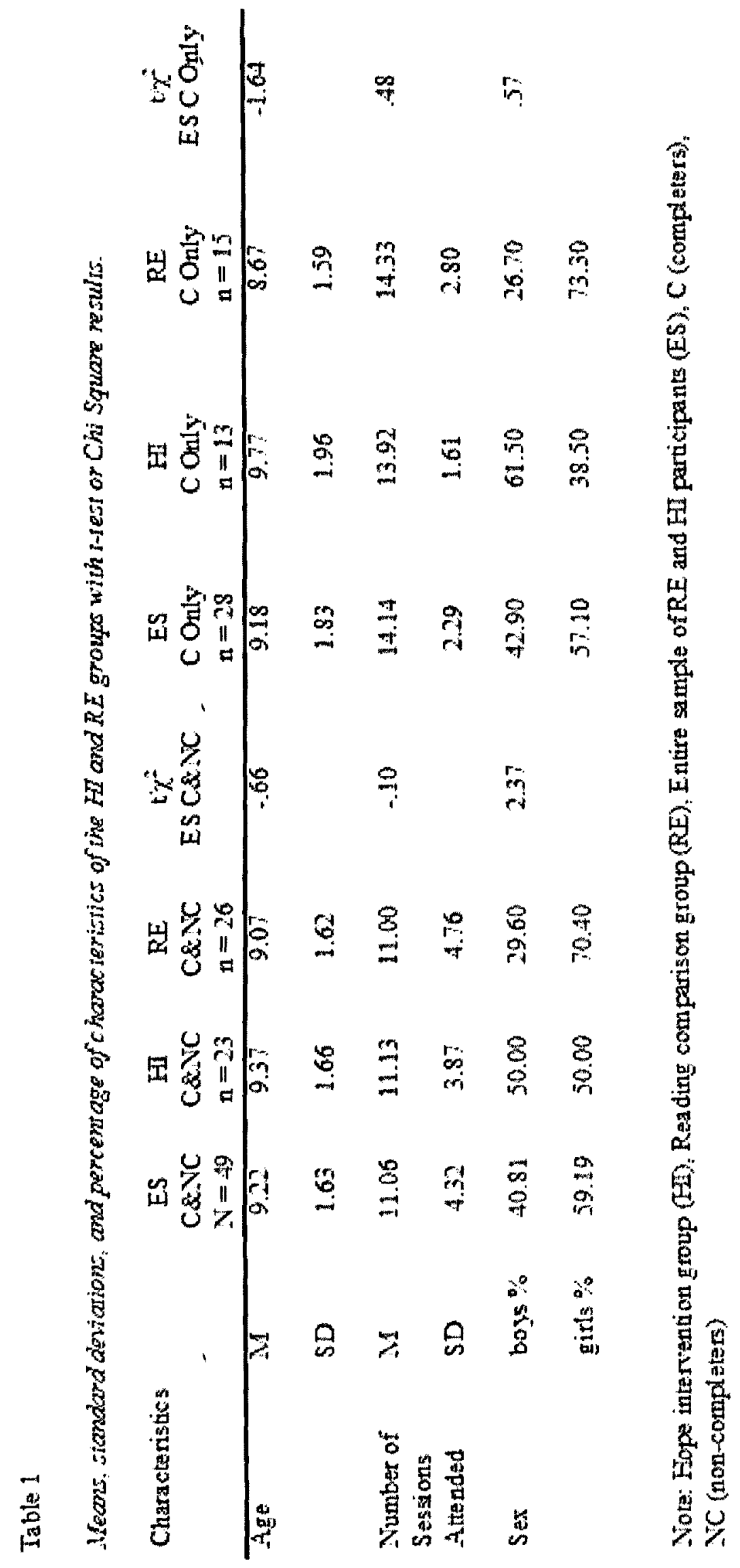




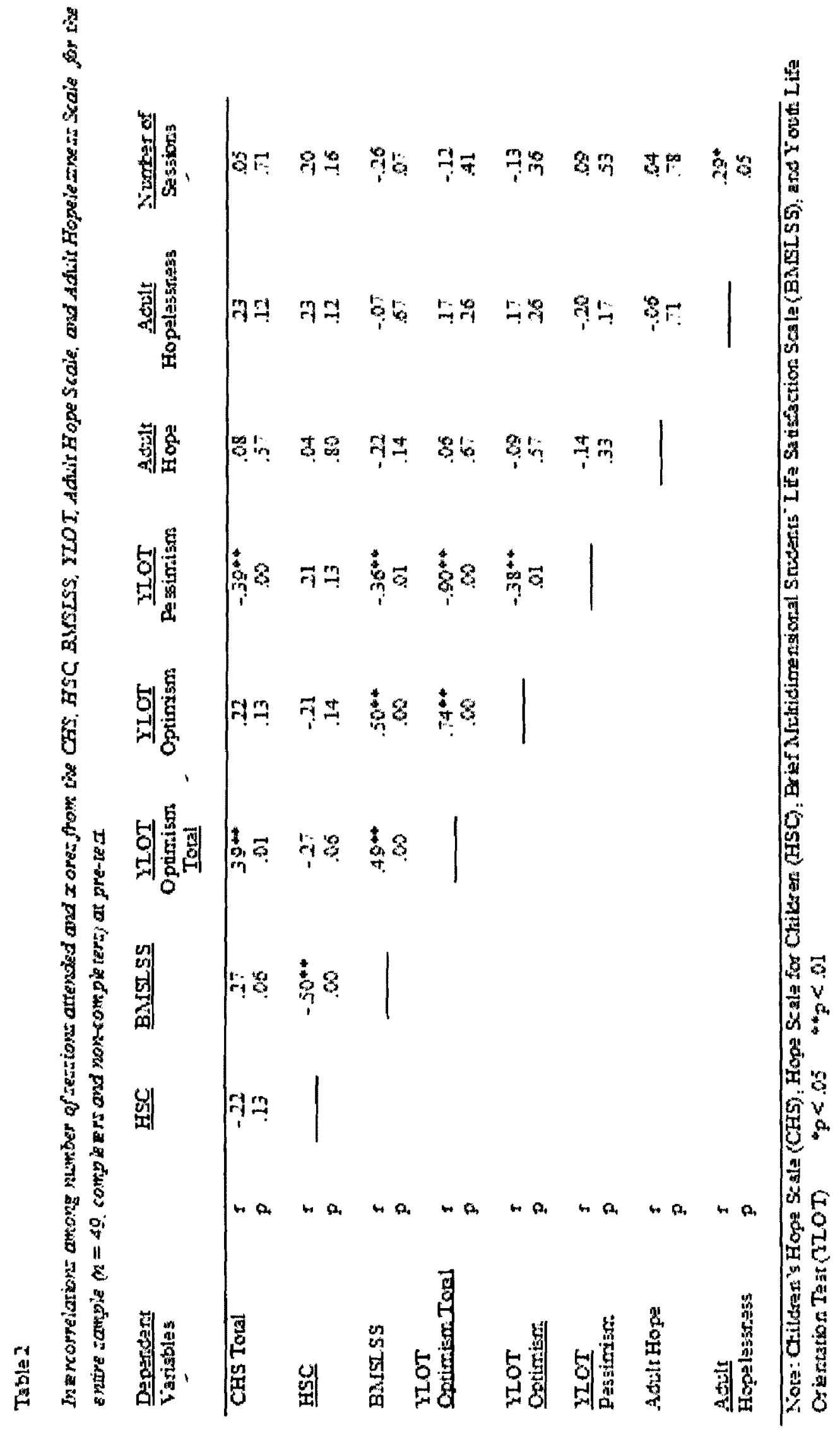




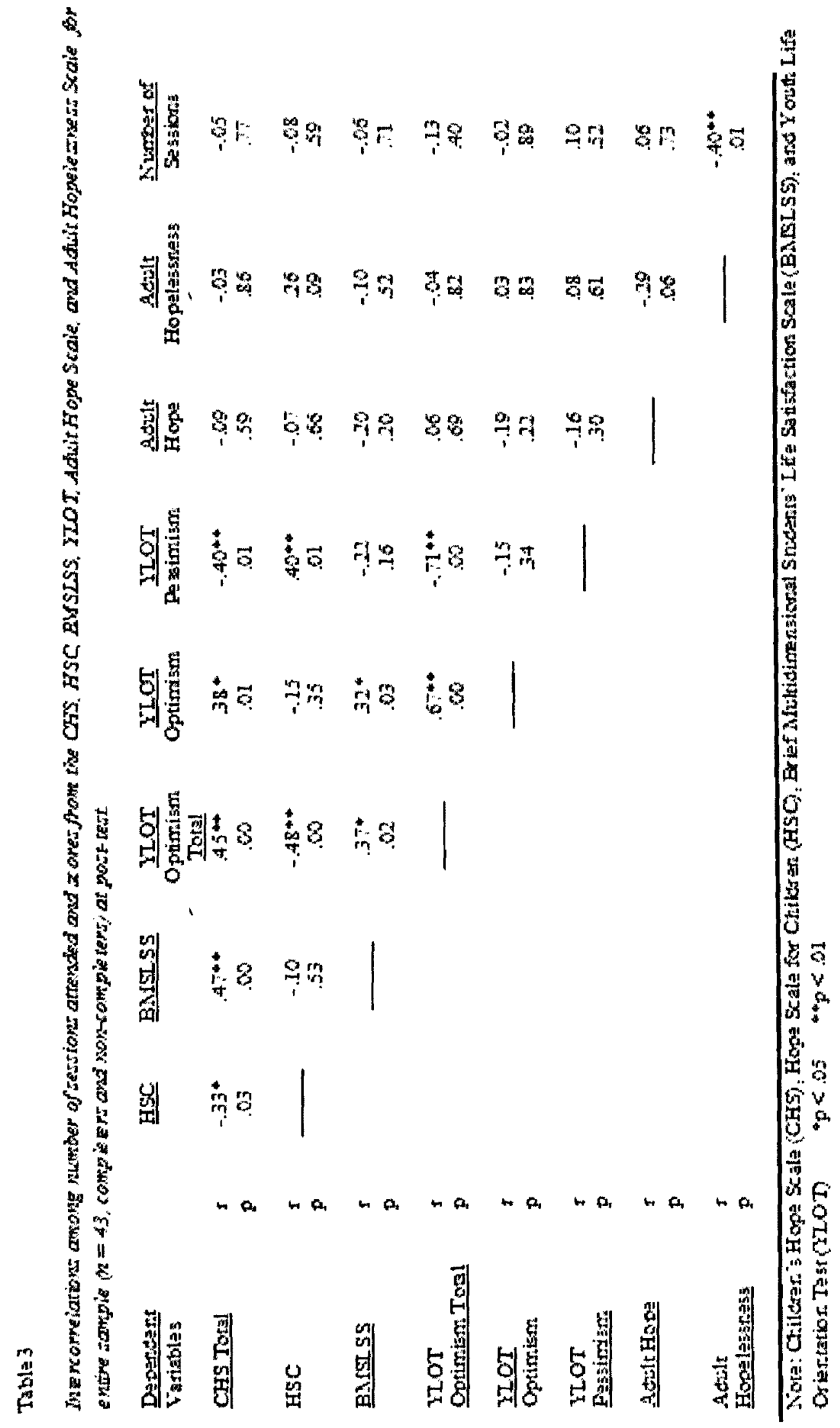




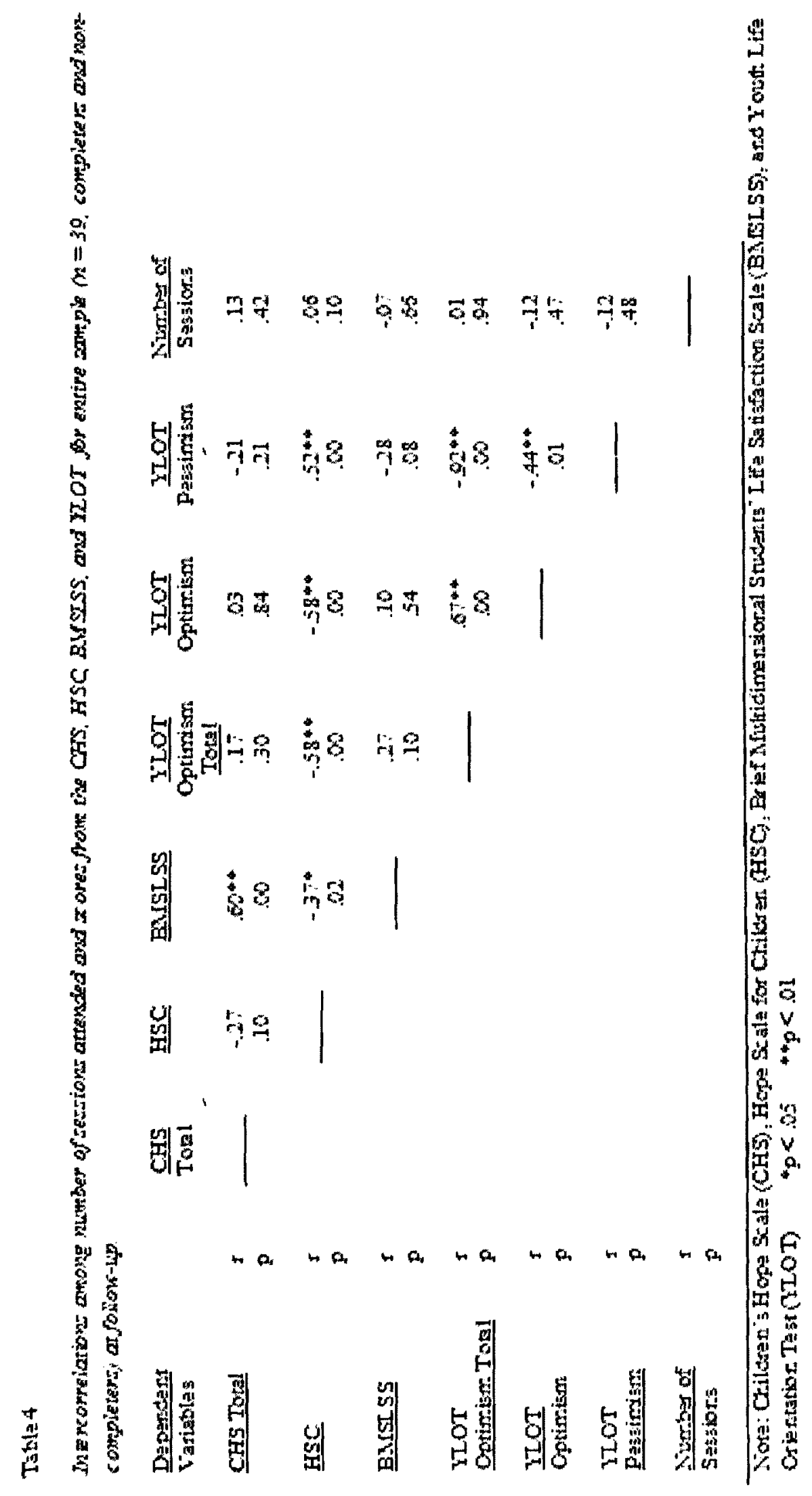


Table 5

Means, Standard Dewations, and Longitudi nal Outcome Mearures for the HI and RE groups.

\begin{tabular}{|c|c|c|c|c|c|c|c|c|}
\hline \multirow[b]{2}{*}{ Child Variables } & \multicolumn{2}{|c|}{ Pretest } & \multicolumn{2}{|c|}{ Pastest } & \multicolumn{2}{|c|}{ Follow-up } & \multicolumn{2}{|c|}{ Changes in Slopes } \\
\hline & $\begin{array}{c}\mathrm{HI} \\
(\mathrm{n}=23)\end{array}$ & $\underset{(\mathrm{n}=26)}{\mathrm{RE}}$ & $\begin{array}{c}\text { HI } \\
(n=21)\end{array}$ & $\begin{array}{c}\mathrm{RE} \\
(\mathrm{n}=22)\end{array}$ & $\begin{array}{c}\text { HII } \\
(n=18)\end{array}$ & $\begin{array}{c}R E \\
(n=21)\end{array}$ & $t$ & $P$ value \\
\hline CFS Ional & $29.04=4.41$ & $29.62 \pm 4.67$ & $29.40 \pm 5.61$ & $28.00=6.88$ & $22.72=4.67$ & $29.52 \pm 3.80$ & .79 & .43 \\
\hline $\mathrm{HSC}$ & $4.30=2.10$ & $3.62=2.53$ & $3.00=2.17$ & $4.23=3.13$ & $3.06=1.80$ & $4.62=3.22$ & 2.10 & .04 \\
\hline BMSLSS & $35.52=4.76$ & $35.23=5.08$ & $36.67 \pm 4.90$ & $36.91=4.28$ & $33.28=6.47$ & $33.43 \pm 5.61$ & .19 & .85 \\
\hline YLOT Optimism Total & $28.04=5.00$ & $27.92=5.78$ & $27.33=6.36$ & $27.73=6.20$ & $27.94=6.18$ & $27.62=7.20$ & .11 & .92 \\
\hline YLOT Optimistn & $15.61=2.35$ & $16.08=2.61$ & $15.24 \pm 3.90$ & $16.18=2.58$ & $16.44=1.85$ & $15.14=3.20$ & -1.51 & .14 \\
\hline YLOT Pessimism & $5.70=3.66$ & $6.19=4.03$ & $6.95=4.77$ & $6.45=5.10$ & $5.83 \pm 4.77$ & $5.29 \pm 4.84$ & -.98 & .33 \\
\hline Adult Tariables & $(n=22)$ & $(n=25)$ & $(n=21)$ & $(n=22)$ & - & - & & \\
\hline Adult Fope & $27.14=3.21$ & $27.88=3.03$ & $26.71 \pm 3.18$ & $26.41=3.70$ & - & - & -.56 & .45 \\
\hline Adult Hopelesiness & $1.50=2.24$ & $1.84=2.25$ & $3.14=3.73$ & $3.18=3.08$ & - & - & -.25 & .80 \\
\hline
\end{tabular}

Tote: Data are reported as Kean $=$ Standard Devistion

Note: Children" ${ }^{2}$ Hope Scale (CHS), Hope Scale for Children (HSC), Brief Multidimensional Sudents ${ }^{*}$ Life Sarisfaction Scale (BMSLSS), and Youth Life Orientation Test (YLOT) 


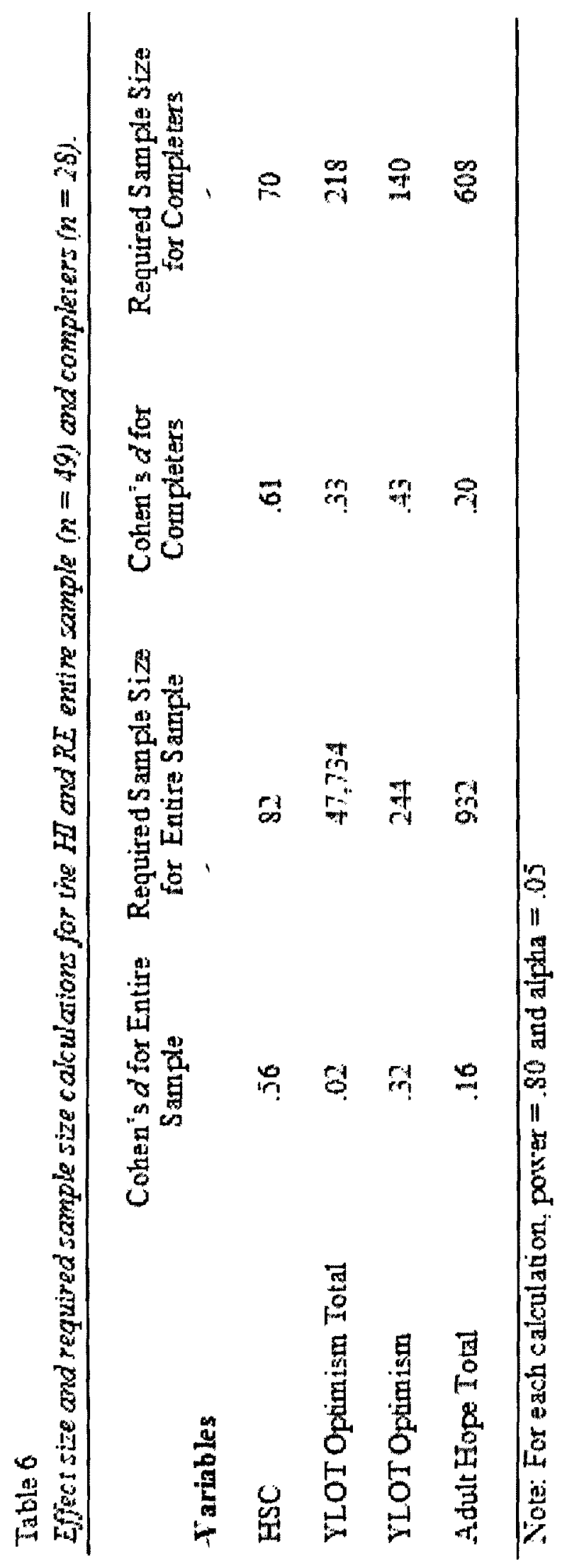




\section{Figure Captions}

Figure 1. Difference in slopes between the HI and RE groups on the HSC from pre-test through follow-up for the entire sample.

Figure 2. Difference in slopes between the HI and RE groups on the HSC from pre-test through follow-up for completers only. 


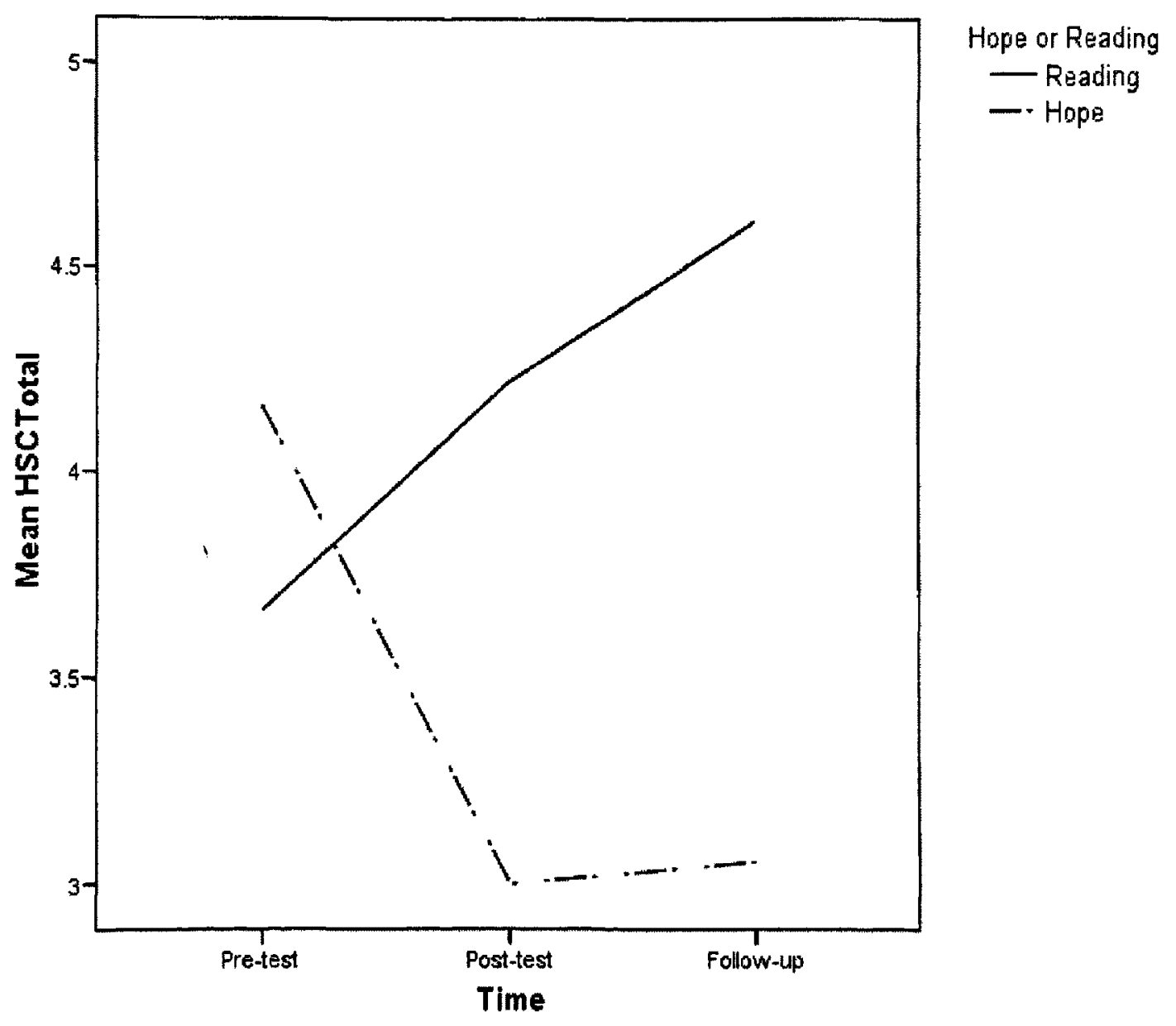




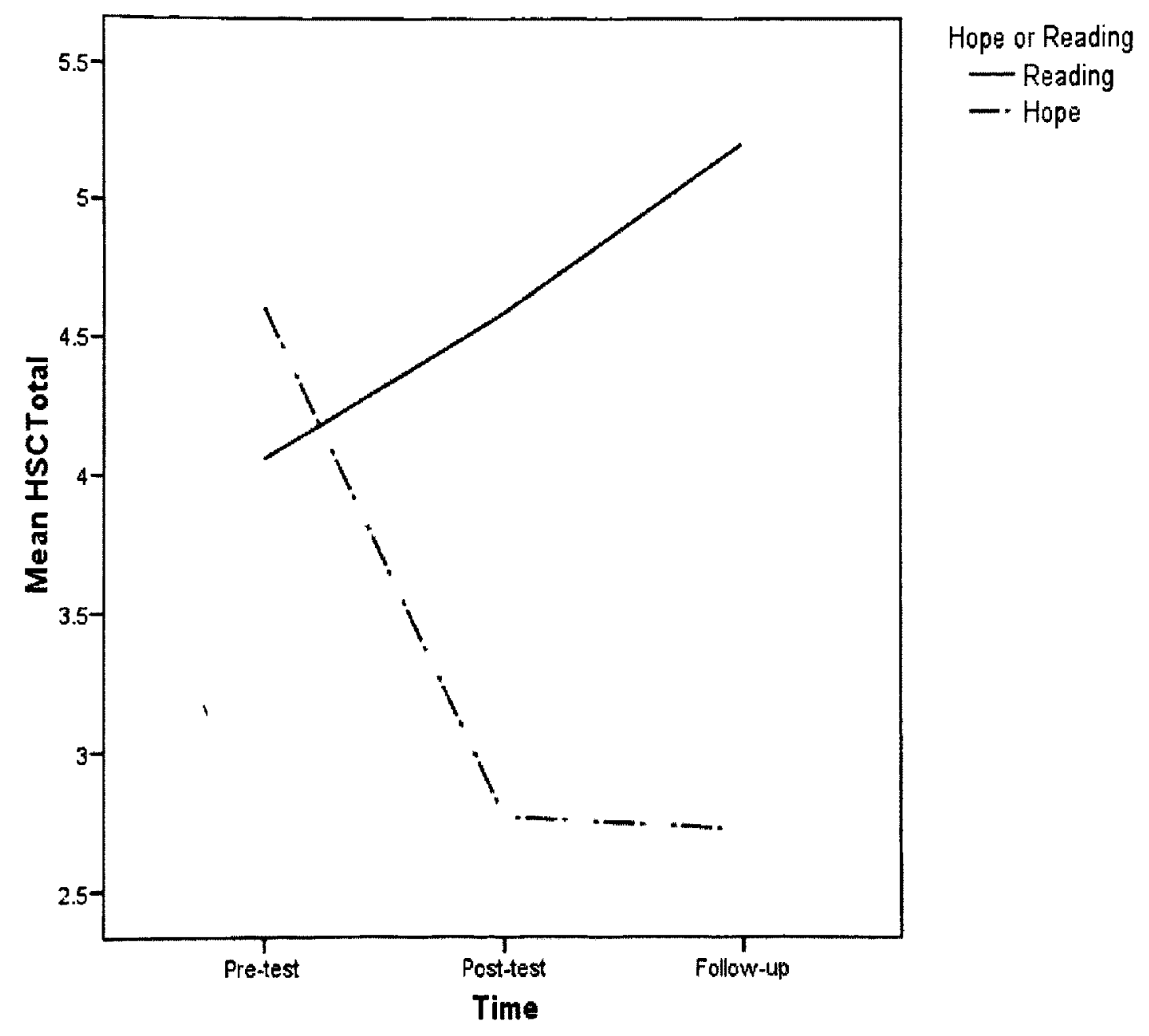


Appendix $N$

Letter of Permission from Cincinnati Metro Housing Authority

-

September 8,2009

RE: Evaluation of After-School Programs at an Urban Community Center

Dear Ms. Karbasi and Eisenman:

I am delighted to write this letter in support of your dissertation projects, "Evaluation of After-School Programs at an Urban Community Center". As Resident Services Manager at the Cincinnati Metropolitan Housing Authority (CMHA), I always look for opportunities to bring programming into our housing communities that effectively address the needs of our children and families. I am especially excited about this program given that it reflects a partnership with Xavier University and Harmony Garden and will allow us to combine forces to more efficiently and effectively use our resources.

For this program, CMHA will work with you and Harmony Garden to recruit eligible children and their parents. We will also provide the community space needed to carry out this after-school program. In addition, in partnership with Harmony Garden, we will help to provide funding support for the leaders to carry out the program.

I understand that you will be using the test scores and other data collected in these projects as part of your dissertation. I enthusiastically look forward to hearing about the results and recommendations that emerge from your program research.

Best regards,

$2,1$.

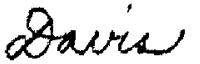

Jackie Davis,

Resident Services Manager

Community Reiations 1627 WESTERN AVENUE, CINCINNATI, OHIO 45214

Phone: (513) 427-8309 - Rax. (513) 665*3100 - TDD: 1800 ) 545-1833 Ext. 260 - Job Line: (513) 977.5659 Website uww clntimha.com Foul Oocoriunitu Emolover. Equal Housing Opportanities 


\section{Appendix $\mathrm{O}$}

\section{Institutional Review Board Approval Letter}
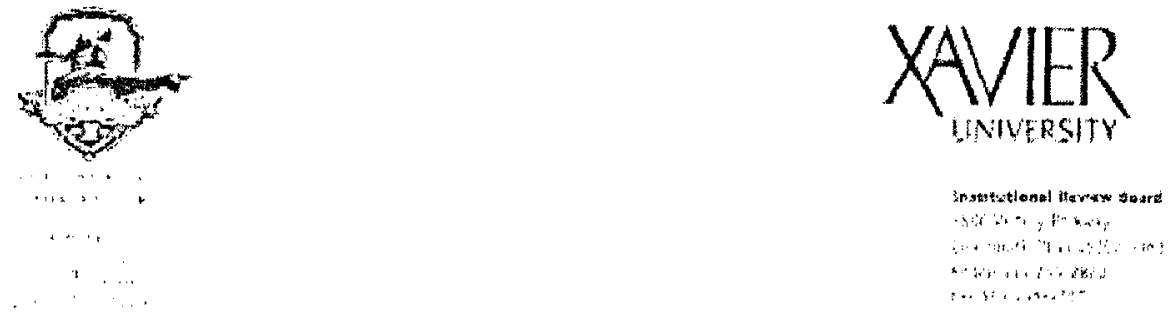

Sentember 4. 2um

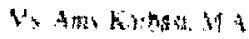

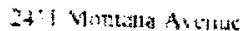

A.t. H.'

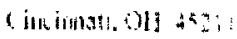

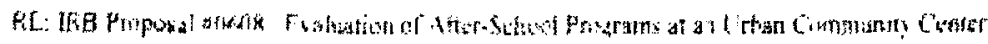

bear Mis harnas,

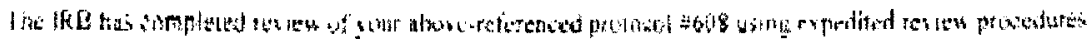

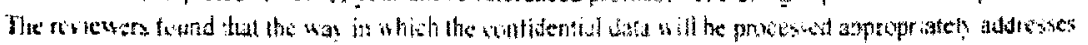

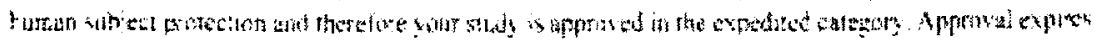

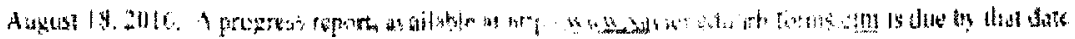

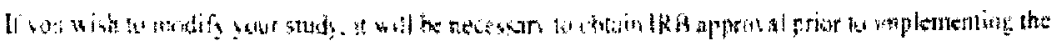

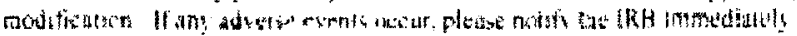

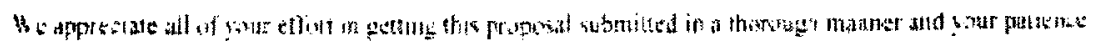

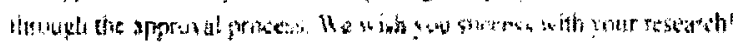

sincerts.

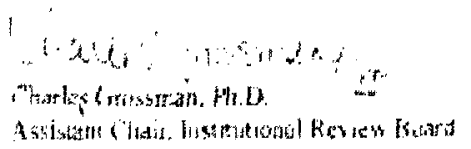

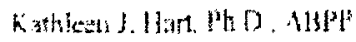


Appendix $P$

F

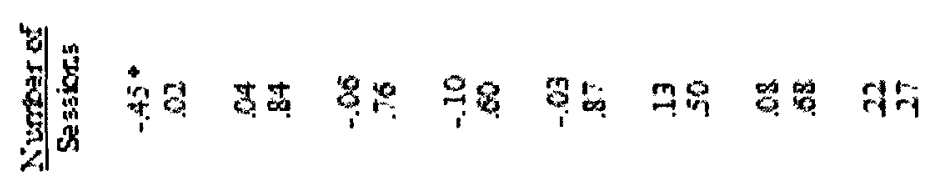

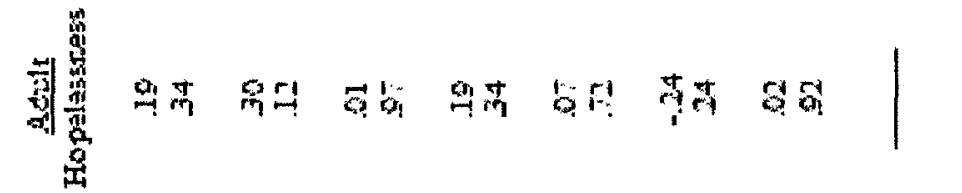

占总

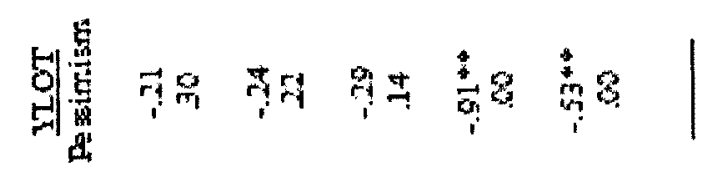

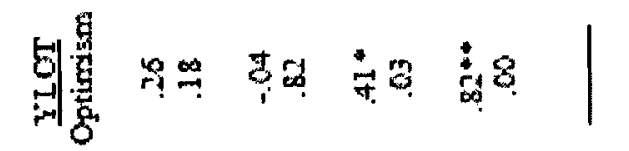

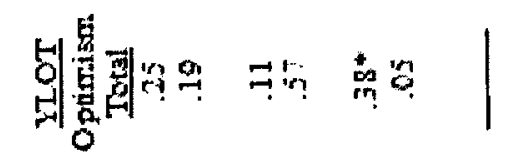

䒺

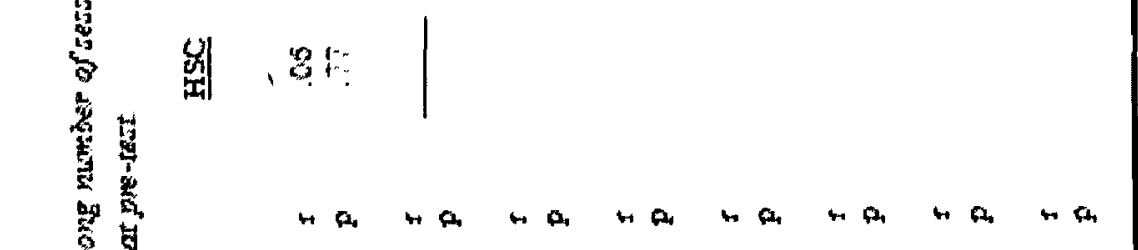

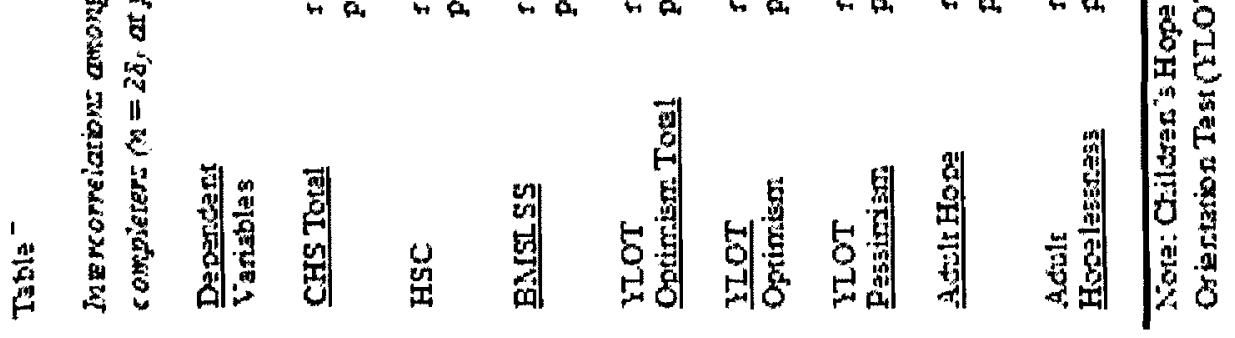




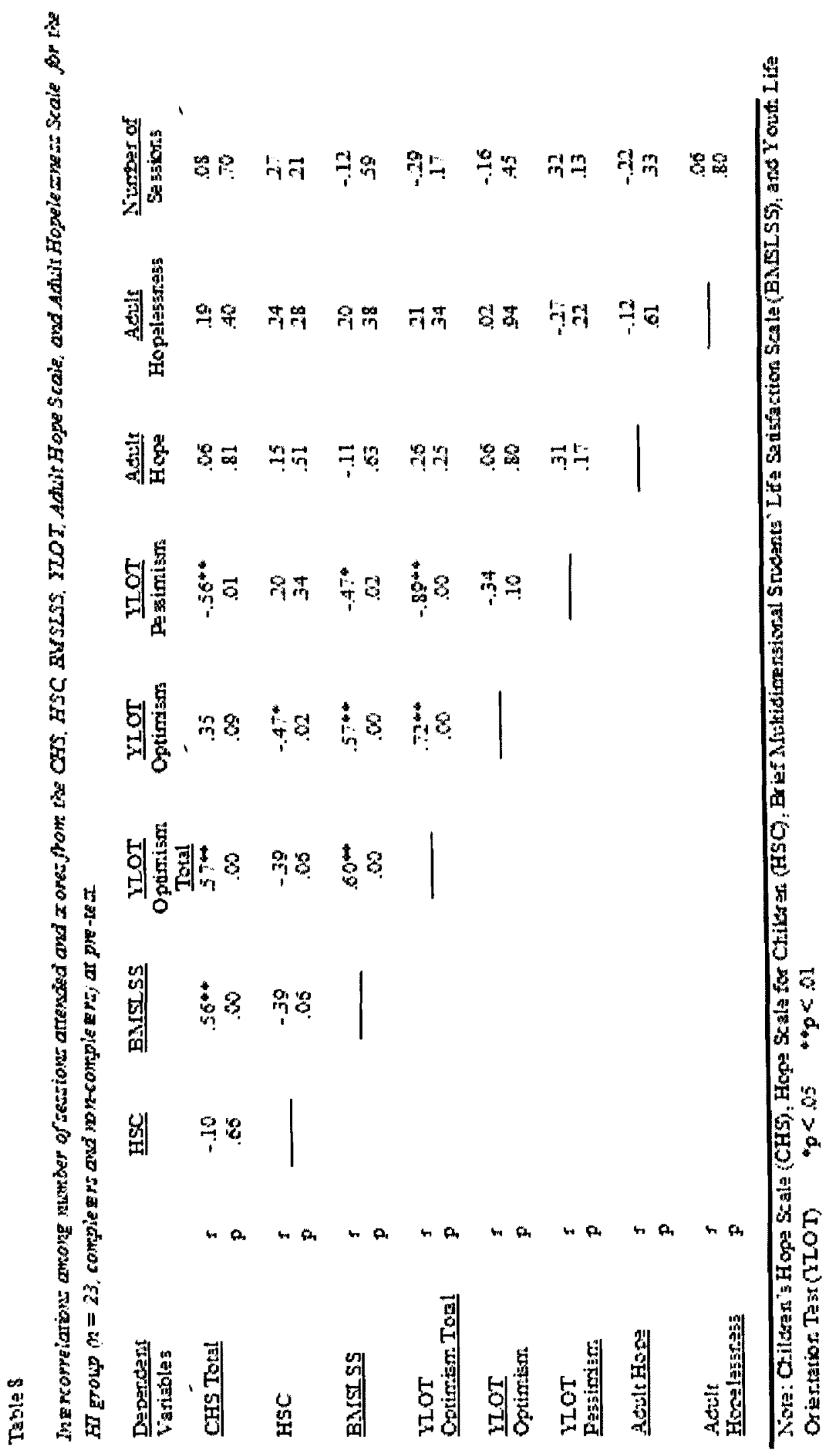




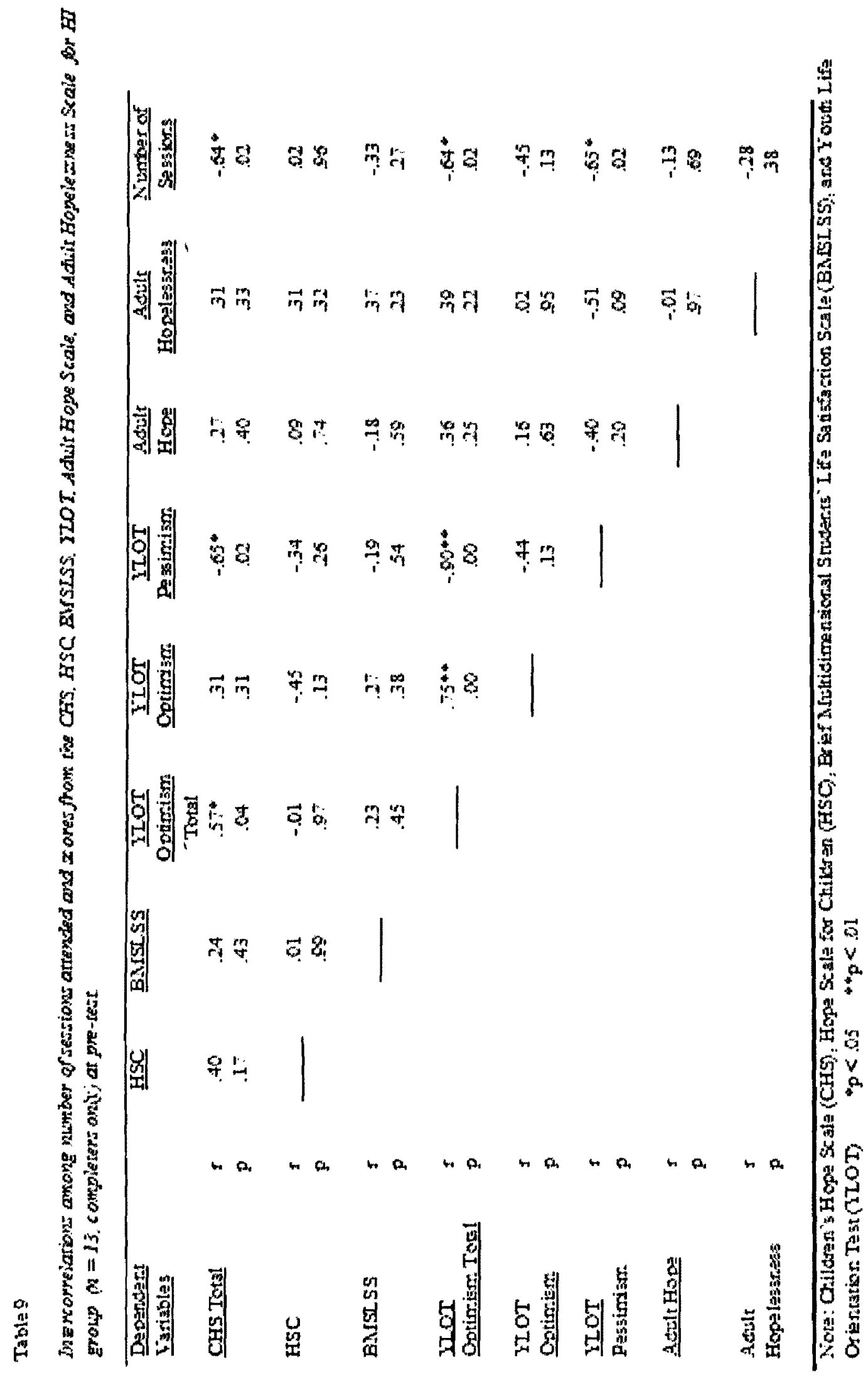




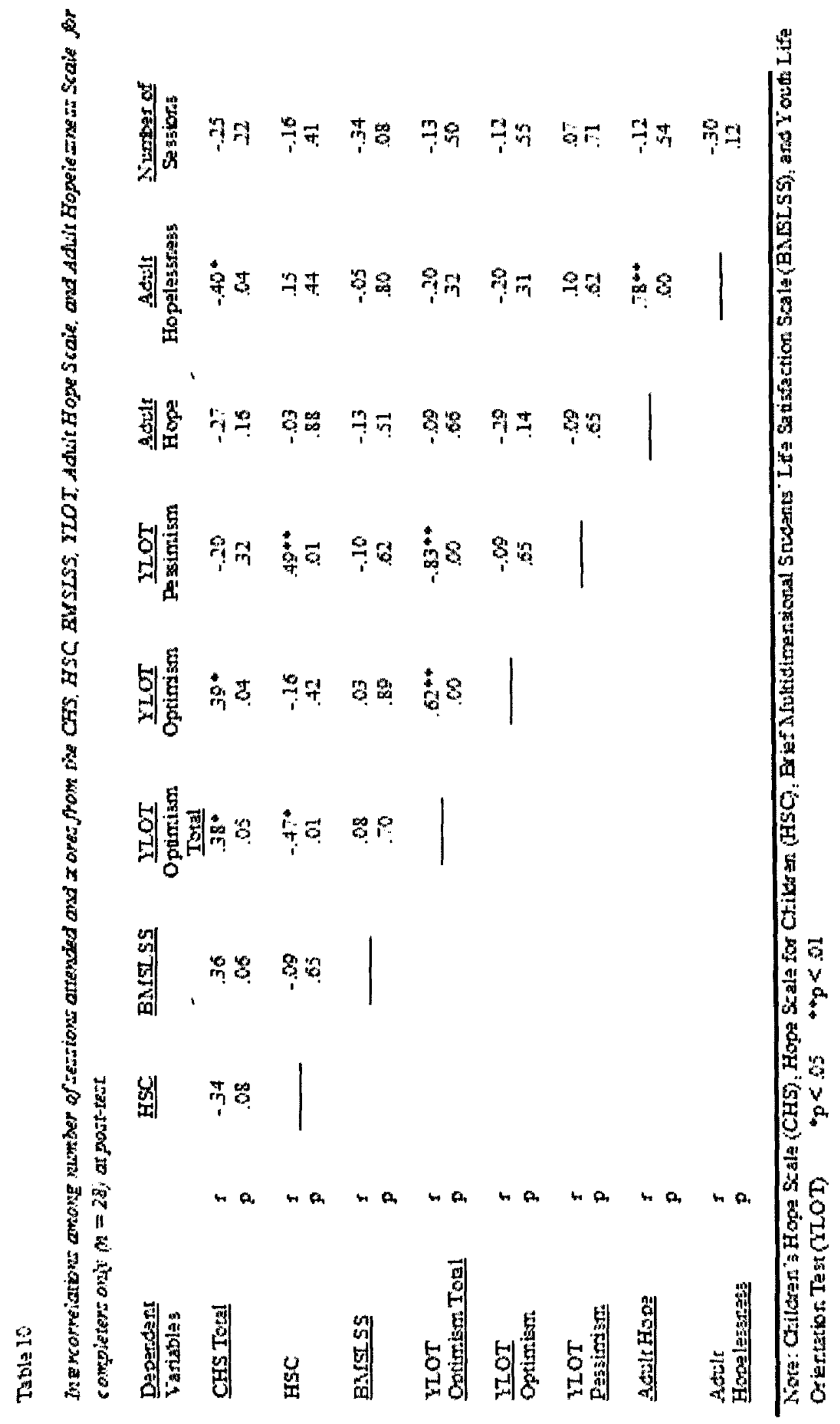




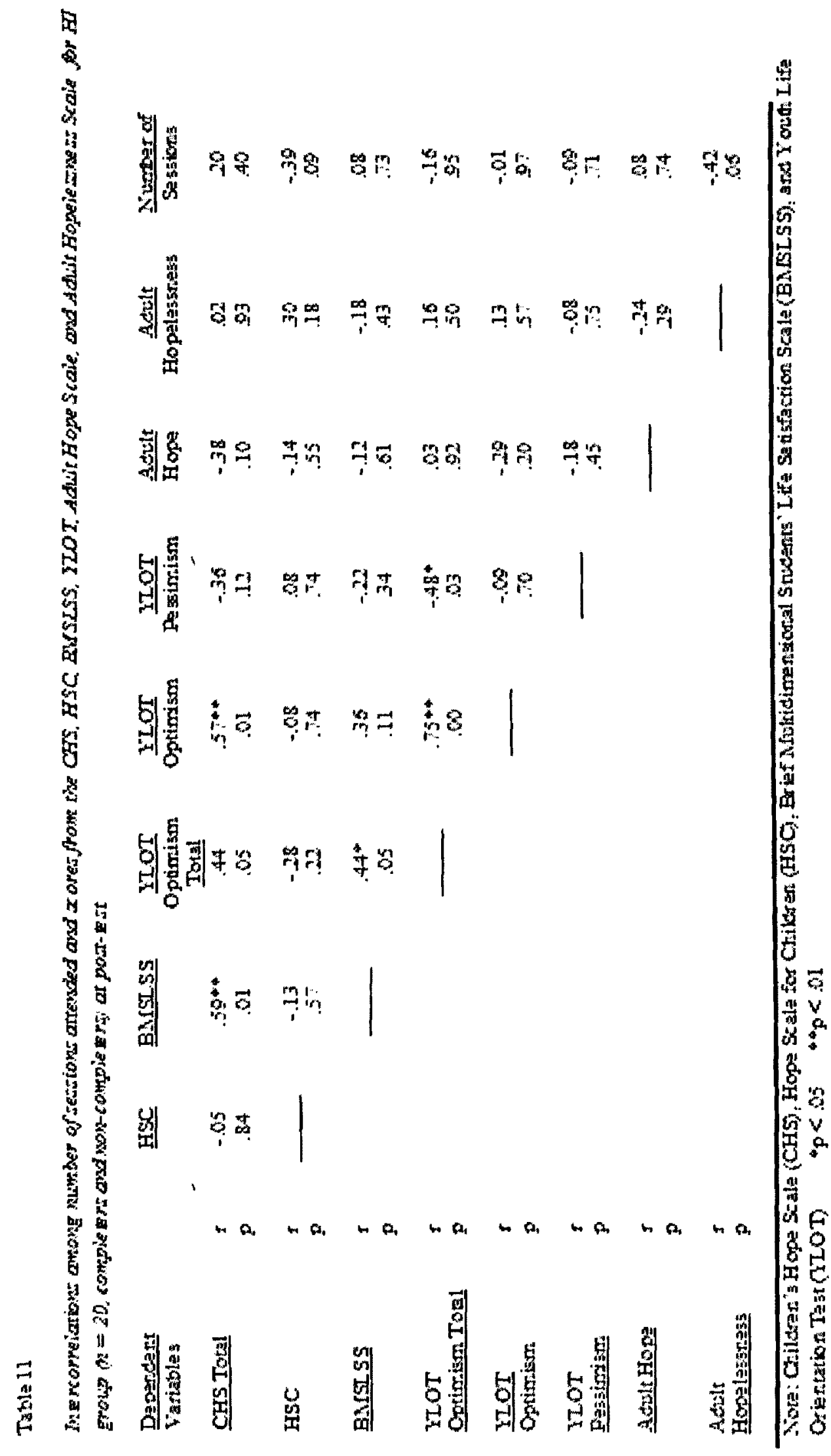




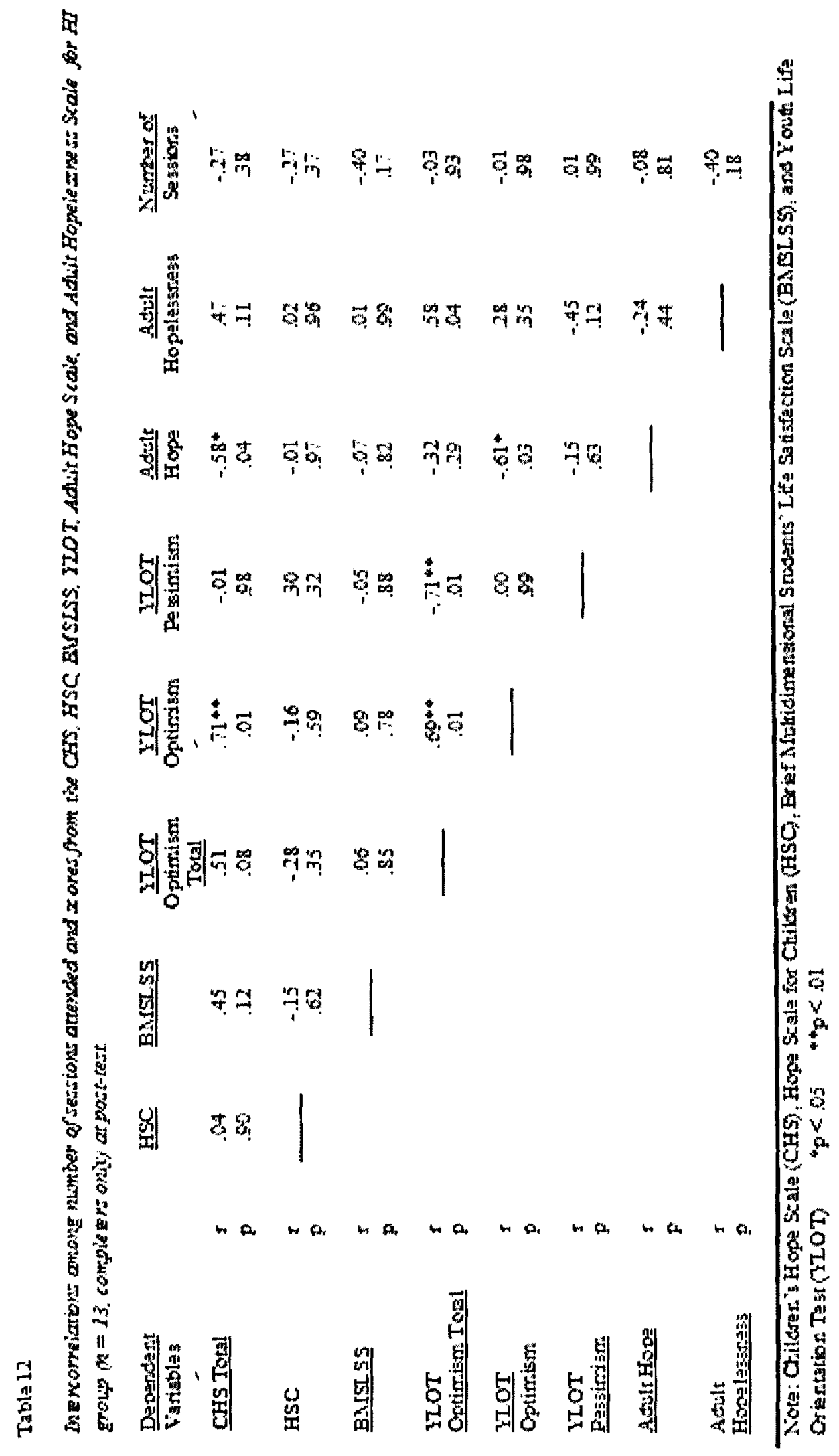




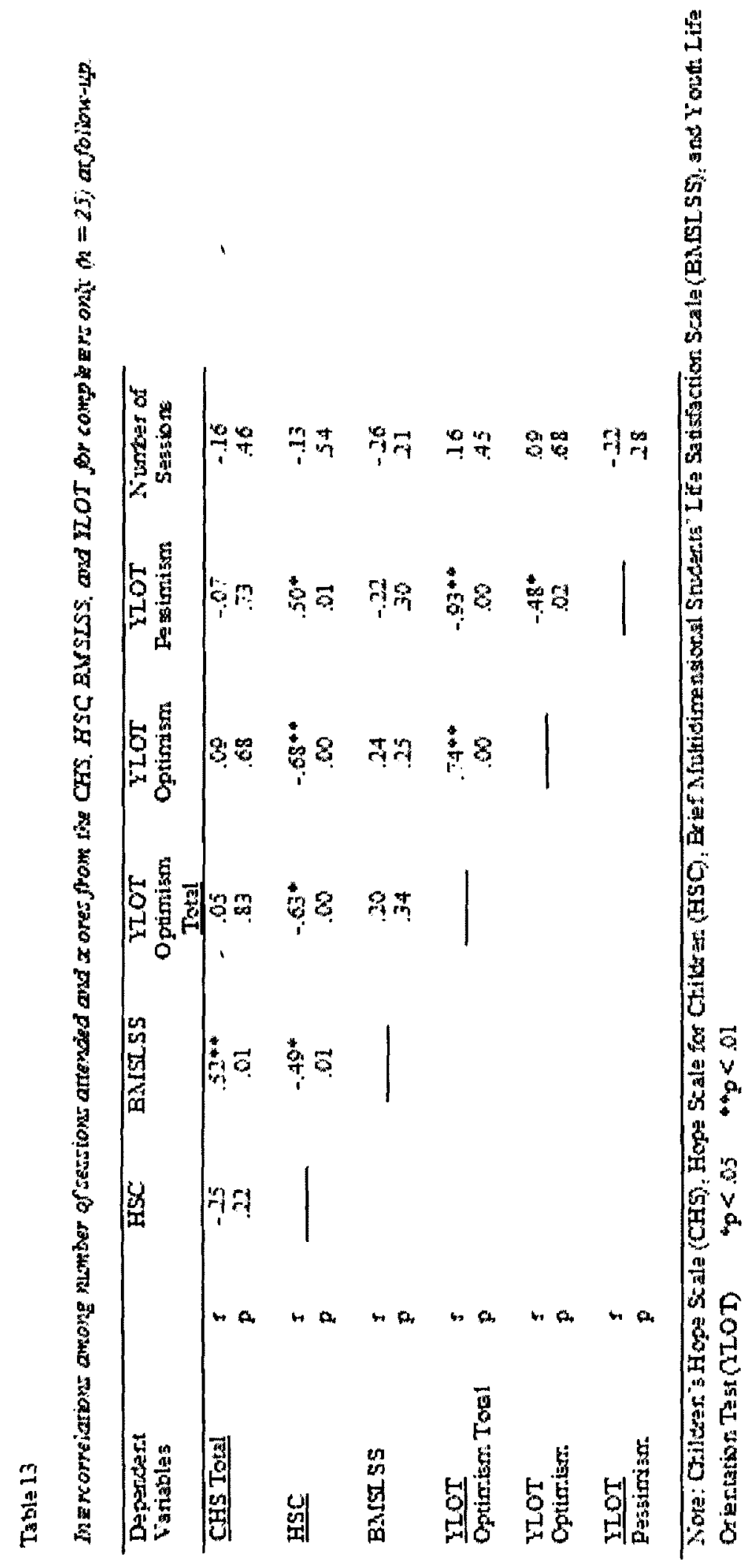




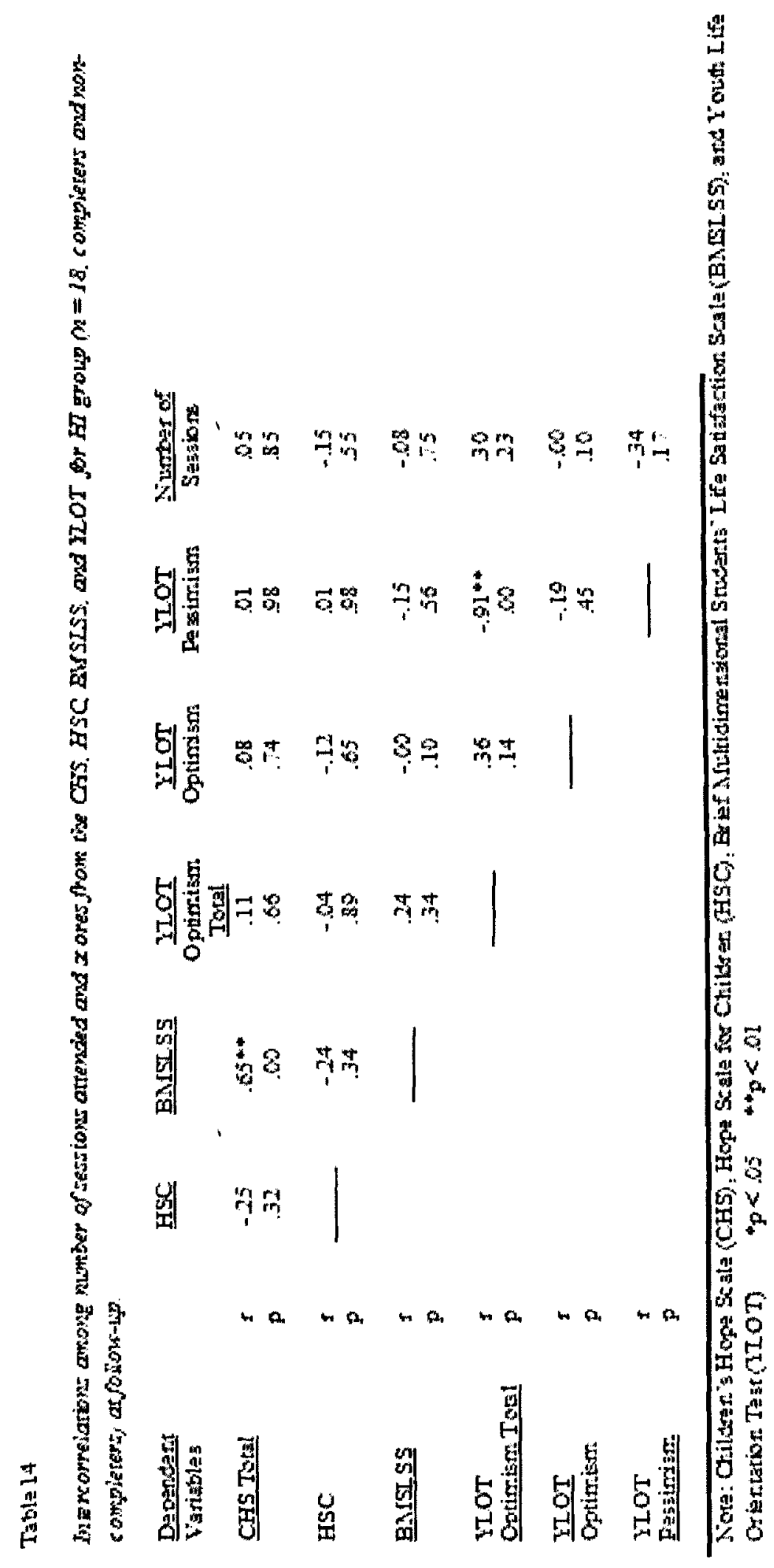




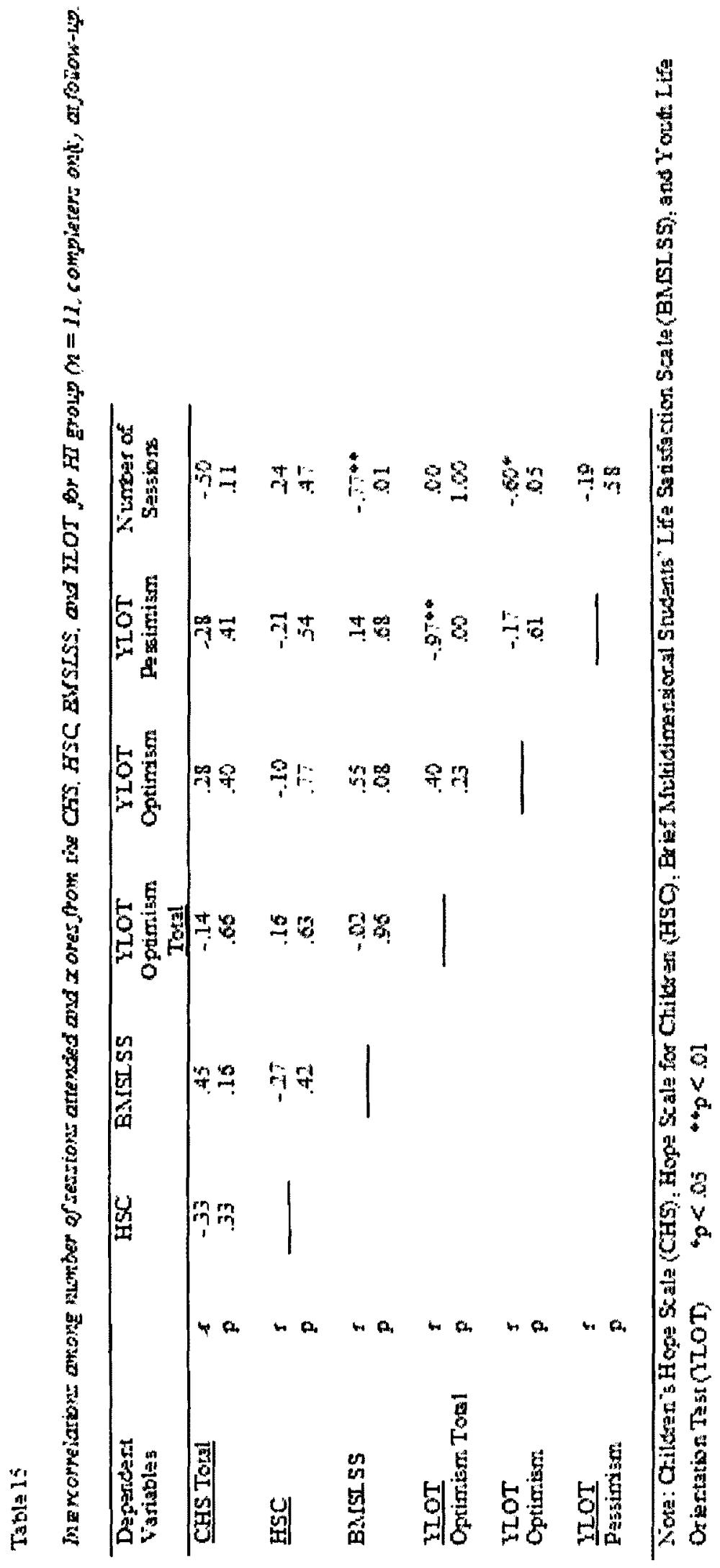


Summary

Title: A Randomized Clinical Trial Examining the Effectiveness of a Hope Intervention for Low SES Children

Statement of the Problem. A growing body of research within the field of positive psychology has examined hope as a protective factor that enhances resiliency. Several studies have investigated the effects of interventions designed to increase hope based on Snyder et al.'s (1991) Hope Theory, currently the most extensively-researched theory of hope. These studies have resulted in changes such as better academic success and psychological adjustment. However, several of these studies have been limited by small sample sizes, a lack of increase in hope scores, a paucity of interventions utilized with child populations, a failure to investigate the relationship between parent and child hope, and a tendency to neglect investigating other variables related to hope. We attempted to correct for these limitations by examining a larger sample size $(n=49)$ of low SES children and their parents and by evaluating a nine-week intervention designed to increase hope with measures of hope, life satisfaction, optimism, and hopelessness.

Participants. Participants were 49 African American children (20 boys, 29 girls) sampled from an after-school urban community center that serves low SES families. The children ranged in age from 7 to 13 years $(M=9.22)$. Completers of the program are defined as those who completed 11 or more $(61 \%)$ sessions $(n=28)$. One parent of each child also participated in the study (i.e., completed pre- and post-intervention measures).

Procedure. Prior to beginning the intervention, children completed the Children's Hope Scale (CHS), the Hopelessness Scale for Children (HSC), the Brief Multidimensional Students' Life Satisfaction Scale (BMSLSS), and the Youth Life Orientation Test (YLOT). Parents completed the Hope Scale and the Hopelessness Scale. Children were randomly divided into four groups: two identical hope intervention (HI) groups and two identical comparison reading ( $\mathrm{RE}$ ) groups. The groups met for one-hour sessions twice per week for nine weeks (18 sessions total). The HI group content was based on Snyder et al.'s (1991) Hope Theory, designed to teach hope and increase resiliency. Children and parents again completed measures at post-test and at three-month follow-up (children only).

Results. A Random Regression Model (RRM) analysis revealed that the slopes differed significantly between the HI and RE groups on the HSC from pre-test through follow-up. Specifically, the HI group demonstrated significantly greater reductions on the HSC than the RE group when analyzing all participants, $t=2.10, p<.05$ and when conducting a post-hoc analysis of only completers of the program, $t=2.19, p<.05$. No significant differences were found between the groups on the other variables. Effect sizes were calculated to determine whether there was a stronger effect for those who completed the 
program compared to the entire sample of participants. Results indicated a stronger effect for completers on the HSC, Adult Hope Total, YLOT Optimism Total, and YLOT Optimism (a subscale of the YLOT) scores. While the effects were stronger for completers of the program, the sample size of this study did not have the power necessary to obtain statistically significant findings on these variables.

Conclusions. Contrary to expectation, CHS did scores did not increase as a result of this intervention. This pattern has been apparent in several recent HI studies (Buchanan, 2008; Delancey, 2005; Dinolfo, 2009). While hope (a protective factor) did not increase, an important, novel finding in this study was that hopelessness (a risk factor) decreased as a result of the intervention. Notably, the CHS scores of these children at pre-test did not indicate low hope prior to beginning the intervention. Future researchers are encouraged to begin turning their attention to investigating ways to reduce hopelessness in children when implementing HIs, as hopelessness may be more relevant and hazardous to children with the demographic characteristics represented in this intervention.

Researchers also might consider utilizing or developing scales to measure hope other than the CHS and begin to re-conceptualize the most effective methods by which to increase (or maintain) hope in children. That is, rather than utilizing a psychoeducational approach, it may be of greater value to focus on experiential, process-oriented content whereby children actively engage in Snyder's process of setting goals and managing frustration. Future researchers are also encouraged to utilize larger sample sizes and develop ways to increase attendance at and completion of these programs, which might produce a greater likelihood of obtaining statistically significant findings. 